CENTRO UNIVERSITÁRIO FEI

ANDRÉ DE SOUZA MENDES

ANÁLISE DE ESTABILIDADE EM GUINADA DE VEÍCULOS ARTICULADOS

São Bernardo do Campo

2016 

ANDRÉ DE SOUZA MENDES

\section{ANÁLISE DE ESTABILIDADE EM GUINADA DE VEÍCULOS ARTICULADOS}

Dissertação de Mestrado apresentada ao Centro Universitário da FEI para obtenção do título de Mestre em Engenharia Mecânica, orientado pelo Prof. Dr. Agenor de Toledo Fleury.

São Bernardo do Campo 
Mendes, André de Souza.

Análise de estabilidade em guinada de veículos articulados / André de Souza Mendes. São Bernardo do Campo, 2016.

123 f. : il.

Dissertação - Centro Universitário FEI.

Orientador: Prof. Dr. Agenor de Toledo Fleury.

1. Dinâmica veicular. 2. Veículos articulados. 3. Análise de estabilidade. 4. Trajetórias de fase. 5. Expoentes de Lyapunov. I. Fleury, Agenor de Toledo, orient. II. Título.

Elaborada pelo sistema de geração automática de ficha catalográfica da FEI com os dados fornecidos pelo(a) autor(a). 
Título do Trabalho: Análise de estabilidade em guinada de veículos articulados

Área de Concentração: Sistemas da Mobilidade

Orientador: Prof. Dr. Agenor de Toledo Fleury

Data da realização da defesa: 07/03/2016

\section{MEMBROS DA BANCA EXAMINADORA}

Prof. Dr. Agenor de Toledo Fleury

Ass.:

Prof. Dr. Milton Dias Junior

Ass.:

Prof. Dr. Flávio Celso Trigo

Ass. :

A Banca Julgadora acima-assinada atribuiu ao aluno o seguinte resultado:

APROVADO \ REPROVADO

\section{VERSÃO FINAL DA DISSERTAČ̃̃O}

APROVO A VERSÃO FINAL DA DISSERTAÇÃO EM QUE FORAM INCLUÍDAS AS RECOMENDAÇÕES DA BANCA EXAMINADORA
Aprovação do Coordenador do Programa de Pós-graduação

Prof. Dr. Rodrigo Magnabosco 



\section{AGRADECIMENTOS}

Ao concluir a graduação de engenharia mecânica em 2013 na cidade do Rio de Janeiro eu não esperava que a minha vida fosse se modificar tanto em tão pouco tempo. Em janeiro de 2014 não sabia o que seria do meu futuro e em março do mesmo ano já estava assistindo as aulas do programa de mestrado do Centro Universtiário FEI na cidade de São Bernardo do Campo. Pela frente se mostravam os desafios de começar uma nova vida, agora sozinho, em outra cidade. O apoio incondicional da minha família esteve presente desde a surgimento da hipótese de mudança, ainda no Rio de Janeiro, até o presente momento. Portanto, é com amor que agradeço todo o carinho, suporte, torcida e bons momentos nas mensagens e telefonemas, quando estavamos distantes, e nos encontros em cada viagem de volta ao Rio de Janeiro.

Meu orientador, professor Agenor de Toledo Fleury, desde o ínicio me proporcionou grandes ensinamentos, orientação e liberdade para perseguir a linha de pesquisa que eu tivesse maior interesse. Os professores Marko Ackermann e Fabrizio Leonardi também participaram na orientação do meu trabalho e contribuiram ativamente no desenvolvimento da pesquisa. Foi um privilégio ter estes mentores brilhantes durante esta etapa. Registro aqui a minha admiração por estes professores e o agradecimento pela confiança depositada em mim. Agradeço, também, a ajuda do professor Tiago Estrela nos estudos sobre o conceito de expoentes de Lyapunov.

Nos primeiros meses em São Bernardo do Campo, antes de alugar um apartamento, morei com um grande amigo, Vinícius Guedes, na casa de sua tia, Rosalina. O apoio de ambos neste início foi fundamental. Nesta mesma época, as aulas estavam acontecendo e fui conhecendo os novos colegas das salas de aula e da sala de estudos. Desde cedo o grupo se ajudava tirando dúvidas e estudando juntos. Conforme o tempo passava o ciclo de convivência se expandiu pelo quinto andar do prédio K. As brincadeiras, debates, encontros e passeios enchem a minha memória de bons momentos. Ao fim desta etapa muitos destes colegas tenho como verdadeiros amigos. 

"Science is more than a body of knowledge, it's a way of thinking. A way of skeptically interrogating the universe with a fine understanding of human fallibility."

Carl Sagan 



\section{RESUMO}

Esta dissertação trata da análise de estabilidade em guinada de veículos articulados utilizando o método de trajetórias de fase. O objetivo deste trabalho consiste em determinar a condição dinâmica que o veículo articulado pode assumir sem que aconteça eventos de instabilidade como o acotovelamento. $\mathrm{O}$ estudo foca na configuração de veículo composta por uma unidade motriz e uma unidade movida como, por exemplo, a combinação formada por um caminhão-trator e um semirreboque. O sistema que representa este conjunto é composto por um modelo não linear de pneu e um modelo de veículo articulado, não linear, do tipo bicicleta e com quatro graus de liberdade. O conceito de expoentes de Lyapunov é apresentado como uma forma de analisar a estabilidade de sistemas dinâmicos não lineares. Primeiramente, esta técnica é descrita elucidando a teoria envolvida, um método de cálculo e exemplos de aplicação. Em seguida, são avaliadas as suas características e aplicabilidade. A análise apresentada nesta dissertação ilustra a região de convergência obtida através da integração numérica das equações de movimento do modelo para diferentes condições iniciais no plano de fase. Além disso, as alterações da região obtida são apresentadas em função da variação da velocidade do caminhão-trator, posicionamento do ponto de articulação entre os dois módulos e carga vertical sobre o eixo do semirreboque.

Palavras-chave: Dinâmica veicular. Veículos articulados. Análise de estabilidade. Trajetórias de fase. Expoentes de Lyapunov. 



\begin{abstract}
This dissertation addresses the yaw stability analysis of articulated vehicles using the phase trajectories method. The goal of this work is to ascertain the dynamic conditions that the articulated vehicle can assume without the occurrence of instability events such as jackknife. The study focuses on the vehicle configuration composed by one tractor unit and a driven unit such as, for instance, a tractor semi-trailer combination. The system consists of a nonlinear tire model and a nonlinear articulated bicycle model with four degrees of freedom. The concept of Lyapunov exponents is presented as a way to analyse the stability of nonlinear dynamic systems. First, this technique is described elucidating the theory involved, a calculation method and examples of applications. Then, their characteristics and applicability are assessed. The analysis presented in this dissertation illustrate the convergence region obtained by numerical integration of the equations of motion of the model for different initial conditions in the phase plane. In addition, the changes in the obtained region are presented as a function of the tractor velocity, the position of the articulation point between the two units and the vertical load on the axle of the semi-trailer.

Keywords: Vehicle dynamics. Articulated vehicles. Stability analysis. Phase trajectories. Lyapunov exponents.
\end{abstract}





\section{LISTA DE FIGURAS}

Figura 1 - Comparação de arraste lateral (offtracking) entre dois veículos, articulado e não articulado, de mesmo comprimento . . . . . . . . . . . 26

Figura 2 - Modos de instabilidade em guinada de veículos articulados . . . . . . 28

Figura 3 - Curva característica típica do pneu (à esquerda) e definição do ângulo

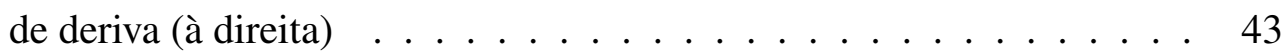

Figura 4 - Comparação dos modelos de pneu linear, polinomial e Pacejka . . . . 48

Figura 5 - Comparação da curva característica para ângulos de deriva com e sem tratamento . . . . . . . . . . . . . . . . . . . 49

Figura 6 - Modelo físico do conjunto caminhão-trator e semirreboque . . . . . . 52

Figura 7 - Diagrama de corpo livre do modelo bicicleta articulado . . . . . . 55

Figura 8 - Modelo do sistema. Combinação dos eixos com propriedades equivalentes ............................ 63

Figura 9 - Evolução do círculo de condições iniciais . . . . . . . . . . . 65

Figura 10 - Evolução dos raios de um sistema bidimensional . . . . . . . . . . 66

Figura 11 - Ortonormalização de Gram-Schmidt para um sistema bidimensional 72

Figura 12 - Modelo bicicleta sem articulação e com dois graus de liberdade . . . 77

Figura 13 - Evolução dos estados para as condições iniciais $\dot{\psi}_{0}=0,1 \mathrm{rad} / \mathrm{s}$ e $v_{y, 0}=1 \mathrm{~m} / \mathrm{s} \ldots \ldots \ldots \ldots \ldots \ldots \ldots$

Figura 14 - Expoentes de Lyapunov para as condições iniciais $\dot{\psi}_{0}=0,1 \mathrm{rad} / \mathrm{s}$ e

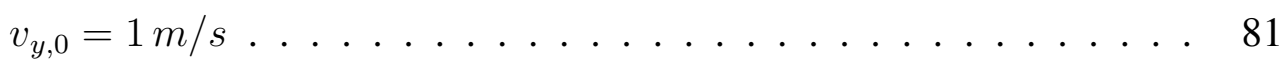

Figura 15 - Evolução dos estados e parte real dos autovalores do modelo linearizado para as condições iniciais $\dot{\psi}_{0}=0,1 \mathrm{rad} / \mathrm{s}$ e $v_{y, 0}=1 \mathrm{~m} / \mathrm{s} \quad \ldots \quad 81$

Figura 16 - Comparação das regiões de estabilidade obtidas através dos expoentes de Lyapunov e método de trajetórias de fase . . . . . . . . . . . . 83

Figura 17 - Comparação da curva característica para diferentes cargas verticais . . 85

Figura 18 - Evolução dos estados em função do tempo . . . . . . . . . . . . . . 89

Figura 19 - Evolução dos ângulos de deriva dos três eixos em função do tempo . . 90

Figura 20 - Evolução da aceleração lateral do centro de massa dos módulos em função do tempo . . . . . . . . . . . . . . . . . . . . 91

Figura 21 - Representação em três dimensões da evolução dos estados. Terceira dimensão dada pelo módulo do vetor velocidade do centro de massa do caminhão-trator $v \ldots \ldots \ldots \ldots$. . . . . . . . . . . . 91 
Figura 22 - Representação em três dimensões da evolução dos estados. Terceira dimensão dada pelo ângulo relativo entre os módulos $\phi \quad \ldots$. . . . . . 92

Figura 23 - Trajetória do veículo articulado . . . . . . . . . . . . . . 92

Figura 24 - Evolução dos estados em função do tempo . . . . . . . . . . . . . . 93

Figura 25 - Evolução dos ângulos de deriva dos três eixos em função do tempo . . 94

Figura 26 - Evolução da aceleração lateral do centro de massa em função do tempo 94

Figura 27 - Representação em três dimensões da evolução dos estados. Terceira dimensão dada pelo módulo do vetor velocidade do centro de massa do caminhão-trator $v \ldots \ldots \ldots \ldots$. . . . . . . . . . . 95

Figura 28 - Representação em três dimensões da evolução dos estados. Terceira dimensão dada pelo ângulo relativo entre os módulos $\phi \quad \ldots$. . . . . 96

Figura 29 - Trajetória do veículo articulado . . . . . . . . . . . . 96

Figura 30 - Região de convergência e as condições iniciais dos casos 1 e 2 da seção $5.3 \ldots \ldots \ldots \ldots \ldots \ldots \ldots$

Figura 31 - Regiões de convergência para diferentes valores de $\alpha_{T, f i n a l} \quad \ldots \ldots 99$

Figura 32 - Curvas de nível do módulo da aceleração lateral máxima no plano de fase para o caminhão-trator e semirreboque . . . . . . . . . . . . 100

Figura 33 - Regiões de estabilidade com trajetória dos estados estendido . . . . . . 101

Figura 34 - Trajetória dos estados no espaço de fase formado pelos estados $\dot{\psi}, \alpha_{T}$ e $v .102$

Figura 35 - Trajetória dos estados no espaço de fase formado pelos estados $\dot{\psi}, \alpha_{T}$ e $\phi 103$

Figura 36 - Regiões de convergência em função da velocidade inicial do centro de massa do caminhão-trator (No plano de fase em duas dimensões) . . 104

Figura 37 - Regiões de convergência em função da velocidade inicial do centro de massa do caminhão-trator (No espaço de fase em três dimensões) . . 105

Figura 38 - Regiões de convergência em função do posicionamento da articulação em relação ao eixo traseiro do caminhão-trator (No plano de fase em duas dimensões $\ldots \ldots \ldots$. . . . . . . . . . . . . . . 107

Figura 39 - Regiões de convergência em função do posicionamento da articulação em relação ao eixo traseiro do caminhão-trator (No espaço de fase em três dimensões $\ldots$. . . . . . . . . . . . . . . . . . . . . . . 108

Figura 40 - Regiões de convergência em função da carga vertical sobre o eixo do semirreboque (No plano de fase em duas dimensões) . . . . . . . . . . 109

Figura 41 - Regiões de convergência em função da carga vertical sobre o eixo do semirreboque (No espaço de fase em três dimensões) . . . . . . . . . . 110 


\section{LISTA DE TABELAS}

Tabela 1 - Extensão da malha rodoviária brasileira $[\mathrm{km}] \ldots \ldots$

Tabela 2 - Frota de veículos emplacados até fevereiro de 2015 . . . . . . . . . . . 27

Tabela 3 - Movimentação anual da matriz de transporte de carga . . . . . . . . . . . 27

Tabela 4 - Número de acidentes fatais por evento inicial . . . . . . . . . . . . 29

Tabela 5 - Número de veículos pesados envolvidos em acidentes fatais por ocorrência de acotovelamento . . . . . . . . . . . . . . . . . . . 29

Tabela 6 - Número de veículos pesados envolvidos em acidentes por ocorrência de acotovelamento e severidade do acidente em $2013 \ldots 29$

Tabela 7 - Veículos pesados envolvidos em acidentes fatais por configuração . . . 30

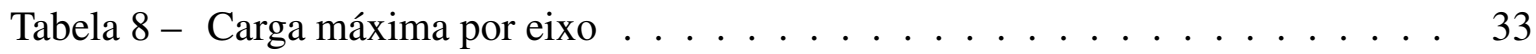

Tabela 9 - Combinações caminhão-trator/semirreboque . . . . . . . . . . . . . 33

Tabela 10 -Combinações caminhão-trator-trucado/semirreboque . . . . . . . . . . . 34

Tabela 11 -Ônibus urbano articulado . . . . . . . . . . . . . . . . . 35

Tabela 12 -Parâmetros do modelo de pneu Pacejka para o exemplo de comparação . . 47

Tabela 13 -Dados do veículo simples, sem articulação, utilizado por Sadri e Wu (2013) 79

Tabela 14 -Parâmetros do modelo de pneu comercial de tamanho 295/80 R22.5 obtidos experimentalmente . . . . . . . . . . . . . 84

Tabela 15 -Parâmetros de medição direta da combinação caminhão-trator e semirre-

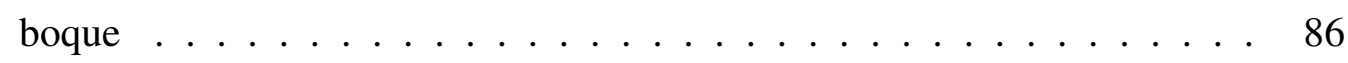

Tabela 16 -Parâmetros do modelo de veículo articulado . . . . . . . . . . . . . . 87

Tabela 17 -Parâmetros de integração e condição inicial . . . . . . . . . . . . . 88

Tabela 18 -Dados computacionais . . . . . . . . . . . . . . . 122 



\section{LISTA DE ABREVIATURAS}

ABS

Anti-lock Break System.

CNT Confederação Nacional de Transporte.

CONTRAN Conselho Nacional de Trânsito.

CTB Código de Trânsito Brasileiro.

CTS caminhão-trator e semirreboque.

CTTS caminhão-trator trucado e semirreboque.

ESC Electronic Stability Control.

LQR Linear-Quadratic Regulator.

OUA ônibus urbano articulado.

PBT peso bruto total.

TKU tonelada transportada por quilômetro útil.

TMA teorema do momento angular.

TMB teorema do movimento do baricentro. 



\section{LISTA DE SÍMBOLOS}

\section{Geral}

A

A

A

a

$a$

a

B

$B$

b

$b$

C

c

D

$d$

E

$e$

e

F

$\mathrm{F}$

F

Matriz dinâmica do sistema linear.

Módulo do vetor aceleração $\left[\mathrm{m} / \mathrm{s}^{2}\right]$.

Ponto que localiza a articulação entre o caminhão-trator e o semirreboque.

Coeficiente do modelo de pneu apresentado por Pacejka e Bakker (1992).

Grandeza escalar que define a posição de $\mathrm{F}$ em relação a $\mathrm{T}[\mathrm{m}]$.

Vetor aceleração $[\mathrm{m} / \mathrm{s}]$.

Matriz de entradas do sistema linear.

Fator de rigidez (Stiffness factor) $[N / \mathrm{rad}]$.

Base exponencial.

Grandeza escalar que define a posição de $\mathrm{T}$ em relação a $\mathrm{R}[\mathrm{m}]$.

Fator de forma (Shape factor).

Grandeza escalar que define a posição de $\mathrm{R}$ em relação a $\mathrm{A}[\mathrm{m}]$.

Fator de pico (Peakfactor) [N].

Grandeza escalar que define a posição de $\mathrm{A}$ em relação a $\mathrm{S}[\mathrm{m}]$.

Fator de curvatura (Curvature factor).

Grandeza escalar que define a posição de $\mathrm{S}$ em relação a $\mathrm{M}[\mathrm{m}]$.

Vetor unitário da base solidária ao eixo dianteiro.

Módulo do vetor força $[N]$.

Ponto que localiza o eixo dianteiro do caminhão-trator.

Vetor força $[N]$.

Elemento da função vetorial.

Função vetorial.

Função que compõe a função vetorial.

Mapa da solução do sistema de equações diferenciais.

Aceleração da gravidade $\left[\mathrm{m} / \mathrm{s}^{2}\right]$.

Matriz modal com as colunas compostas pelos autovetores.

Matriz identidade.

Índice.

Momento de inércia $\left[\mathrm{kg} \cdot \mathrm{m}^{2}\right]$.

Elemento da matriz jacobiana do sistema.

Matriz jacobiana do sistema. 
Índice.

Coeficiente de rigidez lateral $[\mathrm{N} / \mathrm{rad}]$.

Coeficiente do modelo polinomial de pneu $\left[\mathrm{N} / \mathrm{rad}^{3}\right]$.

Elemento da matriz de massa.

Matriz de massa.

Ponto que localiza o eixo do semirreboque.

Massa $[k g]$.

Número de pontos de solução na simulação.

Dimensão do sistema.

Vetor que armazena os denominadores do vetor dos raios a cada iteração.

Distância entre o eixo dianteiro e o eixo traseiro do caminhão-trator $[m]$.

Vetor de raio inicial da base ortonormal.

Vetor velocidade angular do caminhão-trator $[\mathrm{rad} / \mathrm{s}]$.

Autovetor da matriz dinâmica.

Distância entre a articulação e o eixo do semirreboque $[\mathrm{m}]$.

Vetor velocidade angular do semirreboque $[\mathrm{rad} / \mathrm{s}]$.

Ponto que localiza o eixo traseiro do caminhão-trator.

Módulo do vetor posição da órbita vizinha em relação à órbita de referência.

Vetor posição da órbita vizinha em relação à órbita de referência.

Ponto que localiza o centro de massa do semirreboque.

Número de iterações do algoritmo para o cálculo dos expoentes de Lyapunov.

Vetor unitário da base solidária ao semirreboque.

Ponto que localiza o centro de massa do caminhão-trator.

Tempo de simulação $[s]$.

Variável tempo $[s]$.

Vetor unitário da base solidária ao caminhão-trator.

Vetor de entradas.

Módulo do vetor velocidade $[\mathrm{m} / \mathrm{s}]$.

Vetor velocidade $[\mathrm{m} / \mathrm{s}]$.

Matriz jacobiana do mapa.

Vetor que compõe a matriz jacobiana do mapa antes da ortonormalização de Gram-Schmidt.

Vetor que compõe a matriz jacobiana do mapa depois da ortonormalização de Gram-Schmidt. 


\section{Grego}

$\alpha$

\section{Subscrito}

0

A

com

$d$

des

$e q$

F

final

h

lim

lin

M

Deslocamento na direção longitudinal no referencial inercial $[\mathrm{m}]$.

Estado do sistema.

Vetor de estados.

Deslocamento na direção transversal no referencial inercial $[\mathrm{m}]$.

Ângulo de deriva $[\mathrm{rad}]$.

Ângulo formado pelo vetor velociade do eixo dianteiro e o eixo longitudinal do módulo dianteiro. $[\mathrm{rad}]$.

Ângulo de esterçamento do eixo dianteiro do caminhão-trator $[\mathrm{rad}]$.

Matriz de transição de estado do modelo linear.

Orientação do semirreboque em relação ao caminhão trator $[\mathrm{rad}]$.

Ângulo de cambagem do pneu $[\mathrm{rad}]$.

Autovalor da matriz dinâmica.

Expoente de Lyapunov.

Coeficiente de atrito.

Parte imaginária do número complexo.

Orientação do caminhão-trator [ $\mathrm{rad}]$.

Parte real do número complexo.

Intervalo de tempo em cada iteração $[s]$.

Inicial.

Referente à articulação entre o caminhão-trator e o semirreboque.

Com tratamento do ângulo de deriva.

Deslizamento.

Desacoplado.

Equivalente.

Referente ao eixo dianteiro do caminhão-trator.

Final.

Homogênea.

Limiar.

Referente ao modelo linear de pneu.

Referente ao eixo do semirreboque.

Máximo. 
Nominal.

Número de pneus no eixo.

Referente ao modelo de pneu apresentado por Pacejka e Bakker (1992).

Referente ao modelo polinomial de pneu.

Referente ao eixo traseiro do caminhão-trator.

Referente ao centro de massa da semirreboque.

Sem tratamento do ângulo de deriva.

Referente ao centro de massa do caminhão-trator.

Direção longitudinal.

Direção transversal.

Direção vertical. 


\section{SUMÁRIO}

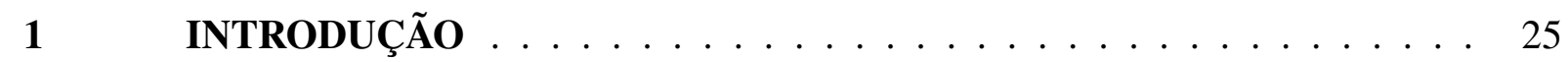

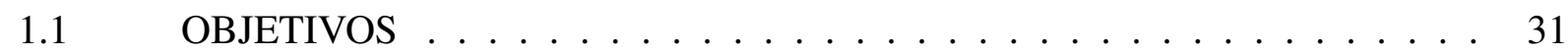

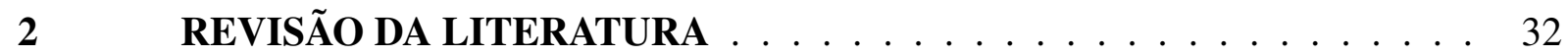

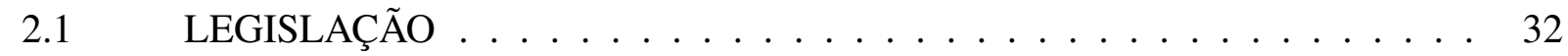

2.2 ESTABILIDADE DE VEÍCULOS ARTICULADOS . . . . . . . . . . 35

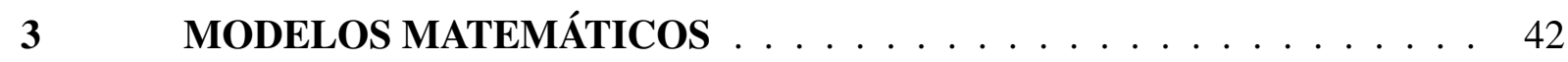

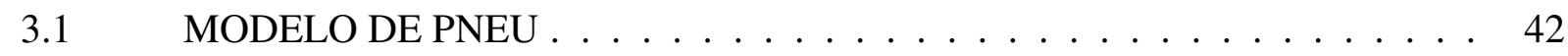

3.2 MODELO DE VEÍCULO ARTICULADO . . . . . . . . . . . . . . . . 49

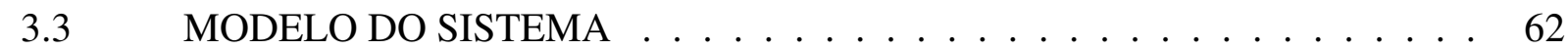

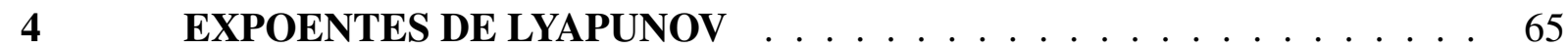

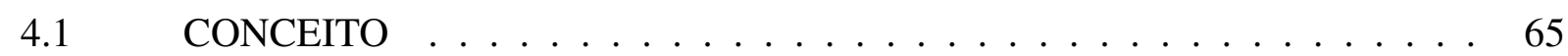

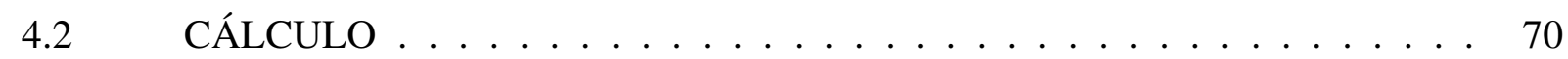

4.3 EXEMPLO LINEAR . . . . . . . . . . . . . . . . . . 73

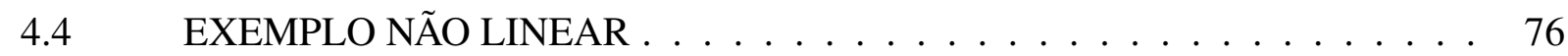

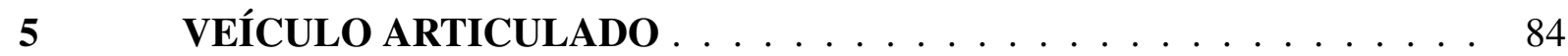

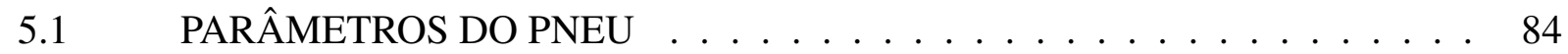

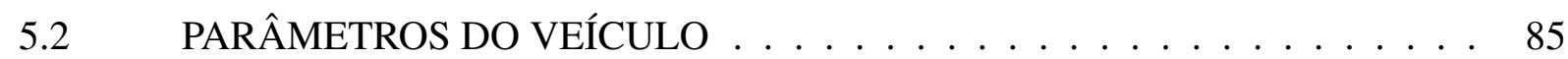

5.3 INTEGRAÇÃO . . . . . . . . . . . . . . . . . . . . . . . . . 87

6 ANÁLISE DE ESTABILIDADE . . . . . . . . . . . . . . . . . . 97

6.1 REGIÃO DE CONVERGÊNCIA . . . . . . . . . . . . . . . . . . . 97

6.2 INFLUÊNCIA DO MÓDULO DA VELOCIDADE . . . . . . . . . . . . 102

6.3 INFLUÊNCIA DO POSICIONAMENTO DA ARTICULAÇÃO . . . . . . . 106

6.4 INFLUÊNCIA DA CARGA SOBRE O EIXO DO SEMIRREBOQUE . . . . . 108

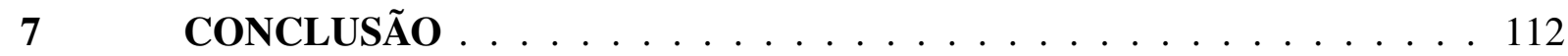

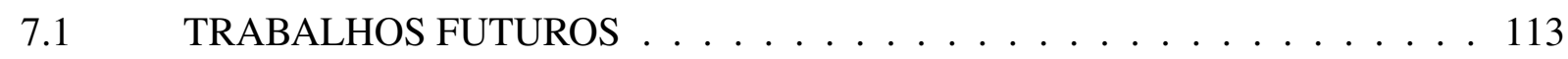

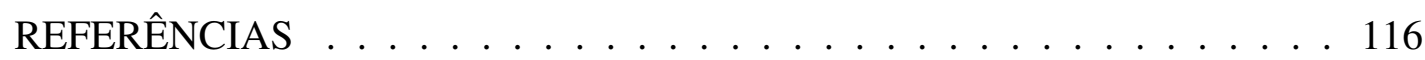

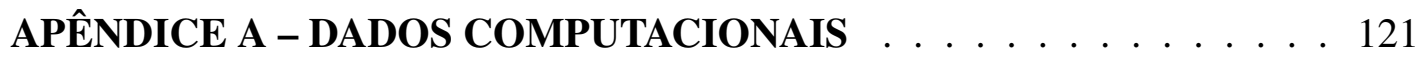





\section{INTRODUÇÃO}

No Brasil, o Conselho Nacional de Trânsito (CONTRAN) é responsável por estabelecer, através de resoluções, certas normas presentes no Código de Trânsito Brasileiro (CTB). Em Conselho Nacional de Trânsito (2011) veículos pesados são definidos como aqueles que possuem peso bruto total (PBT) acima de 3,5 toneladas como, por exemplo, ônibus, caminhão e combinações de caminhão-trator e semirreboque. Estes veículos variam em capacidade de carga, dimensões e aspectos construtivos e são responsáveis pelo transporte de carga e passageiros. Eles são utilizados em todo o território nacional e fazem uso da malha rodoviária como via de tráfego.

Condutor e combustível são fontes significativas de custo nas operações desse tipo de transporte. Logo, em termos econômicos, é do interesse dos proprietários carregar o máximo de carga por motorista e com o menor peso de veículo possível (FANCHER; WINKLER, 2007). Porém, o aumento da capacidade de carga implica, na maioria dos casos, no aumento das dimensões do veículo, que são limitadas pela legislação e pelas características físicas das vias. Veículos muito compridos não são capazes de realizar curvas fechadas pois o eixo traseiro avança sobre os limites laterais da via não conseguindo seguir a trajetória imposta pelo eixo dianteiro. Este fenômeno é chamado de arraste lateral (offtracking) (EJZENBERG, 2009). Dividindo os veículos longos em diversos módulos com distâncias entre eixos menores e conectando-os por meio de articulações um maior nível de manobrabilidade pode ser atingido e curvas fechadas podem ser realizadas. A figura 1 ilustra o movimento circular no sentido anti-horário de dois veículos longos de mesmo comprimento sendo um deles articulado. Para a mesma trajetória do eixo dianteiro o raio da trajetória do eixo traseiro do veículo sem articulação é menor que o raio da trajetória do eixo do semirreboque do veículo articulado. Logo, a presença de articulação diminui a largura mínima de pista necessária para a realização de uma movimentação circular.

Em geral, veículos articulados são compostos por uma unidade motriz, que traciona todo o conjunto, e uma ou mais unidades movidas. As características dinâmicas destas combinações diferem das de veículos simples, sem articulação. Tombamento (rollover) e acotovelamento (jackknife) são exemplos de consequências de fenômenos de instabilidade aos quais estes veículos são sucetíveis. Tombamento é a consequência da instabilidade em rolagem (roll) que pode ser entendida como o crescimento ilimitado do ângulo de inclinação lateral do veículo. Já o acotovelamento é uma das consequências possíveis da instabilidade em guinada (yaw) que pode ser entendida, neste caso, como o crescimento ilimitado do ângulo formado pela unidade 
Figura 1 - Comparação de arraste lateral (offtracking) entre dois veículos, articulado e não articulado, de mesmo comprimento

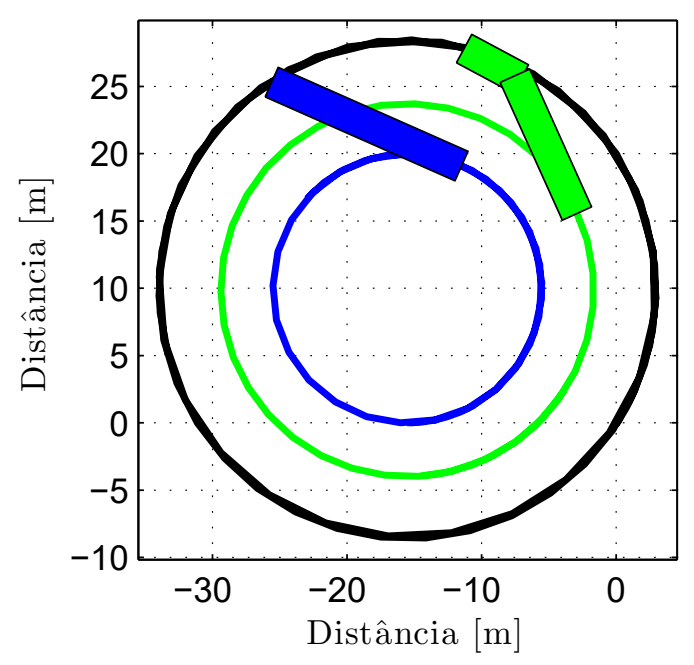

Fonte: Autor

motora e a unidade movida (OREH; KAZEMI; AZADI, 2013). Esta dissertação, em especial, trata da análise de estabilidade em guinada de veículos articulados.

No ano de 2015, a Confederação Nacional de Transporte (CNT) disponibilizou mensalmente, os chamados, boletins estatísticos sobre os sistemas de transporte brasileiros. Segundo Confederação Nacional do Transporte (2015), o Brasil apresenta uma extensa malha rodoviária com mais de 1,5 milhão de quilômetros que engloba todas as esferas administrativas (Federal, estadual e municipal) como pode ser observado na tabela 1 . Na esfera federal mais de $80 \%$ das estradas são pavimentadas, enquanto que cerca de $79 \%$ de toda a malha rodoviária é composta por estradas municipais não pavimentadas representando um risco para o tráfego de veículos pesados devido às más condições de pista.

Tabela 1 - Extensão da malha rodoviária brasileira $[\mathrm{km}]$

\begin{tabular}{lrrr}
\hline- & Pavimentada & Não pavimentada & Total \\
\hline Federal & $66.712,2$ & $12.665,8$ & $79.378,0$ \\
Estadual & $119.691,0$ & $105.600,6$ & $225.291,6$ \\
Municipal & $26.826,7$ & $1.234 .918,3$ & $1.261 .745,0$ \\
Total & $\mathbf{2 1 3 . 2 2 9 , 9}$ & $\mathbf{1 . 3 5 3 . 1 8 4 , 7}$ & $\mathbf{1 . 5 6 6 . 4 1 4 , 6}$ \\
\hline
\end{tabular}

Fonte: Autor "adaptado de" Confederação Nacional do Transporte, 2015

A tabela 2 apresenta o tamanho da frota de alguns veículos pesados que trafegam nas estradas brasileiras discriminando os tipos de meio de transporte. De um total de 5.807.818 veí- 
culos, 5.230.270 são destinados ao transporte de carga como caminhão, semirreboque e reboque e 577.548 são destinados ao transporte de passageiros. O número de veículos combinados em atividade no Brasil é dado pelo número de cavalos mecânicos, 581.087, somada à parcela de ônibus com pelo menos uma articulação que não se encontra discriminada nesta estatística.

Tabela 2 - Frota de veículos emplacados até fevereiro de 2015

\begin{tabular}{lr}
\hline Veículo & Frota \\
\hline Caminhão & 2.599 .527 \\
Caminhão-trator & 581.087 \\
Semirreboque & 847.648 \\
Reboque & 1.202 .008 \\
Ônibus & 577.548 \\
Total & $\mathbf{5 . 8 0 7 . 8 1 8}$
\end{tabular}

Fonte: Autor "adaptado de" Departamento Nacional de Trânsito, 2015

O setor rodoviário domina a matriz de transporte brasileira com mais de $60 \%$ de toda mercadoria transportada com o valor da tonelada transportada por quilômetro útil (TKU) sendo cerca de três vezes maior que o segundo colocado, o setor ferroviário. O setor aquaviário com mais de $13 \%$ de participação ocupa a terceira colocação seguido do setor dutoviário com 4,2\% e o aéreo com apenas $0,4 \%$. Na tabela 3 é possível verificar os detalhes dessa distribuição.

Tabela 3 - Movimentação anual da matriz de transporte de carga

\begin{tabular}{lrr}
\hline Modal & Milhões [TKU] & Participação (\%) \\
\hline Rodoviário & 485.625 & 61,1 \\
Ferroviário & 164.809 & 20,7 \\
Aquaviário & 108.000 & 13,6 \\
Dutoviário & 33.300 & 4,2 \\
Aéreo & 3.169 & 0,4 \\
Total & $\mathbf{7 9 4 . 9 0 3}$ & $\mathbf{1 0 0 , 0}$ \\
\hline
\end{tabular}

Fonte: Autor "adaptado de" Confederação Nacional do Transporte, 2015

Os veículos pesados possuem normalmente elevado centro de massa devido, principalmente, às suas características construtivas e à carga. Esta particularidade aumenta a possibilidade de ocorrência de tombamentos ocasionados por altos níveis de acelação lateral (ERVIN, 1984). Em uma curva, quando a acelaração lateral ultrapassa um determinado limite, as rodas internas à curva tendem a perder contato com a pista. Ao manter esta aceleração é possível instabilizar o sistema, fazendo com que ele não consiga retornar à posição de equilíbrio, provocando o tombamento. 
Dentre os veículos pesados citados acima encontram-se, também, os veículos articulados que se destacam pela elevada capacidade de carga. As combinações, de duas ou mais unidades estão sujeitas à instabilidade em guinada. Os modos deste tipo de instabilidade são dados por: Acotovelamento (jackknife), divergência em guinada do reboque (trailer swing) e oscilação lateral do reboque (snaking ou trailer lateral oscillations) (JI-HUA; JIN-LIANG; JAN, 2011). Estes modos de instabilidade são ilustrados na figura 2.

Figura 2 - Modos de instabilidade em guinada de veículos articulados

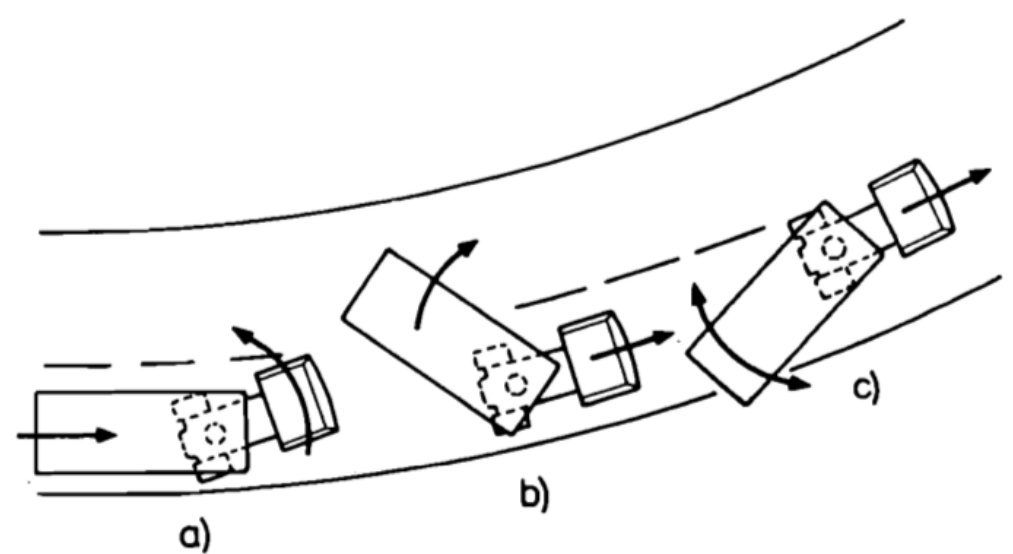

Fonte: Autor "adaptado de" Vlk, 1982

Notas: a) Acotovelamento. b) Divergência em guinada do reboque. c) Oscilação lateral do reboque

Eventos de instabilidade, como os citados acima, podem ser responsáveis por acidentes com ferimentos, mortes e perdas materiais. Nos Estados Unidos, Federal Motor Carrier Safety Administration (2015) apresenta com detalhes informações envolvendo os acidentes de veículos pesados ocorridos no país. Na tabela 4 é possível observar o número de acidentes fatais ocorridos de 2011 a 2013 discriminados por alguns dos eventos prejudiciais iniciais, ou seja, que ocorreram primeiro e ocasionaram ferimentos, mortes ou perdas materiais. A grande maioria dos acidentes fatais teve como primeiro evento prejudicial colisões entre veículos em movimento, com mais de $70 \%$ das ocorrências nos três anos consecutivos. Em seguida, com cerca de $10 \%$ das ocorrências, aparecem acidentes devido à colisão com objetos fixos como, por exemplo, árvores, postes e barreiras de concreto. Em terceiro lugar estão os atropelamentos de pedestres com cerca de $8 \%$ das ocorrências. Os dois útimos eventos iniciais são consequências de situações de instabilidade comentadas acima. Tombamento representa cerca de $4,5 \%$ das causas que desencadearam eventos prejudiciais. Acotovelamento ocorreu como evento inicial em apenas três acidentes fatais em 2011 e dois em 2012. Em 2013 esse número subiu para nove. 
Tabela 4 - Número de acidentes fatais por evento inicial

\begin{tabular}{|c|c|c|c|}
\hline Evento Inicial & 2011 & 2012 & 2013 \\
\hline Colisão com outro veículo & $2.434(72,3 \%)$ & $2.574(73,8 \%)$ & $2.568(72,5 \%)$ \\
\hline Colisão com objetos fixos & $322(9,6 \%)$ & $350(10,0 \%)$ & $348(9,8 \%)$ \\
\hline Colisão com pedestres & $279(8,3 \%)$ & $253(7,3 \%)$ & $283(8,0 \%)$ \\
\hline Tombamento (Rollover) & $158(4,7 \%)$ & $153(4,4 \%)$ & $163(4,6 \%)$ \\
\hline Acotovelamento (Jackknife) & $3(0.1 \%)$ & $2(0.1 \%)$ & $9(0,3 \%)$ \\
\hline Outros & $169(5,0 \%)$ & $154(4,4 \%)$ & $170(4,8 \%)$ \\
\hline Total & $3.365(100,0 \%)$ & $3.486(100,0 \%)$ & $3.541(100,0 \%)$ \\
\hline
\end{tabular}

Fonte: Autor “adaptado de” Federal Motor Carrier Safety Administration, 2015

Na tabela 5 está listado o número de veículos pesados envolvidos em acidentes fatais em que houve a ocorrência de acotovelamento. De 2011 à 2013 este número foi 137, 164 e 183, respectivamente, representando de $3,8 \%$ à $4,7 \%$ do total de veículos envolvidos para cada ano.

Tabela 5 - Número de veículos pesados envolvidos em acidentes fatais por ocorrência de acotovelamento

\begin{tabular}{|c|c|c|c|}
\hline Acotovelamento & 2011 & 2012 & 2013 \\
\hline Sim & $137(3,8 \%)$ & $164(4,3 \%)$ & $183(4,7 \%)$ \\
\hline Não & $3.496(96,2 \%)$ & $3.661(95,7 \%)$ & $3,723(95,3 \%)$ \\
\hline Total & $3.633(100,0 \%)$ & $3.825(100,0 \%)$ & $3.903(100,0 \%)$ \\
\hline
\end{tabular}

Fonte: Autor "adaptado de" Federal Motor Carrier Safety Administration, 2015

Na tabela 6 é apresentada a ocorrência de acotovelamento detalhando a severidade do acidente. Em 2013, 183 veículos pesados estiveram envolvidos em acidentes fatais com ocorrência de acotovelamento. Este número sobe para 1.000 veículos quando se trata de acidentes apenas com pessoas feridas. Por fim, 5.000 veículos pesados se envolveram em acidentes com apenas danos materiais e com ocorrência de acotovelamento.

Tabela 6 - Número de veículos pesados envolvidos em acidentes por ocorrência de acotovelamento e severidade do acidente em 2013

\begin{tabular}{lrrr}
\hline Acotovelamento & Acidentes fatais & Acidentes com ferimentos & Danos materiais apenas \\
\hline Sim & $183(4,7 \%)$ & $1.000(1,7 \%)$ & $5.000(1,8 \%)$ \\
Não & $3.723(95,3 \%)$ & $72.000(98,3 \%)$ & $260.000(98,2 \%)$ \\
Total & $\mathbf{3 . 9 0 6 ( 1 0 0 , 0 \% )}$ & $\mathbf{7 3 . 0 0 0}(\mathbf{1 0 0 , 0 \%})$ & $\mathbf{2 6 0 . 0 0 0}(\mathbf{1 0 0 , 0 \% )}$ \\
\hline
\end{tabular}

Fonte: Autor "adaptado de” Federal Motor Carrier Safety Administration, 2015 
A tabela 7 apresenta o número de veículos pesados envolvidos em acidentes fatais discriminados por configuração, onde o caminhão-trator/duplo (Tractor/Double), também conhecido como Romeu e Julieta, é a combinação formada pela unidade motora e dois reboques. O caminhão-trator/triplo (Tractor/Triple), também chamado de treminhão, é semelhante ao duplo, porém, apresenta três reboques conectados em série. A combinação caminhão-trator e semirreboque é a configuração de veículos pesados mais presente em acidentes fatais com cerca de 60\% das ocorrências nos anos de 2011 a 2013. Os caminhões simples, sem articulação, vem em segundo com quase $30 \%$ das ocorrências. Por fim, completando a tabela, são apresentadas as ocorrências de veículos articulados com um, dois e três reboques. Apesar da tabela 7 não mostrar os eventos que aconteceram nos acidentes, atenção deve ser dada para o elevado número de acidentes fatais envolvendo a combinação caminhão-trator/semirreboque.

Tabela 7 - Veículos pesados envolvidos em acidentes fatais por configuração

\begin{tabular}{|c|c|c|c|}
\hline Configuração & 2011 & 2012 & 2013 \\
\hline Caminhão simples (2 e 3+ eixos) & $1.061(29,2 \%)$ & $1.066(27,9 \%)$ & $1.097(28,1 \%)$ \\
\hline Caminhão-trator/Semirreboque & $2.219(61,1 \%)$ & $2.315(60,5 \%)$ & $2.342(60,0 \%)$ \\
\hline Caminhão-trator/Reboque & $132(3,6 \%)$ & $224(5,9 \%)$ & $270(6,9 \%)$ \\
\hline Caminhão-trator/Duplo & $102(2,8 \%)$ & $103(2,7 \%)$ & $91(2,3 \%)$ \\
\hline Caminhão-trator/Triplo & $4(0,1 \%)$ & $1(<0,05 \%)$ & $1(<0,05 \%)$ \\
\hline Outros & $115(3,2 \%)$ & $116(3,0 \%)$ & $105(2,7 \%)$ \\
\hline Total & $3.633(100,0 \%)$ & $3.825(100,0 \%)$ & $3.906(100,0 \%)$ \\
\hline
\end{tabular}

Fonte: Autor "adaptado de" Federal Motor Carrier Safety Administration, 2015

A partir das tabelas apresentadas é possível observar a importância do transporte e infraestrutura rodoviária na circulação de bens e pessoas. Além disso, dados estatísticos permitem quantificar a contribuição de determinados eventos na ocorrência de acidentes. Tombamento e acotovelamento são exemplos de consequências de situações de instabilidade dinâmica de veículos articulados e ocorrem dependendo das características construtivas e do regime de operação. Uma das formas de evitar essas situações é através do projeto mais rigoroso dos componentes mecânicos e/ou a introdução de controladores que possam intervir em condições dinâmicas desfavoráveis. Por isso, é importante o investimento no conhecimento dos fenômenos envolvidos e de tecnologias que possam diminuir a ocorrência e os impactos de acidentes relacionados a esses tipos de transportes. Os ensaios experimentais para a análise da segurança e estabilidade são caros e demorados e exigem uma elevada infra-estrutura. Para contornar estes altos investimentos é possível realizar simulações computacionais a partir de modelos matemáticos que forneçam informações sobre o comportamento real dos veículos. Porém, para que 
as simulações possam representar a realidade com um nível de precisão aceitável é necessário aperfeiçoar e validar os modelos.

Sistemas de controle vem sendo empregados em veículos pesados para fins de estabilidade como Anti-lock Break System (ABS) e Electronic Stability Control (ESC). Para o desenvolvimento desses controladores é conveniente ter o bom conhecimento do sistema que se deseja controlar e sua região de estabilidade. Como discutido até aqui, acotovelamento representa um risco para a integridade de pessoas e bens materiais ao redor. Portanto, uma mais completa compreensão do fenômeno pode permitir o projeto de veículos mais seguros e estratégias de controle mais robustas. Desta forma, é possível melhorar a eficiência do sistema rodoviário aumentando a capacidade de carga e segurança dos transportes, diminuindo os custos com projeto e desenvolvimento.

\subsection{OBJETIVOS}

Um veículo trafegando em linha reta pode receber atuações do condutor para aumentar ou diminuir a velocidade através, principalmente, das forças longitudinais do pneu que freiam ou aceleram o veículo. Além disso, é possível atuar no sistema de maneira que ele mude a orientação e siga uma trajetória desejada. Isto é feito típicamente por meio da força lateral do pneu que é obtida devido ao ângulo de deriva que é gerado pela entrada de um ângulo de esterçamento. Portanto, para impor uma mudança de orientação é necessário empregar um ângulo de esterçamento em algum conjunto de rodas. Em manobras desta natureza o veículo apresenta uma condição dinâmica a cada instante que pode ser traduzida pelos estados do modelo que o representa. Como estas condições dinâmicas são obtidas a partir das atuações descritas acima, é razável admitir que é do interesse prático que cessando os esforços longitudinais e o esterçamento o veículo retorne à movimentação em linha reta sem que haja consequências de instabilidade em guinada.

O objetivo desta dissertação consiste em verificar para quais situações dinâmicas o sistema, sem atuação, retorna para a movimentação em linha reta sem que haja qualquer fenômeno de instabilidade em guinada. A partir destas informações é possível obter uma região que reune o conjunto de condições dinâmicas que satisfazem esta hipótese. Além disso, deve ser verificada a influência de algumas grandezas nesta região obtida, como por exemplo, o módulo do vetor velocidade do centro de massa do caminhão-trator, o posicionamento da articulação com relação ao eixo traseiro do caminhão-trator e a carga vertical sobre eixo do semirreboque. 


\section{REVISÃO DA LITERATURA}

Para abordar o tema de estabilidade em guinada de veículos articulados é feito, primeiramente, uma revisão da legislação brasileira. Em seguida são apresentadas as bibliografias que discutem a estabilidade de veículos articulados.

\subsection{LEGISLAÇÃO}

Os artigos 99 e 100 do CTB são regulamentados pelas resoluções 62/98, 210/06 e 211/06 do CONTRAN. Estas resoluções especificam limites para distâncias, peso por eixo e peso bruto total de veículos de carga que trafegam nas vias terrestes. Uma extensa revisão da legislação brasileira é feita por Boaretto (2012).

As dimensões máximas dos veículos são dadas por (CONSELHO NACIONAL DE TRÂNSITO, 2006):

a) altura: $4.40 \mathrm{~m}$;

b) largura: $2.60 \mathrm{~m}$;

c) comprimento total:

- veículos articulados de transporte coletivo de passageiros: 18,60 m;

- veículos articulados do tipo caminhão-trator e semirreboque: 18,60 m;

- veículos articulados do tipo caminhão ou ônibus e reboque: 19,80 m.

Na tabela 8 estão resumidas as cargas máximas por tipo de eixo, rodagem, tipo de suspensão e distância entre eixos. Eixo isolado, duplo e triplo são os conjuntos com um, dois e três eixos, respectivamente. As rodagens simples e dupla possuem dois e quatro pneus por eixo, respectivamente. Eixos em tandem são conjuntos de eixos que compartilham o mesmo sistema de suspensão e se encontram entre 1,20 e 2,40 metros de distância entre si.

As tabelas 9, 10 e 11 apresentam exemplos de alguns veículos com uma única articulação que são regulamentados para trafegar nas vias brasileiras. A lista completa das configurações possíveis de veículos pesados e articulados está disponível em Departamento Nacional de Infraestrutura de Transportes (2012). A tabela 9 mostra alguns exemplos de configurações de caminhão-trator e semirreboque (CTS). Nesta tabela o tipo do caminhão-trator é sempre o mesmo variando apenas o tipo do semirreboque. O caminhão-trator possui um eixo dianteiro, 
Tabela 8 - Carga máxima por eixo

\begin{tabular}{llrrr}
\hline Tipo & Rodagem & Suspensão & Entre eixo [m] & Carga Máx. [kg] \\
\hline Isolado & Simples & Direcional & - & 6.000 \\
Isolado & Dupla & - & - & 10.000 \\
Duplo & Simples e simples & Direcional & $\geq 1,2$ & 12.000 \\
Duplo & Dupla e dupla & Tandem & $>1,2 ; \leq 2,4$ & 17.000 \\
Duplo & Dupla e dupla & Não tandem & $>1,2 ; \leq 2,4$ & 15.000 \\
Duplo & Simples e dupla & Especial & $\leq 1,2$ & 9.000 \\
Duplo & Simples e dupla & Especial & $>1,2 ; \leq 2,4$ & 13.500 \\
Triplo & Dupla, dupla e dupla & Tandem & $>1,2 ; \leq 2,4$ & 25.500 \\
\hline
\end{tabular}

Fonte: Autor "adaptado de” Departamento Nacional de Infraestrutura de Transportes, 2012

$E 1$, direcional com rodado simples e um eixo traseiro, $E 2$, de tração com rodado duplo. O eixo $E 1$ tem capacidade de carga de 6,0 toneladas e o eixo $E 2$ tem capacidade de carga de 10,0 toneladas. A diferença entre os semirreboques se encontra na quantidade de eixos em tandem. No primeiro exemplo, CTS-1, o eixo do semirreboque, E3, é isolado com rodado duplo possuindo capacidade de carga de 10,0 toneladas. A configuração CTS-2 apresenta os eixos do semirreboque em tandem duplo com 17,0 toneladas de capacidade carga. Por fim, na configuração CTS-3 os eixos $E 3, E 4$ e $E 5$ se encontram em tandem triplo elevando a capacidade de carga para 25,5 toneladas.

Tabela 9 - Combinações caminhão-trator/semirreboque

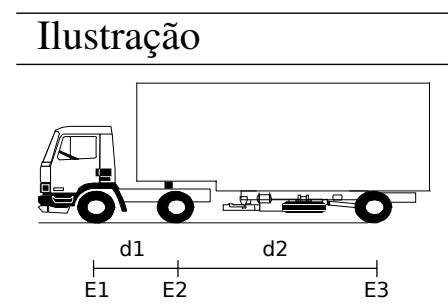

Configuração / Descrição

caminhão-trator e semirreboque (CTS)-1

E1 = eixo simples; carga máxima 6,0 ton

E2 = eixo duplo; carga máxima 10 ton

$\mathrm{E} 3$ = eixo duplo; carga máxima 10 ton

$\mathrm{d} 1, \mathrm{~d} 2>2,40 \mathrm{~m}$

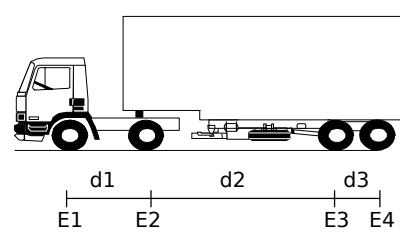

caminhão-trator e semirreboque (CTS)-2

E1 = eixo simples; carga máxima 6,0 ton

E2 = eixo duplo; carga máxima 10 ton

E3 E4 = Tandem duplo; carga máxima 17 ton

$\mathrm{d} 1, \mathrm{~d} 2>2,40 \mathrm{~m} ; 1,20 \mathrm{~m}<\mathrm{d} 3<2,40 \mathrm{~m}$

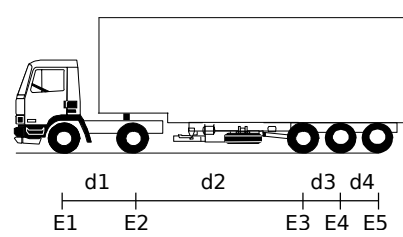

caminhão-trator e semirreboque (CTS)-3

E1 = eixo simples; carga máxima 6,0 ton

E2 = eixo duplo; carga máxima 10 ton

E3 E4 E5 = Tandem triplo; carga máxima 25,5 ton.

$\mathrm{d} 1, \mathrm{~d} 2>2,40 \mathrm{~m} ; 1,20 \mathrm{~m}<\mathrm{d} 3, \mathrm{~d} 4<2,40 \mathrm{~m}$

Fonte: Autor "adaptado de" Departamento Nacional de Infraestrutura de Transportes, 2012 
Na tabela 10 estão outros exemplos, porém agora, as configurações são de caminhãotrator trucado e semirreboque (CTTS). O eixo dianteiro direcional E1 é equivalente ao caminhão trator visto na tabela 9 e os eixos $E 2$ e $E 3$ estão dispostos em tandem duplo. Este conjunto de eixos traseiros do caminhão-trator possui capacidade de carga de 17,0 toneladas. Os três tipos de semirreboque determinam a configuração do veículo. A configuração CTTS-1 apresenta um eixo isolado com rodado duplo e 10,0 toneladas de capacidade de carga. Em seguida, a configuração CTTS-2 possui os eixos E4 e E5 em tandem duplo capazes de suportar 17,0 toneladas. Por fim, os eixos do semirreboque em tandem triplo compõem a configuração CTTS-3 e suportam até 25,5 toneladas.

Tabela 10 - Combinações caminhão-trator-trucado/semirreboque
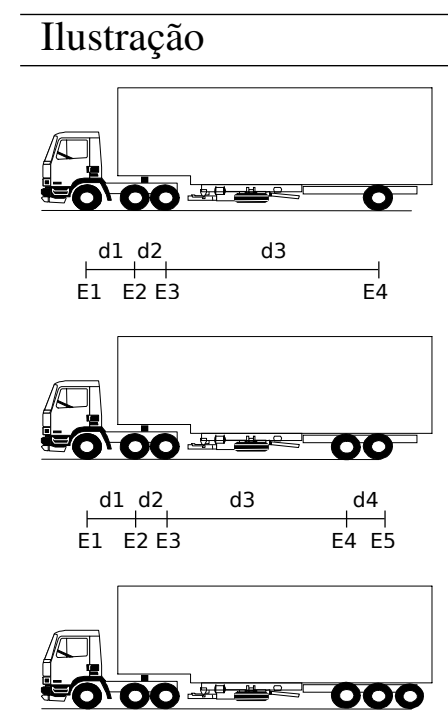

E1 E2 E3
Configuração / Descrição caminhão-trator trucado e semirreboque (CTTS)-1

$\mathrm{E} 1$ = eixo simples; carga máxima 6,0 ton

E2 E3 = Tandem duplo; carga máxima 17 ton

E4 = eixo duplo; carga máxima 10 ton $\mathrm{d} 1, \mathrm{~d} 3>2,40 \mathrm{~m} ; 1,20 \mathrm{~m}<\mathrm{d} 2<2,40 \mathrm{~m}$ caminhão-trator trucado e semirreboque (CTTS)-2

$\mathrm{E} 1$ = eixo simples; carga máxima 6,0 ton E2 E3 = Tandem duplo; carga máxima 17 ton E4 E5 = Tandem duplo; carga máxima 17 ton $\mathrm{d} 1, \mathrm{~d} 3>2,40 \mathrm{~m} ; 1,20 \mathrm{~m}<\mathrm{d} 2, \mathrm{~d} 4<2,40 \mathrm{~m}$ caminhão-trator trucado e semirreboque (CTTS)-3

$\mathrm{E} 1$ = eixo simples; carga máxima 6,0 ton E2 E3 = Tandem duplo; carga máxima 17 ton E4 E5 E6 = Tandem triplo; carga máxima 25,5 ton $\mathrm{d} 1, \mathrm{~d} 3>2,40 \mathrm{~m} ; 1,20 \mathrm{~m}<\mathrm{d} 2, \mathrm{~d} 4<2,40 \mathrm{~m}$

Fonte: Autor “adaptado de” Departamento Nacional de Infraestrutura de Transportes, 2012

Além dos veículos de carga, existem os veículos de transporte de passageiros, que podem assumir a configuração de ônibus urbano articulado (OUA). Alguns exemplos podem ser encontrados na tabela 11. Assim como nos veículos de carga o eixo direcional, $E 1$, é isolado com rodado simples e capacidade de carga de 6,0 toneladas. Na configuração OUA-1 os outros dois eixos são isolados, com rodado duplo e 10,0 toneladas de capacidade de carga cada. As configurações OUA-2 e OUA-3 possuem eixos em tandem, a primeira na unidade dianteira e a última na unidade traseira, ambos com capacidade de carga de 17,0 toneladas.

Diante das configurações apresentadas nas tabelas 9, 10 e 11 é possível verificar a variabilidade possível da capacidade de carga, posicionamento do centro de massa e localização 
Tabela 11 - Ônibus urbano articulado

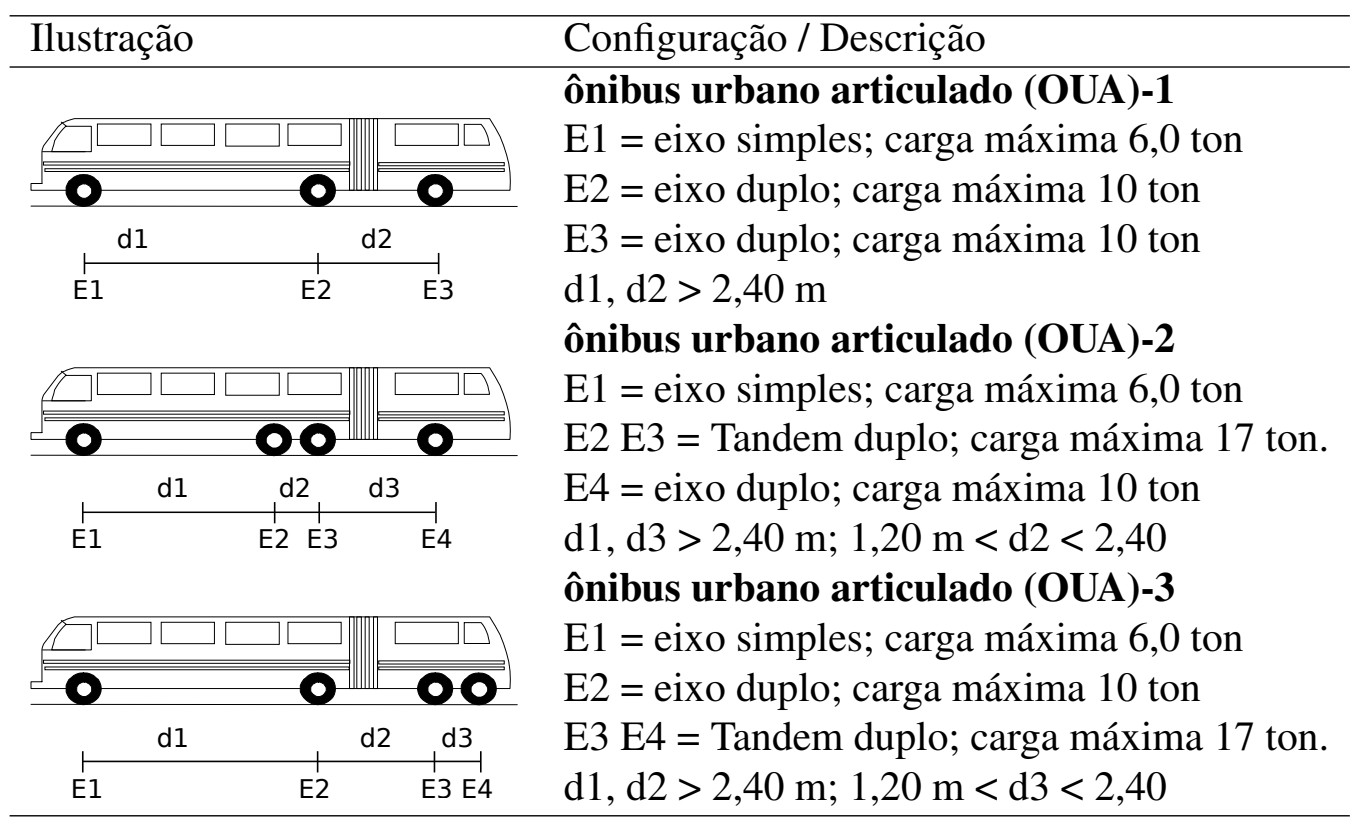

Fonte: Autor "adaptado de” Departamento Nacional de Infraestrutura de Transportes, 2012

do ponto de articulação. Cada arranjo dos eixos implica em diferentes curvas características de pneu, inércias e distâncias relativas dos centros de massa das unidades. Estes e outros parâmetros devem ser levados em consideração nos estudos de estabilidade.

\subsection{ESTABILIDADE DE VEÍCULOS ARTICULADOS}

A estabilidade considerada nesta dissertação é entendida como a estabilidade assintótica no sentido de Lyapunov em que toda solução partindo de um conjunto de condições inicias converge para o ponto de equilíbrio quando o tempo aumenta indefinidamente (OGATA; YANG, 1982). Neste sentido, um dos primeiros estudos de estabilidade lateral aplicados à veículos articulados foi realizado por Ziegler (1938) utilizando o critério de estabilidade de Routh-Hurwitz. Este trabalho é mencionado décadas depois na extensa revisão realizada por Vlk (1982) que cita mais de 250 artigos sobre a estabilidade de veículos articulados e os organiza de acordo com o método de análise e as categorias de desempenho. Os métodos de análise foram divididos em teórico e experimental e as categorias de desempenho incluem o desempenho direcional, de rolagem, de frenagem e combinado (frenagem e esterçamento). Até 1982, a maioria dos trabalhos utilizava métodos teóricos através de modelos matemáticos para o estudo de combinações com uma, duas e três articulações. Modelos lineares, típicamente, eram avaliados através do 
critério de Routh-Hurwitz enquanto modelos não lineares, já naquela época, eram tratados por meio da teoria de Lyapunov. Métodos experimentais como, por exemplo, testes práticos com combinações estavam presentes num menor número de publicações e poucos autores tratavam da comparação entre as análises teóricas e experimentais. Além disso, a revisão fornece informações sobre a evolução das análises no que diz respeito aos modelos de pneu e complexidade dos sistemas utilizados. Até a década de 1960 todas as análises se limitavam a explorar apenas a estabilidade das unidades movidas desconsiderando a sua correlação com o caminhão-trator. A partir de então os autores começaram a utilizar as combinações completas para os estudos de estabilidade como, por exemplo, as significantes contribuições de Jindra, Hales e Schmid (VLK, 1982).

Na década de 1970 o departamento de transporte norte americano iniciou o patrocínio de uma série de pesquisas desenvolvidas pela Universidade de Michigan relacionadas à dinâmica de veículos pesados, simples e articulados. Três relatórios provenientes destas pesquisas são notáveis pela abordagem dada à estabilidade em guinada de veículos articulados. Primeiramente, Ervin et al. (1979) realizaram um estudo de estabilidade em guinada de combinações do tipo caminhão-trator/semirreboque a velocidade constante e sem a presença de frenagem. Foram realizados testes práticos e simulações numéricas em que os veículos e modelos foram submetidos à curvas estacionárias e mudanças simples de pista. Além disso, os autores verificaram a influência na estabilidade de alguns parâmetros do veículo como, por exemplo, rigidez da suspensão, rigidez torcional do chassis e posicionamento da quinta roda. Anos mais tarde, Winkler, Fancher e MacAdam (1983) continuaram os estudos por meio de soluções analíticas e simulações numéricas com a intenção de deteterminar a sensibilidade paramétrica dos limites de estabilidade em rolagem e em guinada. Veículos articulados foram analisados novamente em mudanças simples de pista. O índice de desempenho das manobras é dado pelo ganho da aceleração lateral nas unidades movidas em relação à aceleração lateral da unidade motora. Este índice é conhecido como amplificação traseira da aceleração lateral (Rearward amplification) (VIEIRA, 2010). Os parâmetros estudados foram o posicionamento relativo dos centros de massa e a rigidez da curva característica dos eixos. No ano seguinte, Ervin (1984) ilustraram alguns tipos de combinações exemplificando os tipos de mecanismos de articulação e descrevendo suas características dinâmicas e operacionais. Além disso, são apresentados os desempenhos destes veículos em diversas condições de frenagem. Tombamento e acotovelamento são tratados no texto comparando cada tipo de combinação. Nestes trabalhos o grupo chegou à conclusão que o fenômeno de acotovelamento pode ocorrer bem abaixo dos limites de estabilidade em rolagem. Além disso, constatou-se que o acotovelamento está fortemente 
associado à estratégias de frenagem desfavoráveis e que este fenômeno pode ser responsável pela ocorrência de tombamento subsequente.

Diversos trabalhos, relativamente recentes, continuam apresentando análises de estabilidade através de modelos lineares. Típicamente, são usados modelos do tipo bicicleta com três graus de liberdade e modelos lineares de pneu. Andrzejewski e Awrejcewicz (2005), por exemplo, analisam a influência dos parâmetros de veículos com uma articulação na estabilidade em guinada através do critério de Routh-Hurwitz. Os autores supõem um veículo padrão e variam cada parâmetro individualmente verificando a sua influência na estabilidade. De maneira semelhante, Maas (2007) descreve as regiões de estabilidade limitadas pelas velocidades críticas do conjunto. Além disso, os efeitos de frenagem são introduzidos no modelo linear por meio de uma variação da Magic Formula proposta por Pacejka e Bakker (1992) e detalhada na seção 3.1. A partir dos autovalores, são apresentadas as frequências naturais e constantes de amortecimento do sistema. Desenvolvimento semelhante pode ser encontrado, também, em Hac, Fulk e Chen (2008). Luijten (2010) apresenta o desenvolvimento analítico das velocidades críticas de veículos com uma e duas articulações. O autor descreve os tipos de comportamentos divergentes em guinada fazendo analogias com os fenômenos que ocorrem em veículos simples, sem articulação. Luijten (2010) ainda dedica parte do trabalho à amplificação traseira da aceleração lateral. Nela, é discutida a obtenção deste índice por meio das abordagens no domínio da frequência e do tempo. Ele opta pela análise no domínio da frequência assim como já realizado por El-Gindy, Tong e Tabarrok (1994) e Mugucia et al. (1996), porém, verificando a influência das características construtivas nos valores obtidos.

A relação não linear da força lateral em função do ângulo de deriva, também conhecida como curva característica do pneu, tem grande influência no comportamento dinâmico de veículos (ERVIN et al., 1979). Esta relação acaba por interferir diretamente nas fronteiras de estabilidade de veículos e sua forma depende principalmente do coeficiente de atrito, da carga vertical e do esforço longitudinal no pneu (PACEJKA, 2006). Na tentativa de levar em consideração o comportamento não linear da curva característica muitos autores utilizam um modelo polinomial de terceira ordem como, por exemplo, Johnson e Huston (1984), Samsundar e Huston (1998) e Sadri e Wu (2013). Uma outra abordagem é proposta por Noomwongs (2003) que utilizam um modelo bicicleta de dois graus de liberdade com o chamado Tire Hardware In-The-Loop Simulator. Este simulador é composto por um programa com o modelo dinâmico do veículo e um equipamento que obtem as reações do pneu em tempo real.

Para simulações puramente numéricas é amplamente utilizada a equação semi-empírica conhecida como Magic Formula encontrada pormenorizadamente, também, em Pacejka (2006). 
Esta equação permite adquirir as curvas de força lateral, força longitudinal e torque autoalinhante em função das respectivas grandezas de escorregamento. Os coeficientes apropriados para cada curva são obtidos experimentalmente. Stotsky e Hu (1997) obtêm um modelo polinômial de terceira ordem a partir do truncamento da expansão em série de Taylor da Magic Formula. Dahlberg e Wideberg (2004) utilizam um modelo bicleta não linear com o modelo de pneu dado pela Magic Formula. Os autores verificam a influência do posicionamento longitudinal da articulação na estabilidade de um caminhão-trator com semirreboque. Pacejka (2006) analisa a estabilidade em guinada de veículos simples levando em consideração as não linearidades do pneu através dos diagramas de manobrabilidade (Handling diagrams). Pauwelussen (2001) estende esta análise para veículos articulados do tipo caminhão-trator/semirreboque. O autor utiliza, também, os diagramas de manobrabilidade e analisa cada módulo da combinação como sendo um veículo simples e faz considerações sobre suas características sub e sobreesterçantes.

Programas de computador para simulação dinâmica de sistemas multicorpos como Adams e TruckSim também são usados nas análises de estabilidade de veículos articulados. Em Dahlberg e Wideberg (2004) o programa Adams foi utilizado para comparar os resultados obtidos pelo modelo bicicleta não linear. Wideberg, Dahlberg e Svensson (2009) realizam análises de estabilidade, também, através do programa Adams verificando a estabilidade dos veículos articulados típicos nos Estados Unidos, Canadá, Escandinávia, Europa, Africa do Sul e Brasil. Os desempenhos comparados foram: fator de amplificação traseira, amortecimento em guinada, arraste lateral em alta velocidade e razão de transferência de carga. Apesar destes artigos, estes programas vem sendo mais comumente empregados nos desenvolvimentos de sistemas ativos de controle. Em veículos articulados, controladores são implementados com o objetivo de manter o sistema na região de estabilidade evitando os fenômenos de divergência em rolagem e em guinada. Zhou e Zhang (2012), Zong et al. (2012) e Elhemly, Fayed e Elmaihy (2013) apresentam estratégias de controle baseadas na frenagem diferencial das rodas. Oreh, Kazemi e Azadi (2013) propõem um controlador do tipo Linear-Quadratic Regulator (LQR) que esterça independentemente os eixos dianteiro e traseiro do caminhão-trator e o eixo do semirreboque para atender requisitos de manobrabilidade e estabilidade. Na tentativa de solucionar o problema da longa distância de frenagem em situações de emergência com diferentes coeficientes de atrito nas rodas (split-mu road surface), Zhou e Zhang (2014) apresentam um controle de estabilidade lateral baseado num equipamento anti acotovelamento (anti-jackknife apparatus) que atua limitando o ângulo de articulação. 
A eficiência e robustez de sistemas de controle podem ser aprimoradas com o melhor entendimento dos fenômenos envolvidos. Em veículos articulados, os controladores podem se beneficiar com o conhecimento preciso da região de estabilidade. Para isto, é importante verificar qual tipo de modelo é o mais indicado para representar o sistema e qual técnica deve ser aplicada para determinar as fronteiras de estabilidade. Com relação ao modelo, Islam et al. (2014) verificam dois modelos lineares de veículos articulados para serem usados em análises de estabilidade e simulações dinâmicas. Um modelo linear de quatro graus de liberdade (somente guinada) e um modelo linear de sete graus de liberdade (guinada e inclinação lateral) são simulados em mudanças simples de pista sob diversas condições. Os resultados dinâmicos são comparados com os de um modelo não linear desenvolvido no programa TruckSim e validado experimentalmente. Excelente concordância foi encontrada entre os modelos lineares. Além disso, boa concordância foi obtida entre os modelos lineares e o não linear para manobras de baixa aceleração lateral $(0,3 g)$. Pra acelereções laterais acima de $0,3 g$ o modelo linear começa a apresentar erros significativos, mostrando as suas limitações em reproduzir a realidade.

Para altos valores de coeficiente de atrito e elevada aceleração lateral a instabilidade em guinada pode não ocorrer, ocasionando, ao invés, tombamento (DING et al., 2014). Em contrapartida, se o coeficiente de atrito for baixo é possível atingir a região não linear da curva característica do pneu mesmo sob baixa aceleração lateral. Logo, para manobras em alta velocidade e baixo coeficiente de atrito o risco de acotovelamento está presente e envolve as características não lineares do sistema. Neste caso, um modelo não linear do veículo se torna necessário. Modelos provenientes de programas como Adams e Trucksim, entretanto, exigem elevado custo computacional e tempo de simulação. Além disso, eles são complexos e possuem elevado número de graus de liberdade o que reduz a percepção e compreensão dos fenômenos envolvidos. Portanto, a solução mais indicada consiste em implementar um modelo simplificado, porém, que leve em consideração as não linearidades do sistema.

A análise de estabilidade de sistemas não lineares, quando não linearizados, pode ser realizada por meio do método de trajetórias de fase e pelo método direto de Lyapunov. O primeiro consiste na análise do comportamento das órbitas dos estados a partir de perturbações aplicadas sobre as condições de equilíbrio do sistema. O segundo consiste na determinação da estabilidade baseada numa função de energia fictícia, chamada função de Lyapunov. Ding et al. (2014) utilizam o método de trajetórias de fase para estudar a estabilidade de um modelo não linear de combinação do tipo caminhão-trator/semirreboque. Os autores, primeiramente, linearizam o modelo nos pontos de equilíbrio do sistema. A partir dos autovalores do modelo linearizado é possível determinar o comportamento convergente da vizinhança em torno dos 
pontos fixos. Os modos de instabilidade são calculados a partir dos autovetores e verificados nos espaços de fase evidenciando quais estados apresentam comportamento divergente. A região de estabilidade do ponto fixo estável é estimada calculando a trajetória dos estados para uma série de condições iniciais. Se os estados convergem para o ponto fixo com o aumento do tempo de simulação a condição inicial é considerada parte da bacia de atração. Além disso, uma métrica, chamada índice de estabilidade (Stability index), é proposta para quantificar o tamanho da região de atração. A variação deste índice em função do coeficiente de atrito e velocidade longitudinal é também apresentada. De maneira semelhante, Sun e He (2015) utilizam o plano de fase para verificar a estabilidade de veículos articulados. Os autores adotam um modelo não linear e simulam manobras de mudança simples de pista através de esterçamento senoidal em malha aberta. Através das trajetórias de fase a estabilidade do sistema ao longo da manobra é verificada. Ou seja, este primeiro método permite obter informações sobre o comportamento dinâmico de um sistema submetendo-o à diversas condições iniciais e modos de operação. Logo, para a estimativa de limites de estabilidade é necessário um elevado número de simulações e nada pode ser afirmado sobre o comportamento do sistema para condições não simuladas.

Através do método direto, Sadri e Wu (2012) verificam a região de estabilidade em guinada de um veículo convencional com dois graus de liberdade a velocidade constante e esterçamento igual a zero. Os autores propõem uma função de Lyapunov e comparam a região de estabilidade obtida com regiões menores apresentadas por outros autores em artigos anteriores. A necessidade de extensão desta análise é evidente, pois os fenômenos de instabilidade ocorrem frequentemente em situações de curva com esterçamento diferente de zero (YIN et al., 2015). Logo, Yin et al. (2015) utilizam o método direto para analisar a estabilidade em curva de um veículo elétrico com tração independente em cada roda. Além disso, os autores apresentam a variação da região de estabilidade em função do coeficiente de atrito, ângulo de esterçamento e velocidade longitudinal. Yan, Xu e Liu (2015) também determinam os limites de estabilidade de veículos simples por meio do método direto. Entretanto, os autores levam em consideração, também, a dinâmica em rolagem, logo, o modelo estudado possui três graus de liberdade. A região de estabilidade obtida com este modelo é verificada com resultados experimentais. Essas três publicações discutem e exemplificam as características fundamentais do método direto. Uma delas é o fato de não existir uma técnica estabelecida ou garantia de obtenção da função de Lyapunov. Além disso, caso a função exista, a região de estabilidade inidicada por ela é apenas uma fração da região de estabilidade real do sistema. Por fim, nas regiões em que as condições de estabilidade não se aplicam nada pode ser dito sobre a dinâmica do sistema. 
Um outro método para se determinar a região de estabilidade de sistemas não lineares é através do conceito de expoentes de Lyapunov. Típicamente, este conceito é empregado nos estudos de dinâmica do caos, pois permite verificar a sensibilidade de sistemas caóticos às condições iniciais, quantificando o comportamento divergente de trajetórias vizinhas (SAVI, 2006). Entretanto, os expoentes podem, também, ser aplicados em análises de estabilidade, identificando o comportamento assintótico de sistemas dinâmicos. Uma das formas de se calcular os expoentes é através de algoritmos que levam em consideração o modelo matemático do sistema. A primeira aplicação dos expoentes de Lyapunov para o estudo de estabilidade em dinâmica veicular foi realizada por Sadri e Wu (2013). Os autores utilizam um modelo bicicleta de veículo simples, sem articulação, com um modelo de pneu não linear. Eles verificam a estabilidade do sistema e a estabilidade estrutural. A primeira se refere à região de estabilidade no plano de fase para uma dada configuração dos parâmetros do veículo. A segunda se refere à região de estabilidade definida no espaço em que as dimensões são dadas pelos parâmetros do sistema. A aplicação dos expoentes de Lyapunov fornece uma métrica para determinar a região de estabilidade associada a um ponto fixo estável e à taxa de convergência de sua região de atração. No ano seguinte, Sadri e Wu (2014) propõem uma modificação no método de obtenção dos expoentes de maneira que eles estejam associados a uma determinada direção no espaço de estados. Portanto, esta modificação visa obter o comportamento assintótico do sistema numa direção específica, o que permite análises de estabilidade alternativas de sistemas dinâmicos.

Wu et al. (2005), por exemplo, estudam o comportamento de um manipulador robótico com dois ligamentos sobre uma base móvel. Uma estratégia de controle é apresentada e a estabilidade do sistema controlado é avaliada por meio dos expoentes de Lyapunov. Segundo o autor, a metodologia aplicada no artigo pode contribuir para o projeto de manipuladores em satélites e submarinos e, também, para estudos de locomoção humana e robôs bípedes. Outra área de aplicação é tratada por Yang, Chen e Jiang (2015) que utilizam os expoentes de Lyapunov como ferramenta para auxiliar a previsão de resposta não linear de rotores. Em contrapartida, uma outra forma de se calcular os expoentes de Lyapunov é a partir de séries temporais. Esta possibilidade é bastante atraente, pois permite obter informações relevantes sobre o comportamento do sistema sem ter o conhecimento de seu modelo matemático. Yang e Wu (2010) abordam os algoritmos existentes associados à obtenção dos expoentes de Lyapunov a partir de séries temporais. Os autores propõem algumas alterações e aplicam o novo algoritmo no estudo de estabilidade de um robô bípede. A comparação de desempenho dos algoritmos mais comumente utilizados pode ser encontrada em Rispens et al. (2014). 
É possível perceber que existe uma tendência na utilização de modelos não lineares em análises de estabilidade de veículos articulados pois, em determinados cenários, os modelos lineares não são capazes de reproduzir os fenômenos com a precisão necessária. Além disso, é evidente a importância de se utilizar um método de análise apropriado que permita identificar os pontos estacionários e as regiões de estabilidade de maneira formal. Portanto, esta dissertação procura contribuir para a discussão à respeito dos tipos de modelos matemáticos e métodos de análise que podem ser empregados na determinação da região de estabilidade de veículos articulados. 


\section{MODELOS MATEMÁTICOS}

Nesta seção são apresentados os modelos matemáticos utilizados na análise de estabilidade em guinada de veículos articulados. Primeiramente, é feita a descrição do modelo de pneu não linear escolhido. Em seguida, se encontra o desenvolvimento analítico das equações de movimento de um modelo não linear do tipo bicicleta com quatro graus de liberdade.

\subsection{MODELO DE PNEU}

O pneu é o principal responsável pela manutenção da trajetória e garantia de estabilidade. É através da interação do pneu com o solo que surgem as forças necessárias para a execução das manobras que o veículo deve desempenhar. Existem diversas abordagens para se caracterizar o comportamento de um pneu. Porém, é importante traduzir esse comportamento em modelos matemáticos praticáveis computacionalmente. Em aplicações de dinâmica o pneu é normalmente caracterizado pelas forças e momentos que ele consegue transmitir ao conjunto de acordo com o estado dinâmico em que o sistema se encontra. Essas forças e momentos dependem de diversos componentes como, por exemplo, carga vertical, dos chamados escorregamentos e do posicionamento e inclinação do eixo da roda em relação à pista.

As cargas verticais são as forças exercidas sobre cada pneu e que, na prática, variam conforme as manobras que estão sendo executadas. Escorregamentos (slip) são, na realidade, deslizamentos aparentes entre o pneu e o solo, pois em geral, na maior parte da região de contato não ocorre movimento relativo entre os dois. Para quantificar esses escorregamentos a análise é separada nas direções longitudinal, lateral e vertical (longitudinal slip, slip angle e turn spin, respectivamente). Em Pacejka (2006) é possível verificar com detalhes as definições dos fenômenos de escorregamento. Nesta dissertação é utilizado, apenas, o conceito de escorregamento lateral que é quantificado através do ângulo de deriva, entendido, aqui, como o ângulo formado pelo plano longitudinal da roda e a direção do vetor velocidade do centro da roda. Este ângulo surge devido à deformação circunferencial do pneu que permite uma componente transversal do vetor velocidade. Em situações em que as acelerações laterais são elevadas os pneus fornecem maior ângulo de deriva para que a força lateral necessária para a manutenção da trajetória seja atingida. 
A figura 3 mostra a relação típica da força lateral do pneu $F_{y}$ em função do ângulo de deriva $\alpha$, a chamada curva característica do pneu, e ilustra, também, a definição de escorregamento lateral.

Figura 3 - Curva característica típica do pneu (à esquerda) e definição do ângulo de deriva (à direita)
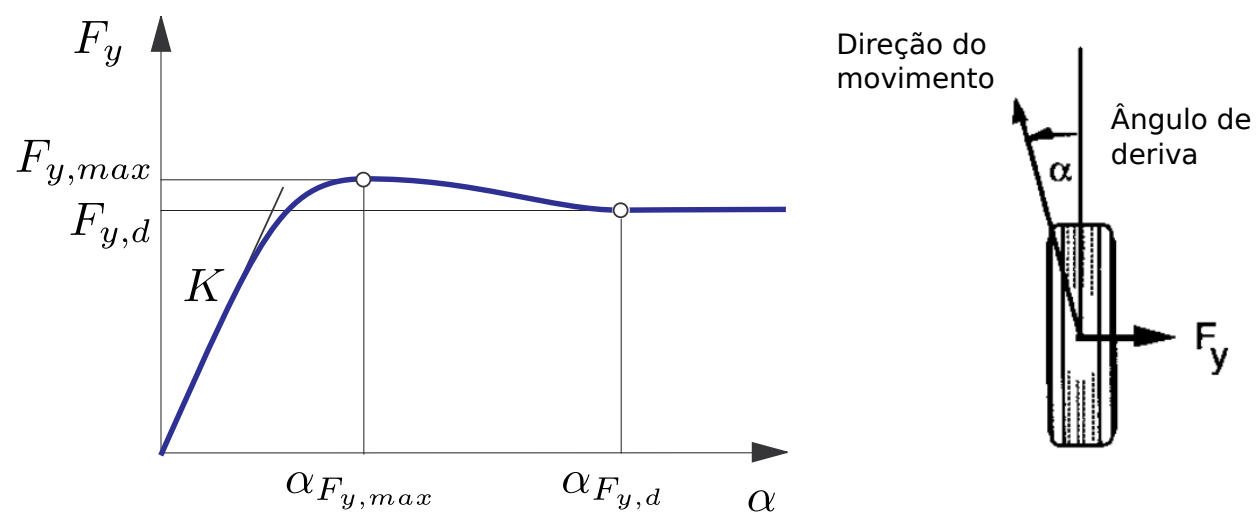

Fonte: Autor “adaptado de” Rill, 2009 e Gillespie, 1992

É possível observar que, para ângulos pequenos, a curva característica apresenta uma relação aproximadamente linear entre as duas grandezas. A inclinação desta reta é dada pelo coeficiente de rigidez de curva (Cornering stiffness) $K$. Além disso, $F_{y, \max }$ é a força lateral máxima, $F_{y, d}$ é a força lateral constante de deslizamento exercida pelo pneu quando o pico de força lateral é ultrapassado. Nesta situação o pneu não possui característica direcional, ou seja, desliza como um bloco sobre a pista.

A força lateral para pequenos ângulos pode ser aproximada pela equação linear

$$
F_{y, \text { lin }}=K \alpha
$$

Na figura 3 é possível observar, também, que o modelo linear só acompanha a curva característica para ângulos pequenos. Logo, conforme o ângulo de deriva cresce a reta apresenta desvios significativos em relação à realidade. Na tentativa de incorporar essa característica não linear diversos autores (ver seção 2.2) fazem uso de um modelo polinomial em que a força lateral é escrita em função do ângulo de deriva como

$$
F_{y, p o l}=k_{1} \alpha-k_{2} \alpha^{3},
$$

onde $k_{1}$ e $k_{2}$ são os coeficientes que definem o modelo. Entretanto, apesar do termo de terceira ordem presente na equação (2) o modelo polinomial não reproduz adequadamente a curva 
característica para todos os valores possíveis de ângulo de deriva. Como é apresentado mais adiante, para ângulos grandes (ângulos maiores que o ângulo em que a força lateral é máxima) a curva característica dada pelo modelo polinomial passa a ser decrescente, o que não ocorre na prática. Portanto, uma outra abordagem deve ser empregada a fim de levar em consideração o aspecto típico da curva característica dos pneus ilustrado na figura 3.

Um modelo de pneu capaz de representar toda a faixa possível de ângulo de deriva é apresentado por Pacejka e Bakker (1992). Este modelo é descrito através de equações algébricas e parâmetros obtidos experimentalmente. A força lateral nominal exercida pelo pneu na condição de escorregamento puro (apenas ângulo de deriva presente) é calculada por meio da expressão

$$
F_{y, n, P a c}(\alpha)=D \sin [C \arctan \{B \alpha-E(B \alpha-\arctan (B \alpha))\}]
$$

que recebe o nome de Magic Formula.

O coeficiente $C$ é chamado de fator de forma (Shape factor) e é dado por

$$
C=\mathrm{a}_{0}
$$

onde $\mathrm{a}_{0}$ é um dos parâmetros experimentais do pneu.

$D$ é o fator de pico (Peak factor) que representa a força lateral máxima do pneu e é escrito em função da carga vertical $F_{z}$ como

$$
D=\mu_{n} F_{z}=\left(\mathrm{a}_{1} F_{z}+\mathrm{a}_{2}\right) F_{z}
$$

onde $\mu_{n}$ é o coeficiente de atrito nominal, $\mathrm{a}_{1}$ define influência da força vertical sobre o coeficiente de atrito nominal e $\mathrm{a}_{2}$ define o nível de atrito lateral.

O coeficiente de rigidez de curva para o ângulo de deriva igual a zero é dado pelo produto $B C D$ que pode ser escrito em função da carga vertical como

$$
B C D=\mathrm{a}_{3} \sin \left\{2 \arctan \left(\frac{F_{z}}{\mathrm{a}_{4}}\right)\right\}\left(1-\mathrm{a}_{5}|\gamma|\right),
$$

onde $a_{3}$ é a máxima rigidez de curva (para $\gamma=0$ ) e $a_{4}$ é a carga vertical em que a rigidez de curva é máxima. $O$ coeficiente $a_{5}$ indica a influência da cambagem sobre a rigidez de curva.

$B$ é o fator de rigidez (Stiffness factor) e pode ser calculado como

$$
B=\frac{B C D}{C D}
$$


fazendo uso das equações (4), (5) e (6).

O fator de curvatura (Curvature factor) $E$ é dado por

$$
E=\mathrm{a}_{6} F_{z}+\mathrm{a}_{7},
$$

onde $\mathrm{a}_{6}$ indica a influência da força vertical sobre a curvatura e $\mathrm{a}_{7}$ quantifica o nível do fator de curvatura.

O modelo de pneu descrito pelas equações (3) a (8) passa pela origem apresentando força lateral igual a zero quando há ausência de ângulo de deriva. Típicamente, esta curva é ligeiramente deslocada na direção verical e horizontal devido a efeitos de acomodação das lonas do pneu (Ply steer), conicidade e cambagem. Entretanto, estes fenômenos não são considerados nesta dissertação.

A curva característica para um valor de coeficiente de atrito diferente do nominal pode ser obtida através do método de similaridade documentado em Pacejka (2006). Logo, a força lateral efetiva é calculada por

$$
F_{y, P a c}=\frac{\mu}{\mu_{n}} F_{y, n, P a c}\left(\alpha_{e q}\right),
$$

onde $\mu$ é o coeficiente de atrito de operação e $\alpha_{e q}$ é ângulo de deriva equivalente definido como

$$
\alpha_{e q}=\frac{\mu_{n}}{\mu} \alpha
$$

Logo, o modelo completo, Magic Formula em conjunto com o ajuste pelo método de similaridade, é chamado de modelo de pneu Pacejka.

Resumindo, as equações (1), (2) e (9) se referem aos modelos de pneu linear, polinomial e Pacejka, respectivamente.

Como apresentado na figura 3 a curva característica típica apresenta três elementos básicos: Inclinação para ângulos de deriva próximos de zero $K$, força lateral máxima $F_{y, \max } \mathrm{e}$ força de deslizamento $F_{y, d}$. Para comparar adequadamente as curvas características dos modelos de pneu apresentados até aqui é necessário ajustar seus parâmetros de maneira que o maior número de elementos das curvas sejam igualados. Ou seja, a rigidez lateral deve ser a mesma para todos os modelos e, além disso, é preciso igualar, também, a força lateral máxima dos modelos polinomial e Pacejka (não aplicável ao modelo linear).

A derivada da força lateral em relação ao ângulo de deriva de cada modelo é dada por 


$$
\begin{aligned}
\frac{d F_{y, l i n}}{d \alpha} & =K \\
\frac{d F_{y, p o l}}{d \alpha} & =k_{1}-3 k_{2} \alpha^{2} \\
\frac{d F_{y, P a c}}{d \alpha} & =\frac{d F_{y, n, P a c}\left(\alpha_{e q}\right)}{d \alpha_{e q}}
\end{aligned}
$$

A mesma rigidez de curva para os três modelos é obtida igualando a derivada das forças laterais em relação ao ângulo de deriva e avaliando o resultado para $\alpha=0$ :

$$
\left.\frac{d F_{y, l i n}}{d \alpha}\right|_{\alpha=0}=\left.\frac{d F_{y, p o l}}{d \alpha}\right|_{\alpha=0}=\left.\frac{d F_{y, P a c}}{d \alpha}\right|_{\alpha=0} .
$$

Logo, a partir das equações em (11) é possível demonstrar que a equação (12) se reduz à

$$
K=k_{1}=B C D
$$

Em cada modelo, o ângulo de deriva em que a força lateral máxima ocorre $\alpha_{\max }$ (não aplicável ao modelo linear) é dado pelo ângulo em que a derivada da força lateral em relação ao ângulo de deriva é zero. Utilizando a equação referente ao modelo polinomial em (11) é possível obter

$$
\alpha_{\text {pol,max }}=\sqrt{\frac{k_{1}}{3 k_{2}}} .
$$

A força lateral máxima do modelo polinomial é obtida substituindo a equação (14) na equação (2):

$$
F_{y, p o l, \max }=\sqrt{\frac{4 k_{1}^{3}}{27 k_{2}}} .
$$

Como visto na equação (5) a constante $D$ representa o pico de força do modelo de pneu Pacejka e deve ser igual à equação (15). Portanto

$$
D=\sqrt{\frac{4 k_{1}^{3}}{27 k_{2}}} .
$$

Logo, para que os três modelos sejam comparados adequadamente as equações (13) e (16) devem ser atendidas. Como base para comparação é escolhido um modelo de pneu Pacejka 
com os parâmetros listados na tabela 12. Neste caso, levando em consideração as restrições impostas pelas equações (13) e (16), o modelo linear tem coeficiente de rigidez lateral dado por $K=114.600 \mathrm{~N} / \mathrm{rad}$ e o modelo polinomial apresenta coeficientes $k_{1}=114.600 \mathrm{~N} / \mathrm{rad} \mathrm{e}$ $k_{2}=558.102 \mathrm{~N} / \mathrm{rad}^{3}$.

Tabela 12 - Parâmetros do modelo de pneu Pacejka para o exemplo de comparação

\begin{tabular}{clrr}
\hline Item & Descrição & Valor & Unidade \\
\hline $\mathrm{a}_{0}$ & Fator de forma (Shape factor) & 1,3 & - \\
$\mathrm{a}_{1}$ & Influência de $F_{z}$ sobre $\mu_{n}(* 1000)$ & 0 & $1 / k N$ \\
$\mathrm{a}_{2}$ & Nível de atrito $(* 1000)$ & 700 & - \\
$\mathrm{a}_{3}$ & Rigidez de curva máxima (para $\gamma=0)$ & $2.0001 e+03$ & $\mathrm{~N} / \mathrm{grau}$ \\
$\mathrm{a}_{4}$ & Carga vertical em que a rigidez de curva é máxima & 28.5542 & $k N$ \\
$\mathrm{a}_{5}$ & Influência de $\gamma$ sobre a rigidez de curva & 0 & $1 /$ grau \\
$\mathrm{a}_{6}$ & Influência de $F_{z}$ sobre a curvatura & 0 & $1 / k N$ \\
$\mathrm{a}_{7}$ & Nível do fator de curvatura & -2.2 & - \\
Fonte: Autor & & &
\end{tabular}

Na figura 4 se encontram as curvas características dos três modelos com os parâmetros ajustados segundo as expressões (13) e (16). É possível observar que para pequenos ângulos de deriva qualquer modelo pode ser utilizado pois todos apresentam mesma inclinação de curva quando o ângulo de deriva se aproxima de zero. Como já discutido acima, conforme o ângulo de deriva cresce, as limitações das hipóteses simplificadoras se tornam evidentes fazendo com que os modelos linear e polinomial não reproduzam com fidelidade os fenômenos que ocorrem na prática. Porém, até o ponto de saturação o modelo polinomial ainda apresenta resultados satisfatórios acompanhando a não linearidade que resulta no valor máximo de força lateral.

Em determinadas condições de operação, na vizinhança da fronteira de estabilidade, o veículo pode ser submetido a rotações com elevada velocidade angular, deslizar lateralmente e até encerrar a manobra trafegando de ré. Logo, é razoável supor que os pneus apresentem ângulos de deriva de até \pm 180 graus. Isto é verificado mais adiante na figura 29. Nestas situações, os modelos linear e polinomial não são capazes de representar as forças laterais de acordo com o comportamento típico dos pneus (Isto pode ser observado comparando as figura 3 e 4). Logo, o modelo de pneu a ser usado nas simulações é o modelo Pacejka descrito na equação (9). A curva característica nominal se encontra na equação (3) e o ângulo de deriva equivalente é dado pela equação (10). Por fim, os coeficientes $B, C, D$ e $E$ são definidos nas equações (4), (5), (7) e (8), respectivamente, e escritos em função dos parâmetros experimentais $\mathrm{a}_{0}, \mathrm{a}_{1}, \mathrm{a}_{2}, \mathrm{a}_{3}, \mathrm{a}_{4}, \mathrm{a}_{5}$, $\mathrm{a}_{6}$ e $\mathrm{a}_{7}$. 
Figura 4 - Comparação dos modelos de pneu linear, polinomial e Pacejka

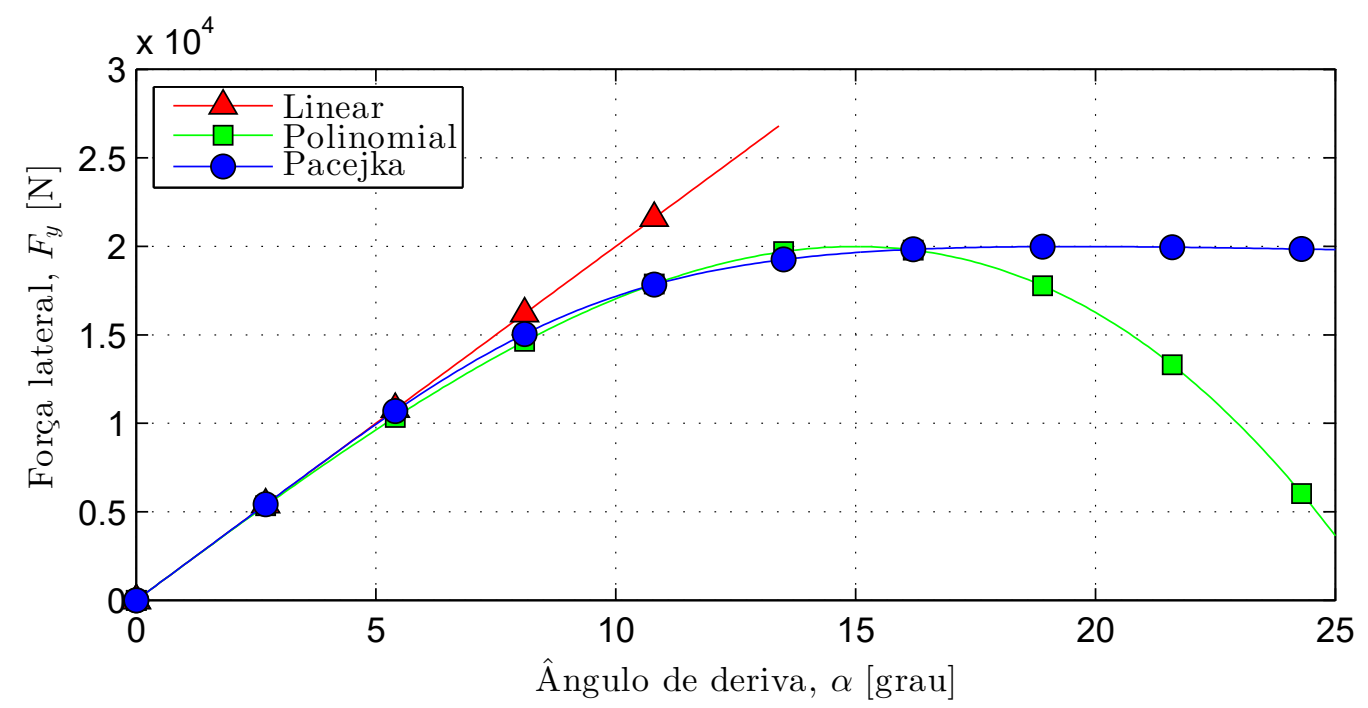

Fonte: Autor

Entretanto, a aplicação direta da equação (9) pode apresentar imprecisões. A equação (9) mantém a força lateral constante e diferente de zero conforme o módulo do ângulo de deriva cresce. Na realidade, isto não ocorre, pois a força lateral retorna a zero quando o ângulo de deriva é igual a \pm 180 graus. A parte positiva (negativa) da curva é simétrica com relação ao eixo vertical imaginário posicionado sobre o ângulo de +90 graus ( -90 graus). Por exemplo, conforme o ângulo de deriva cresce e ultrapassa o valor de 90 graus a força lateral deve se comportar como se estivesse voltando no sentido contrário da curva característica. Ou seja, a evolução da força lateral para um ângulo de deriva crescente indo de 90 a 180 graus deve ser igual à evolução da força lateral para um ângulos de deriva decrescente indo de 90 a 0 graus. De maneira análoga o mesmo deve ser feito com valores negativos do ângulo de deriva. Este comportamento é obtido realizando o tratamento do ângulo de deriva por meio do cálculo da expressão

$$
\alpha_{\text {com }}=\arcsin \left(\sin \left(\alpha_{\text {sem }}\right)\right)
$$

onde $\alpha_{c o m}$ é o ângulo de deriva tratado e $\alpha_{\text {sem }}$ é o ângulo de deriva decorrente da dinâmica do sistema. Este tratamento só é efetivo quando a função arcsin retorna o valor do ângulo nos quadrantes um e quatro. O efeito gerado pelo tratamento do ângulo de deriva definido na equação (17) pode ser observado na figura 5. Nesta figura, duas curvas do modelo de pneu Pacejka com os mesmos parâmetros são apresentadas. Numa curva é feito o tratamento do ângulo de deriva e na outra não. 
Figura 5 - Comparação da curva característica para ângulos de deriva com e sem tratamento

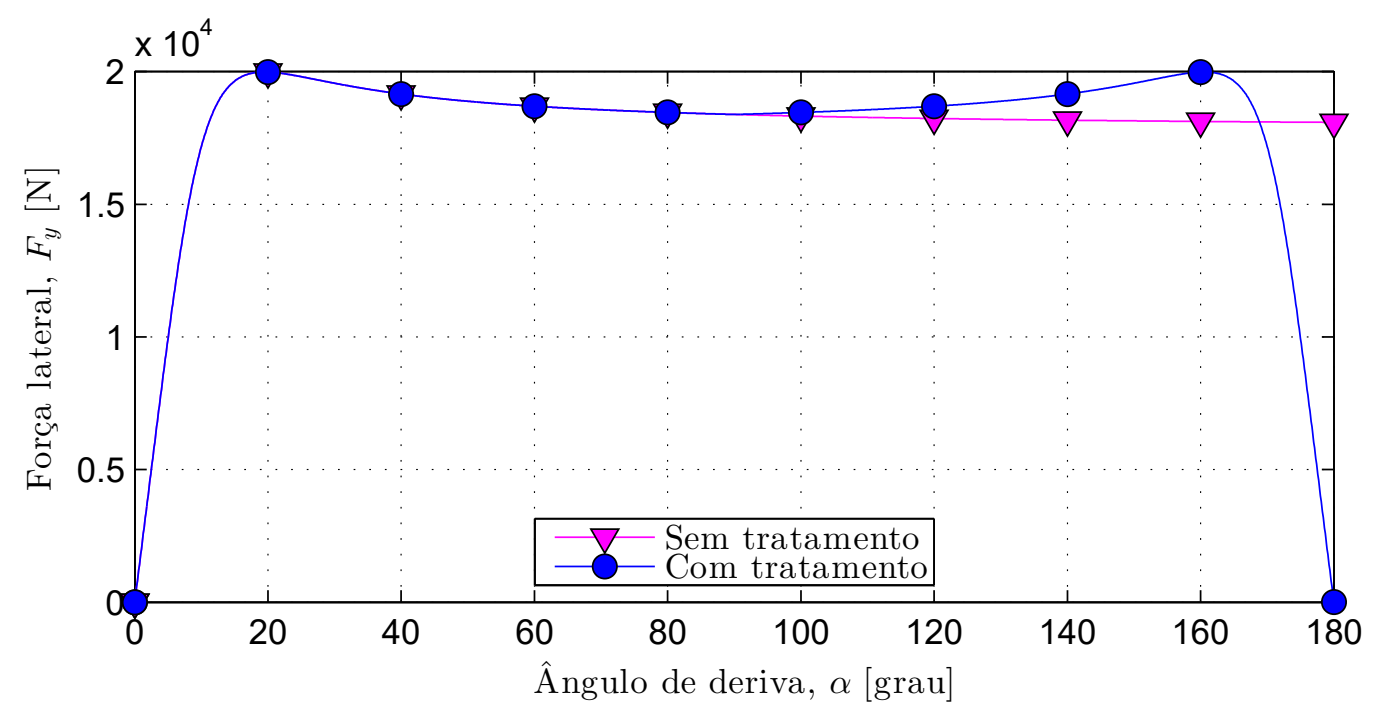

Fonte: Autor

Resumindo, as hipóteses do modelo de pneu não linear utilizado são:

a) só é considerado escorregamento na direção lateral;

b) torque auto alinhante é desprezado;

c) ângulo de cambagem $\gamma$ é igual a zero;

d) forças laterais decorrentes da acomodação das lonas do pneu e conicidade são desprezadas;

e) ângulo de deriva varia de -180 a 180 graus;

f) tratamento do ângulo de deriva é aplicado para que a força lateral volte a zero para $\alpha= \pm 180$ graus.

\subsection{MODELO DE VEÍCULO ARTICULADO}

O objetivo desta seção consiste em desenvolver o modelo matemático da dinâmica em guinada do conjunto caminhão-trator e semirreboque. Como discutido na revisão bibliográfica (seção 2.2), o modelo deve ser o mais simples possível, porém, ao mesmo tempo, deve ser capaz de representar adequadamente os fenômenos envolvidos. Em aplicações voltadas para a análise de estabilidade em guinada de veículos articulados, Andrzejewski e Awrejcewicz (2005), Hac, Fulk e Chen (2008), Luijten (2010) e outros autores fazem uso de um modelo do tipo bicicleta, 
linear e com três graus de liberdade. Os estados utilizados e que indicam a dinâmica em guinada são: velocidade angular do caminhão-trator $\dot{\psi}$, o ângulo de deriva do vetor velocidade do centro de massa do caminhão-trator $\alpha_{T}$ e ângulo formado entre as duas unidades $\phi$. Os ângulos referentes a estes estados podem ser vistos na figura 6. O modelo em questão é relativamente simples e o seu desenvolvimento matemático é usado como base para o desenvolvimento das equações de movimento utilizadas nesta dissertação. Porém, é necessário, primeiramente, verficiar se as hipóteses simplificadoras utilizadas pelos autores são aplicáveis às condições de operação na vizinhança da fronteira de estabilidade.

O modelo do sistema é essencialmente não linear principalmente por conta da curva característica do pneu apresentada na seção 3.1. Porém, o próprio modelo do veículo apresenta não linearidades devido às funções trigonométricas presentes nas equações de movimento. Como parte da estratégia de simplificação o modelo é linearizado em torno dos valores nulos das coordenadas que descrevem o sistema. Este procedimento faz uso das aproximações $\sin \theta \approx \tan \theta \approx \theta$ e $\cos \theta \approx 1$. Estas simplificações, por sua vez, para serem atendidas implicam na hipótese de pequenos desvios do ponto de operação e pequenos valores de esterçamento. A própria condição dinâmica inicial a ser testada na seção 6 já se encontra fora da região em que esta aproximação gera erros satisfatórios. Logo, as não linearidade do modelo de veículo devem ser consideradas.

A movimentação com velocidade do centro de massa constante fornece uma restriçao equivalente a uma atuação externa no centro de massa do caminhão-trator sem interferir diretamente na orientação do veículo. Como discutido na seção 1.1 e 3.1 as manobras na vizinhança da região de estabilidade podem submeter o veículo a condições dinâmicas em que o vetor velocidade apresente elevada componente transversal. Caso a velocidade seja constante a dissipação de energia esperada não ocorre. Isto prejudica a representatividade do modelo proporcionando condições dinâmicas atípicas. Portanto, esta hipótese também não é considerada, introduzindo mais um estado na caracterização do sistema, o módulo do vetor velocidade do centro de massa do caminhão-trator $v$.

A dinâmica em arfagem (pitch) e rolagem (roll) não estão presentes no modelo. Desprezar a primeira é possível, pois esforços longitudinais no pneu não estão presentes. Além disso, o veículo trafega numa pista com elevação constante. A dinâmica de rolagem, por sua vez, apresenta grande influência neste tipo de veículo, devido a seu elevado centro de massa, que aumenta a possibilidade de tombamento. Entretanto, a instabilidade em rolagem ocorre quando a aceleração lateral ultrapassa um determinado valor, conhecido como limiar de tombamento (rollover threshold) (WINKLER; ERVIN, 1999). O valor típico deste limite de aceleração lateral se 
encontra entre 0,2 e $0,5 g$. Uma abordagem possível consiste em monitorar a aceleração lateral e considerar apenas as análises em que ela se mantém abaixo do limiar. Desta forma é possível desprezar a dinâmica em rolagem e, ao mesmo tempo, verificar a ausência de tombamento de acordo com o valor máximo da aceleração lateral ao longo da manobra.

Considerando as hipóteses discutidas até aqui, o modelo de veículo articulado utilizado nas análises de estabilidade em guinada é, portanto, não linear, do tipo bicicleta, possui quatro graus de liberdade e se encontra ilustrado na figura 6. As variáveis que definem o sistema são $\dot{\psi}, \phi, v$ e $\alpha_{T}$. Assim como no modelo linear o ângulo $\psi$ define a orientação do caminhão-trator em relação ao referencial inercial. O estado $\phi$ é o ângulo formado entre o caminhão-trator e o semirreboque. O ângulo $\alpha_{T}$ é o ângulo de deriva do módulo dianteiro e é formado pelo vetor velocidade do centro de massa e a linha longitudinal do caminhão-trator. $v$ é o módulo do vetor velocidade do centro de massa do caminhão- trator. Os pontos $T$ e $S$ são coincidentes com os centros de massa do caminhão-trator e semirreboque, respectivamente. Os pontos $F$ e R são coincidentes com os eixos dianteiro e traseiro do caminhão-trator, respectivamente. $M$ é o ponto que representa o eixo do semirreboque e A é o ponto de articulação entre as duas unidades. As grandezas escalares $a, b$ e $c$ auxiliam a localização dos pontos $\mathrm{F}, \mathrm{T}, \mathrm{R}$ e A do caminhão-trator. As grandezas escalares $d$ e $e$ auxiliam a localização dos pontos $\mathrm{A}, \mathrm{S}$ e $\mathrm{M}$ no semirreboque. A localização destes pontos entre si é definida como:

$$
\begin{aligned}
& (\mathrm{F}-\mathrm{T})=a \mathbf{t}_{x} \\
& (\mathrm{~T}-\mathrm{R})=b \mathbf{t}_{x} \\
& (\mathrm{R}-\mathrm{A})=c \mathbf{t}_{x} \\
& (\mathrm{~A}-\mathrm{S})=d \mathbf{s}_{x} \\
& (\mathrm{~S}-\mathrm{M})=e \mathbf{s}_{x}
\end{aligned}
$$

Os módulos $|a|$, $|b|$ e $|c|$ da unidade motora são as distâncias entre os pontos $\mathrm{F}-\mathrm{T}$, $\mathrm{T}-\mathrm{R}$ e $\mathrm{R}-\mathrm{A}$, respectivamente. Na unidade movida, $|d|$ e $|e|$ definem as distâncias entre os pontos A-S e S-M, respectivamente. Importante notar que as grandezas escalares da equação (18) podem assumir valores negativos.

As bases usadas para a descrição do sistema são $\left\{\mathrm{Tt}_{x} \mathbf{t}_{y} \mathbf{t}_{z}\right\},\left\{\mathrm{Ss}_{x} \mathbf{s}_{y} \mathbf{s}_{z}\right\}$ e $\left\{\mathrm{Fe}_{x} \mathbf{e}_{y} \mathbf{e}_{z}\right\}$. A base $\left\{T \mathbf{t}_{x} \mathbf{t}_{y} \mathbf{t}_{z}\right\}$ é solidária ao módulo dianteiro com a origem dada pelo ponto $\mathrm{T}$ e o vetor unitário $\mathbf{t}_{x}$ paralelo à direção longituinal do veículo apontando para a frente. $\mathrm{O}$ vetor $\mathbf{t}_{y}$ se 
Figura 6 - Modelo físico do conjunto caminhão-trator e semirreboque

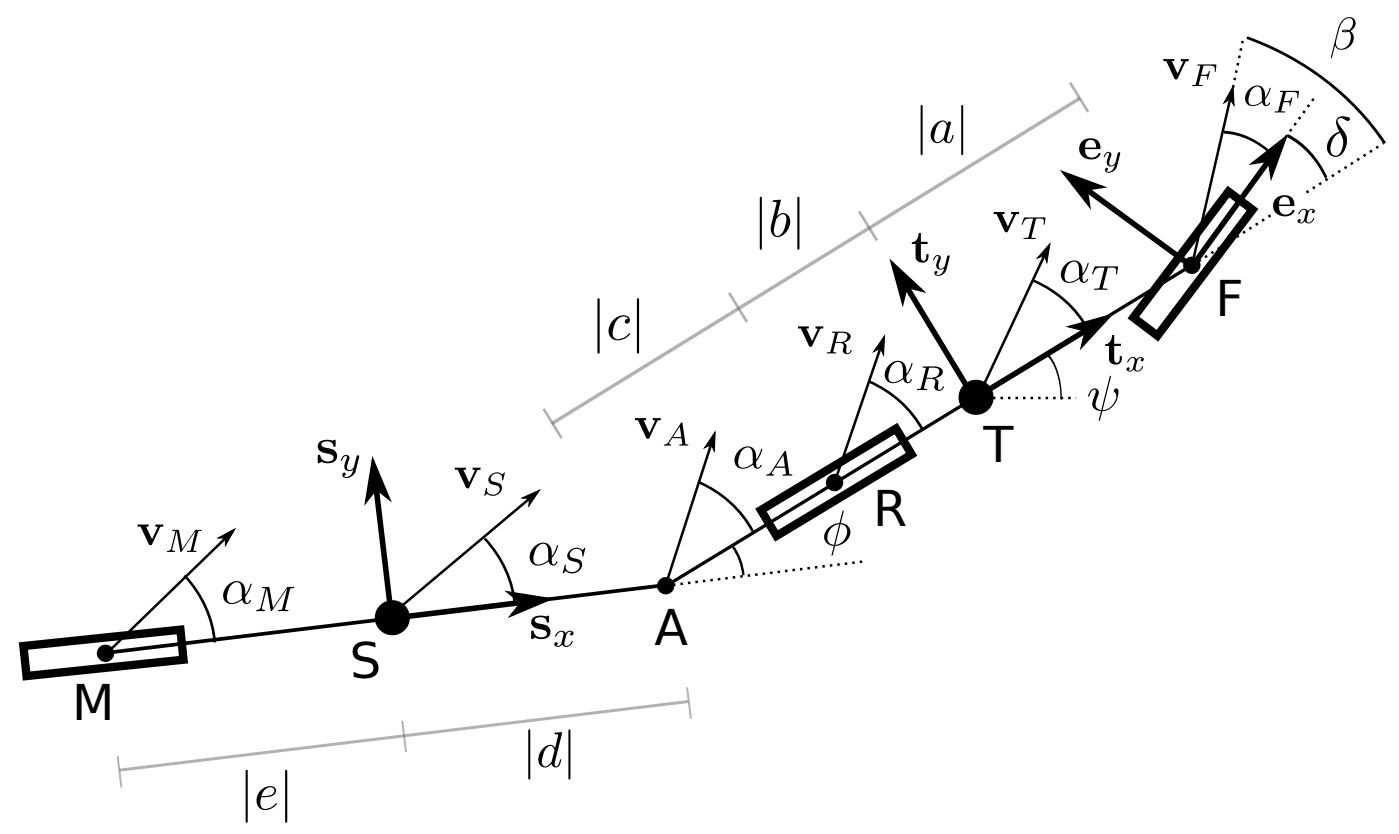

Fonte: Autor

encontra na direção transversal e aponta para esquerda. De maneira análoga, a base $\left\{\mathrm{Ss}_{x} \mathbf{s}_{y} \mathbf{s}_{z}\right\}$ está posicionada no módulo traseiro com a origem dada pelo ponto S. Para uma descrição mais clara das grandezas associadas ao eixo dianteiro uma base adicional é definida, $\left\{\mathrm{Fe}_{x} \mathbf{e}_{y} \mathbf{e}_{z}\right\}$. A origem é dada pelo ponto $\mathrm{F}$ e o vetor $\mathbf{e}_{x}$ é definido na direção longitudinal do pneu dianteiro e aponta para frente do veículo. $\mathrm{O}$ eixo $\mathbf{e}_{y}$ se encontra posicionado na direção normal ao plano longitudinal do pneu e aponta para a esquerda. Em todas as bases o vetor na direção vertical é obtido, naturalmente, pela regra da mão direita.

O vetor velocidade no ponto $T$ é dado por

$$
\mathbf{v}_{T}=v \cos \alpha_{T} \mathbf{t}_{x}+v \sin \alpha_{T} \mathbf{t}_{y}
$$

Os vetores velocidade no ponto $F, R$ e A podem ser obtidos através de

$$
\begin{aligned}
& \mathbf{v}_{F}=\mathbf{v}_{T}+\mathbf{p} \wedge(\mathrm{F}-\mathrm{T}) \\
& \mathbf{v}_{R}=\mathbf{v}_{T}+\mathbf{p} \wedge(\mathrm{R}-\mathrm{T}) \\
& \mathbf{v}_{A}=\mathbf{v}_{T}+\mathbf{p} \wedge(\mathrm{A}-\mathrm{T}),
\end{aligned}
$$


onde $\mathbf{p}=\dot{\psi} \mathbf{t}_{z}$ é o vetor velocidade angular do módulo dianteiro e $\wedge$ representa o produto vetorial entre dois vetores. $(F-T),(R-T)$ e $(A-T)$ são os vetores que apontam para os pontos $\mathrm{F}, \mathrm{R}$ e $\mathrm{A}$ a partir do ponto $\mathrm{T}$, respectivamente. Em detalhes

$$
\begin{aligned}
(\mathrm{F}-\mathrm{T}) & =a \mathbf{t}_{x} \\
(\mathrm{R}-\mathrm{T}) & =-b \mathbf{t}_{x} \\
(\mathrm{~A}-\mathrm{T}) & =-(b+c) \mathbf{t}_{x} .
\end{aligned}
$$

Logo, substituindo as equações (19) e (21) em (20), os vetores velocidade nos pontos pertencentes ao módulo de tração podem ser reescritos como

$$
\begin{aligned}
& \mathbf{v}_{F}=v \cos \alpha_{T} \mathbf{t}_{x}+\left[v \sin \alpha_{T}+a \dot{\psi}\right] \mathbf{t}_{y} \\
& \mathbf{v}_{R}=v \cos \alpha_{T} \mathbf{t}_{x}+\left[v \sin \alpha_{T}-b \dot{\psi}\right] \mathbf{t}_{y} \\
& \mathbf{v}_{A}=v \cos \alpha_{T} \mathbf{t}_{x}+\left[v \sin \alpha_{T}-(b+c) \dot{\psi}\right] \mathbf{t}_{y} .
\end{aligned}
$$

Como discutido na seção 3.1, o ângulo de deriva é definido como o ângulo formado pelo vetor velocidade e o plano da roda. A partir do vetor velocidade $\mathbf{v}_{F}$ escrito na base $\left\{\mathrm{Tt}_{x} \mathbf{t}_{y} \mathbf{t}_{z}\right\}$ é possível verificar que o ângulo formado pelo vetor velocidade e o eixo longitudinal do módulo dianteiro é dado por:

$$
\beta=\arctan \left(\frac{v \sin \alpha_{T}+a \dot{\psi}}{v \cos \alpha_{T}}\right) .
$$

O ângulo de deriva no eixo dianteiro é dado por:

$$
\alpha_{F}=\beta-\delta
$$

onde $\delta$ é o angulo de esterçamento da roda dianteira.

Logo, substituindo a equação (23) na equação (24) o ângulo de deriva no eixo dianteiro é dado por

$$
\alpha_{F}=\arctan \left(\frac{v \sin \alpha_{T}+a \dot{\psi}}{v \cos \alpha_{T}}\right)-\delta
$$


De maneira semelhante, o ângulo de deriva no ponto R é calculado como

$$
\alpha_{R}=\arctan \left(\frac{v \sin \alpha_{T}-b \dot{\psi}}{v \cos \alpha_{T}}\right) .
$$

$\mathrm{O}$ vetor $\mathbf{v}_{A}$ da equação (22) pode ser escrito também na base $\left\{S \mathbf{s}_{x} \mathbf{s}_{y} \mathbf{s}_{z}\right\}$ como

$$
\mathbf{v}_{A}=\left[v \cos \left(\alpha_{T}+\phi\right)+(b+c) \dot{\psi} \sin \phi\right] \mathbf{s}_{x}+\left[v \sin \left(\alpha_{T}+\phi\right)-(b+c) \dot{\psi} \cos \phi\right] \mathbf{s}_{y}
$$

O vetor velocidade do eixo do semirreboque pode ser obtido através da equação

$$
\mathbf{v}_{M}=\mathbf{v}_{A}+\mathbf{q} \wedge(\mathrm{M}-\mathrm{A})
$$

onde $\mathbf{q}=(\dot{\psi}-\dot{\phi}) \mathbf{s}_{z}$ é o vetor velocidade angular do semirreboque e o vetor

$$
(\mathrm{M}-\mathrm{A})=-(d+e) \mathbf{s}_{x}
$$

Logo, subtituindo as equações (27) e (29) em (28) temos

$$
\begin{aligned}
\mathbf{v}_{M}= & {\left[v \cos \left(\alpha_{T}+\phi\right)+(b+c) \dot{\psi} \sin \phi\right] \mathbf{s}_{x}+\ldots } \\
& \ldots+\left[v \sin \left(\alpha_{T}+\phi\right)-(b+c) \dot{\psi} \cos \phi-(d+e)(\dot{\psi}-\dot{\phi})\right] \mathbf{s}_{y}
\end{aligned}
$$

Portanto, fazendo uso da equação (30), o ângulo de deriva em M é

$$
\alpha_{M}=\arctan \left(\frac{v \sin \left(\alpha_{T}+\phi\right)-(b+c) \dot{\psi} \cos \phi-(d+e)(\dot{\psi}-\dot{\phi})}{v \cos \left(\alpha_{T}+\phi\right)+(b+c) \dot{\psi} \sin \phi}\right) .
$$

Derivando o vetor velocidade da equação (19), a aceleração do centro de massa do caminhão-trator é dada por

$$
\frac{\mathrm{d} \mathbf{v}_{T}}{\mathrm{~d} t}=\mathbf{a}_{T}=\left[\dot{v} \cos \alpha_{T}-v\left(\dot{\alpha}_{T}+\dot{\psi}\right) \sin \alpha_{T}\right] \mathbf{t}_{x}+\left[\dot{v} \sin \alpha_{T}+v\left(\dot{\alpha}_{T}+\dot{\psi}\right) \cos \alpha_{T}\right] \mathbf{t}_{y}
$$

A equação (32) é obtida fazendo uso, também, das relações $\dot{\mathbf{t}}_{x}=\dot{\psi} \mathbf{t}_{y}$ e $\dot{\mathbf{t}}_{y}=-\dot{\psi} \mathbf{t}_{x}$. A aceleração do ponto $A$ pode ser calculada como 


$$
\frac{\mathrm{d} \mathbf{v}_{A}}{\mathrm{~d} t}=\mathbf{a}_{A}=\mathbf{a}_{T}+\dot{\mathbf{p}} \wedge(\mathrm{A}-\mathrm{T})+\mathbf{p} \wedge[\mathbf{p} \wedge(\mathrm{A}-\mathrm{T})] .
$$

De maneira semelhante, a aceleração no ponto S é dada por

$$
\frac{\mathrm{d} \mathbf{v}_{S}}{\mathrm{~d} t}=\mathbf{a}_{S}=\mathbf{a}_{A}+\dot{\mathbf{q}} \wedge(\mathrm{S}-\mathrm{A})+\mathbf{q} \wedge[\mathbf{q} \wedge(\mathrm{S}-\mathrm{A})]
$$

onde $(\mathrm{S}-\mathrm{A})=-d \mathbf{s}_{x}$.

Portanto, fazendo uso das equações (32) e (33), a equação (34) pode ser escrita na base $\left\{\mathrm{S}_{x} \mathbf{s}_{y} \mathbf{s}_{z}\right\}$ como

$$
\begin{aligned}
\frac{\mathrm{d} \mathbf{v}_{S}}{\mathrm{~d} t}=\mathbf{a}_{S}= & \left\{d(\dot{\phi}-\dot{\psi})^{2}-\sin \phi\left[\dot{v} \sin \alpha_{T}-\ddot{\psi}(b+c)+v\left(\dot{\alpha}_{T}+\dot{\psi}\right) \cos \alpha_{T}\right]+\ldots\right. \\
& \left.\ldots+\cos \phi\left[\dot{\psi}^{2}(b+c)+\dot{v} \cos \alpha_{T}-v\left(\dot{\alpha}_{T}+\dot{\psi}\right) \sin \alpha_{T}\right]\right\} \mathbf{s}_{x}+\ldots \\
& \ldots+\left\{d(\ddot{\phi}-\ddot{\psi})+\cos \phi\left[\dot{v} \sin \alpha_{T}-\ddot{\psi}(b+c)+v\left(\dot{\alpha}_{T}+\dot{\psi}\right) \cos \alpha_{T}\right]+\ldots\right. \\
& \left.\ldots+\sin \phi\left[\dot{\psi}^{2}(b+c)+\dot{v} \cos \alpha_{T}-v\left(\dot{\alpha}_{T}+\dot{\psi}\right) \sin \alpha_{T}\right]\right\} \mathbf{s}_{y} .
\end{aligned}
$$

Figura 7 - Diagrama de corpo livre do modelo bicicleta articulado

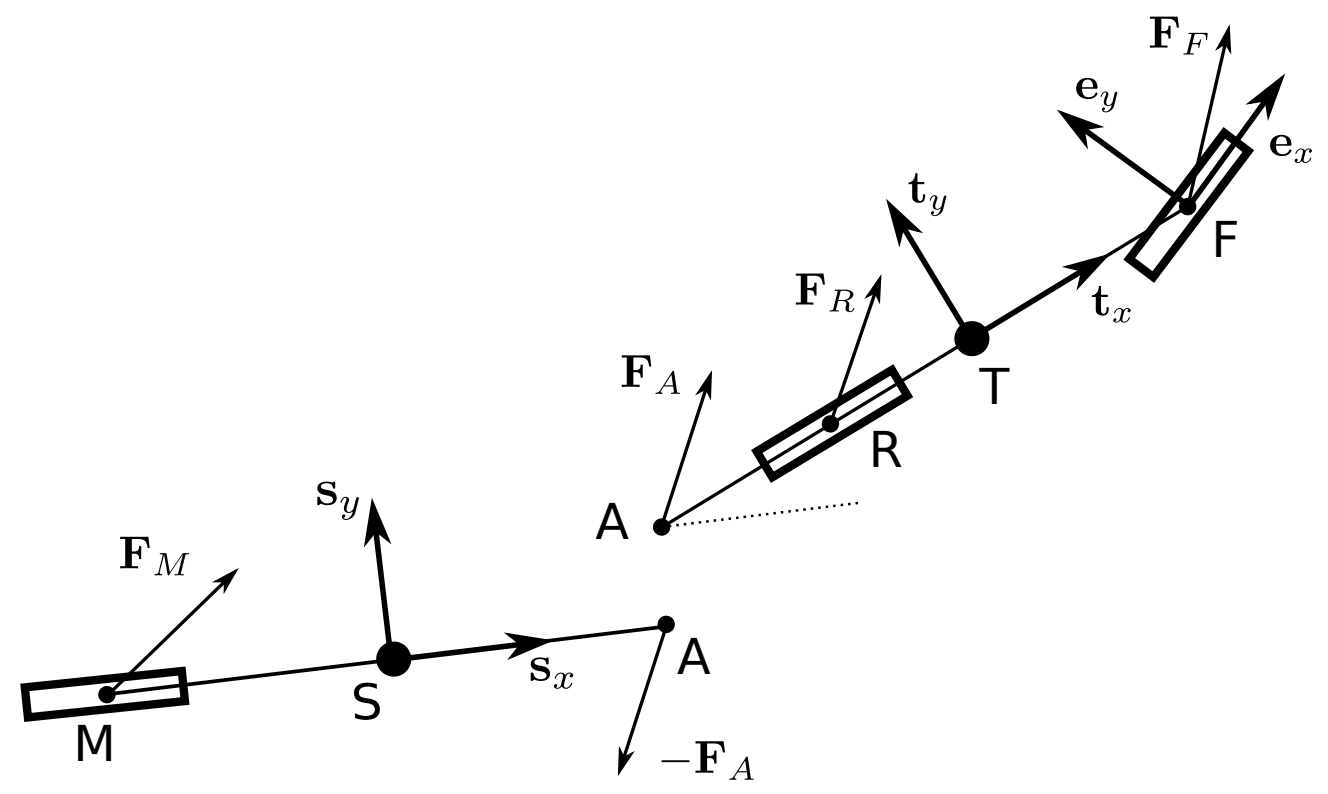

Fonte: Autor

A figura 7 ilustra o diagrama de corpo livre dos módulos dianteiro e traseiro do veículo e todas as forças consideradas. Aplicando o teorema do movimento do baricentro (TMB) no módulo dianteiro temos que: 


$$
m_{T} \mathbf{a}_{T}=\mathbf{F}_{F}+\mathbf{F}_{R}+\mathbf{F}_{A},
$$

onde $m_{T}$ é a massa do caminhão-trator e $\mathbf{a}_{T}$ é o vetor aceleração do ponto $\mathbf{T}$. Os vetores $\mathbf{F}_{F}$ e $\mathbf{F}_{R}$ são as forças atuantes nos eixos dianteiro e traseiro do caminhão-trator, respectivamente. $\mathrm{O}$ vetor $\mathbf{F}_{A}$ é a força atuante no ponto de articulação $A$.

A força $\mathbf{F}_{F}$ é escrita em detalhes na base $\left\{\mathrm{Fe}_{x} \mathbf{e}_{y} \mathbf{e}_{z}\right\}$ :

$$
\mathbf{F}_{F}=F_{x, F} \mathbf{e}_{x}+F_{y, F} \mathbf{e}_{y}
$$

onde $F_{x, F}$ e $F_{y, F}$ são as componentes longitudinal e transversal das forças atuantes no eixo dianteiro, respectivamente. Na base $\left\{\mathrm{Tt}_{x} \mathbf{t}_{y} \mathbf{t}_{z}\right\}$ a equação (37) é escrita como

$$
\mathbf{F}_{F}=\left[F_{x, F} \cos \delta-F_{y, F} \sin \delta\right] \mathbf{t}_{x}+\left[F_{x, F} \sin \delta+F_{y, F} \cos \delta\right] \mathbf{t}_{y}
$$

Nesta mesma base, os vetores $\mathbf{F}_{R}$ e $\mathbf{F}_{A}$ são escritos como

$$
\mathbf{F}_{R}=F_{x, R} \mathbf{t}_{x}+F_{y, R} \mathbf{t}_{y}
$$

$\mathrm{e}$

$$
\mathbf{F}_{A}=\left[F_{x, A} \cos \phi+F_{y, A} \sin \phi\right] \mathbf{t}_{x}+\left[-F_{x, A} \sin \phi+F_{y, A} \cos \phi\right] \mathbf{t}_{y},
$$

onde os índices $x$ e $y$ indicam as componentes longitudinal e transversal das forças em relação ao plano longitudinal do veículo, respectivamente.

Substituindo as equações (32), (38), (39) e (40) em (36), na direção longitudinal tem-se $m_{T}\left[\dot{v} \cos \alpha_{T}-v\left(\dot{\alpha}_{T}+\dot{\psi}\right) \sin \alpha_{T}\right]=F_{x, F} \cos \delta-F_{y, F} \sin \delta+F_{x, R}+F_{x, A} \cos \phi+F_{y, A} \sin \phi$

e na direção transversal

$m_{T}\left[\dot{v} \sin \alpha_{T}+v\left(\dot{\alpha}_{T}+\dot{\psi}\right) \cos \alpha_{T}\right]=F_{x, F} \sin \delta+F_{y, F} \cos \delta+F_{y, R}-F_{x, A} \sin \phi+F_{y, A} \cos \phi$.

Aplicando o TMB no módulo traseiro temos: 


$$
m_{S} \mathbf{a}_{S}=\mathbf{F}_{M}-\mathbf{F}_{A},
$$

onde $m_{S}$ é a massa do semirreboque e $\mathbf{a}_{S}$ é o vetor aceleração do ponto $\mathrm{S}$. O vetor $\mathbf{F}_{A}$ é a força na articulação decorrente da interação entre os dois módulos. $\mathbf{F}_{M}$ é a força atuante no ponto $\mathrm{M}$ do semirreboque.

A força $\mathbf{F}_{A}$ escrita na base $\left\{\mathrm{Ss}_{x} \mathbf{s}_{y} \mathbf{s}_{z}\right\}$ é dada por

$$
\mathbf{F}_{A}=F_{x, A} \mathbf{s}_{x}+F_{y, A} \mathbf{s}_{y}
$$

$\mathrm{O}$ vetor $\mathbf{F}_{M}$ é dado por

$$
\mathbf{F}_{M}=F_{x, M} \mathbf{s}_{x}+F_{y, M} \mathbf{s}_{y}
$$

onde $F_{x, M}$ e $F_{y, M}$ são as componentes longitudinal e transversal da força no ponto M, respectivamente.

Substituindo as equações (35), (44) e (45) em (43), na direção longitudinal tem-se

$$
\begin{aligned}
m_{S}\left\{d(\dot{\phi}-\dot{\psi})^{2}-\sin \phi\left[\dot{v} \sin \alpha_{T}-\ddot{\psi}(b+c)+v\left(\dot{\alpha}_{T}+\dot{\psi}\right) \cos \alpha_{T}\right]+\ldots\right. \\
\left.\ldots+\cos \phi\left[\dot{\psi}^{2}(b+c)+\dot{v} \cos \alpha_{T}-v\left(\dot{\alpha}_{T}+\dot{\psi}\right) \sin \alpha_{T}\right]\right\}=-F_{x, A}+F_{x, M}
\end{aligned}
$$

e na direção transversal

$$
\begin{aligned}
m_{S}\left\{d(\ddot{\phi}-\ddot{\psi})+\cos \phi\left[\dot{v} \sin \alpha_{T}-\ddot{\psi}(b+c)+v\left(\dot{\alpha}_{T}+\dot{\psi}\right) \cos \alpha_{T}\right]+\ldots\right. \\
\\
\left.\ldots+\sin \phi\left[\dot{\psi}^{2}(b+c)+\dot{v} \cos \alpha_{T}-v\left(\dot{\alpha}_{T}+\dot{\psi}\right) \sin \alpha_{T}\right]\right\}=F_{y, A}+F_{y, M} .
\end{aligned}
$$

Como toda dinâmica está contida no plano horizontal o teorema do momento angular (TMA), para o caminhão-trator, aplicado no ponto T pode ser escrito como

$$
I_{T} \ddot{\psi} \mathbf{t}_{z}=(\mathrm{F}-\mathrm{T}) \wedge \mathbf{F}_{F}+(\mathrm{R}-\mathrm{T}) \wedge \mathbf{F}_{R}+(\mathrm{A}-\mathrm{T}) \wedge \mathbf{F}_{A}
$$

onde as forças são dadas pelas equações (38), (39) e (40). Esta equação vetorial apresenta apenas componente vertical resultando na equação diferencial 


$$
I_{T} \ddot{\psi}=a\left(F_{y, F} \cos \delta+F_{x, F} \sin \delta\right)-b F_{y, R}-(b+c)\left(F_{y, A} \cos \phi-F_{x, A} \sin \phi\right) .
$$

De maneira análoga, aplicando o TMA no semirreboque, no ponto S, temos a expressão

$$
I_{S}(\ddot{\psi}-\ddot{\phi}) \mathbf{t}_{z}=(\mathrm{A}-\mathrm{S}) \wedge\left(-\mathbf{F}_{A}\right)+(\mathrm{M}-\mathrm{S}) \wedge \mathbf{F}_{M} .
$$

As forças na equação (50) são dadas pelas equações (44) e (45). Os vetores $(A-S)$ e $(M-S)$ apontam os pontos $A$ e $M$ em relação ao ponto $S$, respectivamente. Ou seja,

$$
\begin{array}{r}
(\mathrm{A}-\mathrm{S})=d \mathbf{s}_{x} \\
(\mathrm{M}-\mathrm{S})=-e \mathbf{S}_{x} .
\end{array}
$$

A equação diferencial resultante é

$$
I_{S}(\ddot{\psi}-\ddot{\phi})=-\left(d F_{y, A}+e F_{y, M}\right) .
$$

Logo, as relações de equilíbrio dinâmico são compostas pelas equações (41), (42), (46), (47), (49) e (52).

O próxmo passo consiste em eliminar a força de vínculo $\mathbf{F}_{A}$. Para isto, a equação (46) é escrita em função de $F_{x, A}$,

$$
\begin{aligned}
F_{x, A}= & -m_{S}\left\{d(\dot{\phi}-\dot{\psi})^{2}-\sin \phi\left[\dot{v} \sin \alpha_{T}-\ddot{\psi}(b+c)+v\left(\dot{\alpha}_{T}+\dot{\psi}\right) \cos \alpha_{T}\right]+\ldots\right. \\
& \left.\ldots+\cos \phi\left[\dot{\psi}^{2}(b+c)+\dot{v} \cos \alpha_{T}-v\left(\dot{\alpha}_{T}+\dot{\psi}\right) \sin \alpha_{T}\right]\right\}+F_{x, M},
\end{aligned}
$$

e a equação (47) é escrita em função de $F_{y, A}$,

$$
\begin{aligned}
F_{y, A}= & -m_{S}\left\{d(\ddot{\phi}-\ddot{\psi})+\cos \phi\left[\dot{v} \sin \alpha_{T}-\ddot{\psi}(b+c)+v \cos \alpha_{T}\left(\dot{\alpha}_{T}+\dot{\psi}\right)\right]+\ldots\right. \\
& \left.\ldots+\sin \phi\left[\dot{\psi}^{2}(b+c)+\dot{v} \cos \alpha_{T}-v \sin \alpha_{T}\left(\dot{\alpha}_{T}+\dot{\psi}\right)\right]\right\}+F_{y, M} .
\end{aligned}
$$


Substituindo as equações (53) e (54) em (41), (42), (49) e (52) temos

$$
\begin{aligned}
m_{T}\left[\dot{v} \cos \alpha_{T}-v\left(\dot{\alpha}_{T}+\dot{\psi}\right) \sin \alpha_{T}\right]= & F_{x, F} \cos \delta-F_{y, F} \sin \delta+F_{x, R}+F_{x, M} \cos \phi \ldots \\
& \ldots+F_{y, M} \sin \phi+m_{S}\left[-\dot{v} \cos \alpha_{T}-\dot{\psi}^{2}(b+c)+\ldots\right. \\
& \ldots+\left(\dot{\psi}+\dot{\alpha}_{T}\right) v \sin \alpha_{T}+(\ddot{\psi}-\ddot{\phi}) d \sin \phi-\ldots \\
& \left.\ldots-(\dot{\psi}-\dot{\phi})^{2} d \cos \phi\right]
\end{aligned}
$$

$$
\begin{aligned}
m_{T}\left[\dot{v} \sin \alpha_{T}+v\left(\dot{\alpha}_{T}+\dot{\psi}\right) \cos \alpha_{T}\right]= & F_{x, F} \sin \delta+F_{y, F} \cos \delta+F_{y, R}-F_{x, M} \sin \phi \ldots \\
& \ldots+F_{y, M} \cos \phi+m_{S}\left[-\dot{v} \sin \alpha_{T}+\ddot{\psi}(b+c)-\ldots\right. \\
& \ldots-\left(\dot{\psi}+\dot{\alpha}_{T}\right) v \cos \alpha_{T}+(\ddot{\psi}-\ddot{\phi}) d \cos \phi+\ldots \\
& \left.\ldots+(\dot{\psi}-\dot{\phi})^{2} d \sin \phi\right],
\end{aligned}
$$

$$
\begin{aligned}
I_{T} \ddot{\psi}= & a\left(F_{y, F} \cos \delta+F_{x, F} \sin \delta\right)-b F_{y, R}-(b+c)\left\{-F_{x, M} \sin \phi+F_{y, M} \cos \phi+\ldots\right. \\
& \ldots+m_{S}\left[-\dot{v} \sin \alpha_{T}+\ddot{\psi}(b+c)-\left(\dot{\psi}+\dot{\alpha}_{T}\right) v \cos \alpha_{T}+(\ddot{\psi}-\ddot{\phi}) d \cos \phi+\ldots\right. \\
& \left.\left.\ldots+(\dot{\psi}-\dot{\phi})^{2} d \sin \phi\right]\right\}
\end{aligned}
$$

$\mathrm{e}$

$$
\begin{aligned}
I_{S}(\ddot{\psi}-\ddot{\phi})= & -e F_{y, M}-d\left\{F_{y, M}-m_{S}\left[d(\ddot{\phi}-\ddot{\psi})+\cos \phi\left(\dot{v} \sin \alpha_{T}-\ddot{\psi}(b+c)+\ldots\right.\right.\right. \\
& \left.\left.\left.\ldots+v \cos \alpha_{T}\left(\dot{\alpha}_{T}+\dot{\psi}\right)\right)+\sin \phi\left(\dot{\psi}^{2}(b+c)+\dot{v} \cos \alpha_{T}-v \sin \alpha_{T}\left(\dot{\alpha}_{T}+\dot{\psi}\right)\right)\right]\right\} .
\end{aligned}
$$

As equações (55), (56), (57) e (58) apresentam as seguintes variáveis e derivadas temporais: $\ddot{\psi}, \dot{\psi}, \ddot{\phi}, \dot{\phi}, \phi, \dot{v}, v, \dot{\alpha}_{T}$ e $\alpha_{T}$. Logo, é possível obter as equações de estado escolhendo, 
por exemplo, os estados $\dot{\psi}, \dot{\phi}, \phi, v$ e $\alpha_{T}$. Além disso as equações de estado podem ser escritas na forma matricial como:

$$
\mathbf{M}(\mathbf{x}) \dot{\mathbf{x}}=\mathbf{f}(\mathbf{x})
$$

Onde $\mathrm{x}$ é o vetor de estados, $\mathbf{M}$ é a matriz de massa do sistema e $\mathbf{f}$ é a função vetorial não linear em função dos estados. $\mathrm{O}$ vetor de estados $\mathrm{x}$ pode ser então escrito como

$$
\mathbf{x}=\left[\begin{array}{c}
\dot{\psi} \\
\alpha_{T} \\
\dot{\phi} \\
v \\
\phi
\end{array}\right]
$$

A matriz de massa $\mathbf{M}$ pode ser escrita como:

$$
\mathbf{M}=\left[\begin{array}{ccccc}
M_{11} & M_{12} & M_{13} & M_{14} & 0 \\
M_{21} & M_{22} & M_{23} & M_{24} & 0 \\
M_{31} & M_{32} & M_{33} & M_{34} & 0 \\
M_{41} & M_{42} & M_{43} & M_{44} & 0 \\
0 & 0 & 0 & 0 & 1
\end{array}\right]
$$

onde 


$$
\begin{aligned}
& M_{11}=-d m_{S} \sin \phi \\
& M_{12}=-v\left(m_{S}+m_{T}\right) \sin \alpha_{T} \\
& M_{12}=d m_{S} \sin \phi \\
& M_{14}=\left(m_{S}+m_{T}\right) \cos \alpha_{T} \\
& M_{21}=-m_{S}(b+c+d \cos \phi) \\
& M_{22}=v\left(m_{S}+m_{T}\right) \cos \alpha_{T} \\
& M_{23}=d m_{S} \cos \phi \\
& M_{24}=\left(m_{S}+m_{T}\right) \sin \alpha_{T} \\
& M_{31}=I_{T}+m_{S}(b+c)(b+c+d \cos \phi) \\
& M_{32}=-v m_{S}(b+c) \cos \alpha_{T} \\
& M_{33}=-d m_{S}(b+c) \cos \phi \\
& M_{34}=-m_{S}(b+c) \sin \alpha_{T} \\
& M_{41}=I_{S}+d m_{S}(d+(b+c) \cos \phi) \\
& M_{42}=-v d m_{S} \cos \alpha_{T}+\phi \\
& M_{43}=-m_{S} d^{2}-I_{S} \\
& M_{44}=-d m_{S} \sin \left(\alpha_{T}+\phi\right) .
\end{aligned}
$$

Por fim, a função vetorial $\mathbf{f}$ é dada por:

$$
\mathbf{f}=\left[\begin{array}{l}
f_{1} \\
f_{2} \\
f_{3} \\
f_{4} \\
f_{5}
\end{array}\right]
$$

onde 


$$
\begin{aligned}
f_{1}= & F_{x, R}+F_{x, F} \cos \delta+F_{x, M} \cos \phi-F_{y, F} \sin \delta+F_{y, M} \sin \phi-(b+c) \dot{\psi}^{2} m_{S}+\ldots \\
& \ldots+\left(m_{T}+m_{S}\right) v \dot{\psi} \sin \alpha_{T}-(\dot{\psi}-\dot{\phi})^{2} d m_{S} \cos \phi \\
f_{2}= & F_{y, R}+F_{y, F} \cos \delta+F_{y, M} \cos \phi+F_{x, F} \sin \delta-F_{x, M} \sin \phi-\ldots \\
& \ldots-\left(m_{T}+m_{S}\right) v \dot{\psi} \cos \alpha_{T}+(\dot{\psi}-\dot{\phi})^{2} d m_{S} \sin \phi \\
f_{3}= & a\left(F_{y, F} \cos \delta+F_{x, F} \sin \delta\right)-F_{y, R} b-(b+c)\left[-F_{x, M} \sin \phi+F_{y, M} \cos \phi-\ldots\right. \\
& \left.\ldots-v m_{S} \cos \alpha_{T} \dot{\psi}+(\dot{\psi}-\dot{\phi})^{2} d m_{S} \sin \phi\right] \ldots \\
f_{4}= & d\left(b \dot{\psi}^{2} m_{S} \sin \phi-F_{y, M}+c \dot{\psi}^{2} m_{S} \sin \phi+v \dot{\psi} m_{S} \cos \left(\alpha_{T}+\phi\right)\right)-F_{y, M} e \\
f_{5}= & \dot{\phi}
\end{aligned}
$$

\subsection{MODELO DO SISTEMA}

O modelo de veículo discutido até aqui representa cada eixo como um único pneu com propriedades dinâmicas equivalentes. Ou seja, o modelo de pneu apresentado na seção 3.1 deve ser usado no desenvolvimento da, chamada, curva característica do eixo. Para isto, é necessário considerar que os ângulos de deriva dos pneus de um mesmo eixo sejam iguais. Desta forma, as curvas características de cada pneu podem, então, ser somadas para caracterizar o comportamento do conjunto associado àquele eixo. O modelo apresentado até aqui é capaz de representar qualquer configuração apresentada nas tabelas 9, 10 e 11. Entretanto, nesta dissertação, é usada a configuração de veículo CTS-2 devido à disponibilidade dos valores dos parâmetros correspondentes a um veículo articulado comercializado no Brasil. Esta configuração é ilustrada na tabela 9, onde o eixo direcional é simples com dois pneus, o eixo traseiro do caminhão-trator é duplo com quatro pneus e o eixo da unidade movida se apresenta em tandem duplo com oito pneus. Cada conjunto de pneus é reduzido a um único pneu central com uma curva característica equivalente que reproduz, aproximadamente, o comportamento que seria obtido a partir do conjunto original de pneus. Esta aproximação é ilustrada na figura 8 para a configuração adotada.

A força transversal em cada eixo é escrita como a soma da curva característica de cada pneu. A carga vertical considerada é dada pela carga vertical do eixo dividida pelo número de pneus que ele contém. Ou seja, a carga de um determinado eixo é distribuida igualmente entre cada pneu. Logo, para a configuração escolhida: 
Figura 8 - Modelo do sistema. Combinação dos eixos com propriedades equivalentes

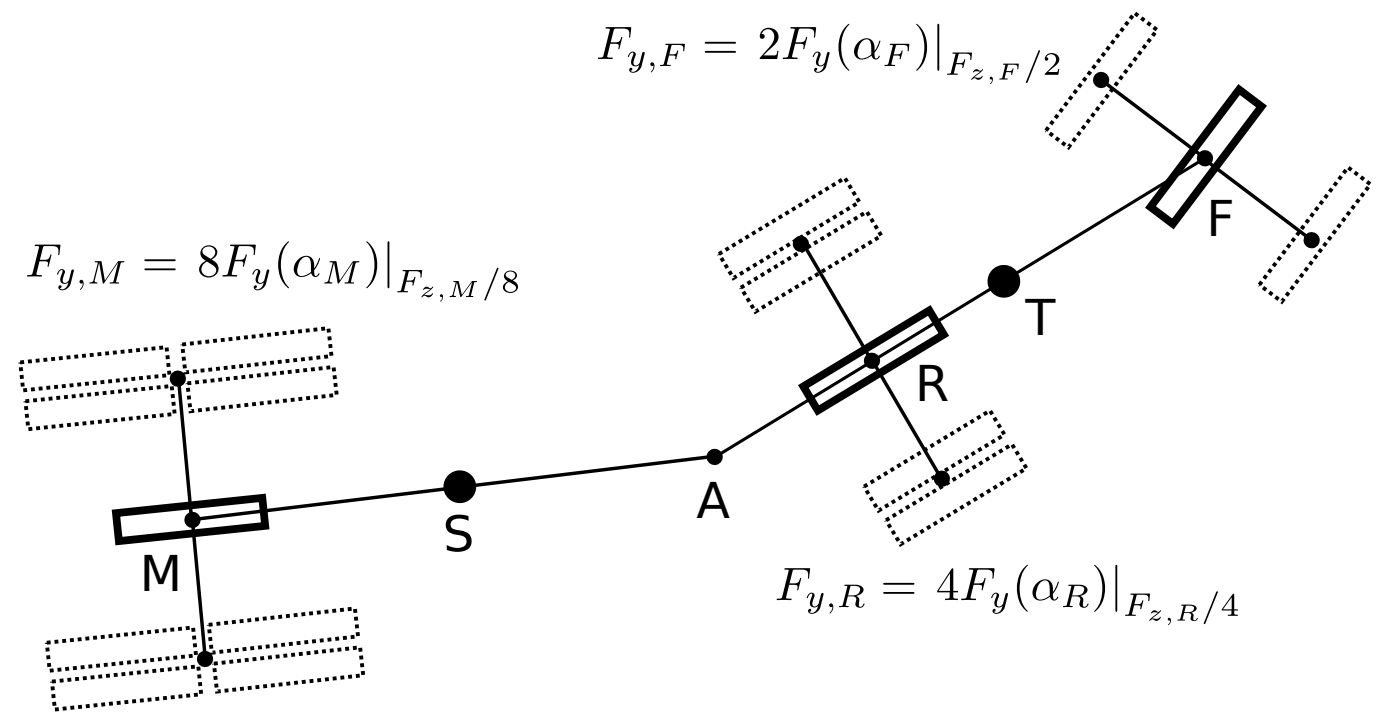

Fonte: Autor

$$
\begin{aligned}
F_{y, F} & =\left.2 F_{y}\left(\alpha_{e q, F}\right)\right|_{F_{z, F} / 2} \\
F_{y, R} & =\left.4 F_{y}\left(\alpha_{e q, R}\right)\right|_{F_{z, R} / 4} \\
F_{y, M} & =\left.8 F_{y}\left(\alpha_{e q, M}\right)\right|_{F_{z, M} / 8}
\end{aligned}
$$

onde $F_{y, F}, F_{y, R}$ e $F_{y, M}$ são as forças laterais nos eixos $\mathrm{F}, \mathrm{R}$ e M, respectivamente. Os ângulos $\alpha_{e q, F}, \alpha_{e q, R}$ e $\alpha_{e q, M}$ são os ângulos de deriva equivalentes (equação (10)) dos pontos F, R e M, respectivamente. Além disso, o termo $F_{y}$ é a curva características de cada pneu obtida a partir da equação (9), supondo um único tipo de pneu equipando todo o veículo. Por fim, $F_{z, F}, F_{z, R}$ e $F_{z, M}$ são as cargas verticais sobre os eixos $\mathrm{F}, \mathrm{R}$ e $\mathrm{M}$, respectivamente.

Resumindo, o modelo do sistema é definido pelo modelo de veículo da equação (59) composto pela matriz de massa descrita na equação (61) e pela função vetorial da equação (63). Detalhes da matriz de massa e função vetorial se encontram nas equações (62) e (64), respectivamente. O vetor de estados é dado pela equação (60). Os parâmetros do modelo são as massas $m_{T}$ e $m_{S}$, os momentos de inércia $I_{T}$ e $I_{S}$ e as distâncias $a, b, c, d$ e $e$. As forças transversais do pneu são dadas pelas equações em (65) que utiliza o modelo de pneu não linear representado na equação (9) onde a equação de referência é dada pela equação (3). O ângulo de deriva equivalente é dado pela equação (10) e faz uso dos ângulos de deriva definidos nas 
equações (25), (26) e (31). Por fim, os coeficientes da equação característica estão descritos nas equações (4), (5), (7) e (8).

A seguir, a lista das principais hipóteses assumidas para o desenvolvimento do modelo do sistema:

a) a curva característica do eixo tem propriedades equivalentes ao conjunto de pneus que o compõem;

b) a carga vertical é distribuida igualmente entre os pneus de um mesmo eixo;

c) o modelo não linear de pneu é empregado nos três eixos ( $F, R$ e $M)$;

d) as transferências lateral e longitudinal de carga são desprezadas. 


\section{EXPOENTES DE LYAPUNOV}

Na literatura existem diversas definições de caos, cada uma apresentando vantagens e desvantagens com relação a sua forma de caracterizar este fenômeno. Entretanto, sistemas caóticos são típicamente associados à imprevisibilidade e à sensível dependência das condições iniciais (SAVI, 2006). Por este motivo, como discutido na seção 2.2, os expoentes de Lyapunov se apresentam como uma importante ferramenta na investigação do comportamento caótico de sistemas dinâmicos. A discussão detalhada sobre o conceito de caos foge do escopo desta dissertação, porém uma interessante revisão sobre algumas das definições de caos pode ser encontrada em Teixeira (2011).

\subsection{CONCEITO}

Para apresentar o conceito de expoentes de Lyapunov é considerado um sistema composto por $n$ equações diferencias

$$
\dot{\mathbf{x}}=\mathbf{f}(\mathbf{x})
$$

onde $\mathbf{f}$ é uma função vetorial de $n$ equações e $\mathbf{x}=\left[\begin{array}{llll}x_{1} & x_{2} & \ldots & x_{n}\end{array}\right]$ é um vetor de $n$ estados.

Um ponto $\mathbf{x}_{0}=\mathbf{x}\left(t_{0}\right)$ aleatório é usado como centro de uma hiper-esfera de condições iniciais. Ao integrar o sistema no tempo a partir dos pontos contidos nesta esfera, as respectivas órbitas evoluem no espaço de estados alterando a forma da representação geométrica do conjunto em que estes pontos se encontram. Esta evolução é ilustrada na figura 9 para um sistema bidimensional em que as condições iniciais contidas no círculo assumem novos valores após a integração, dando origem a uma nova região deformada no instante $t$.

Figura 9 - Evolução do círculo de condições iniciais

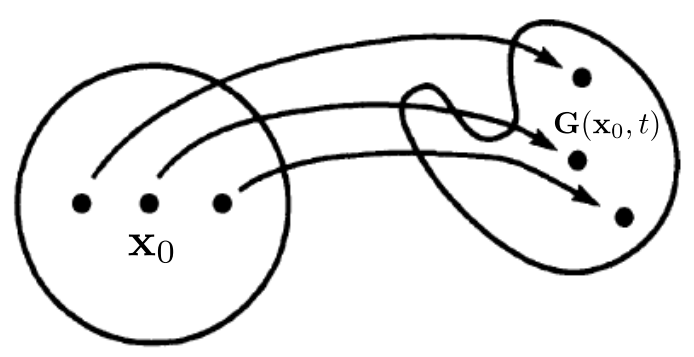

Fonte: Autor "adaptado de” Alligood, Sauer e Yorke, 1997 
Entretanto, para o cálculo dos expoentes de Lyapunov são consideradas apenas as órbitas de $n$ condições iniciais em torno da órbita de referência que parte de $\mathbf{x}_{0}$. Para cada estado do sistema considera-se uma condição inicial contida na superfície da hiper-esfera. $\mathrm{O}$ vetor posição destas condições iniciais em relação a $\mathbf{x}_{0}$ é dado por $\mathbf{r}_{i 0}=\mathbf{r}_{i}\left(t_{0}\right), i=1,2, \ldots, n$. O módulo deste vetor estabelece o raio inicial $r_{i}\left(t_{0}\right)=\left|\mathbf{r}_{i}\left(t_{0}\right)\right|$ que mede a distância do ponto $\mathbf{x}_{0}$ até a superfície da hiper-esfera ao longo de $n$ direções, que devem ser linearmente independentes. Conforme o tempo passa, cada condição inicial desenvolve uma órbita específica. $\mathrm{O}$ vetor $\mathbf{r}_{i}(t)$ define, no instante $t$, a posição do ponto da órbita que partiu de uma condição inicial vizinha em relação ao ponto da órbita de referência que, por sua vez, partiu da condição inicial $\mathbf{x}_{0}$. Logo, a distância entre estes dois pontos é dada por $r_{i}(t)=\left|\mathbf{r}_{i}(t)\right|$.

A figura 10 ilustra a evolução das condições iniciais usadas para a determinação dos expoentes de Lyapunov em um sistema bidimensional entre os instantes $t_{0}$ e $t$. No instante inicial as distâncias $r_{i}$ são iguais e definem um círculo em torno de $\mathbf{x}_{0}$. Conforme a evolução da trajetória dos estados, este cículo se deforma em um elipsoide que permanece em constante deformação ao longo do tempo.

Figura 10 - Evolução dos raios de um sistema bidimensional

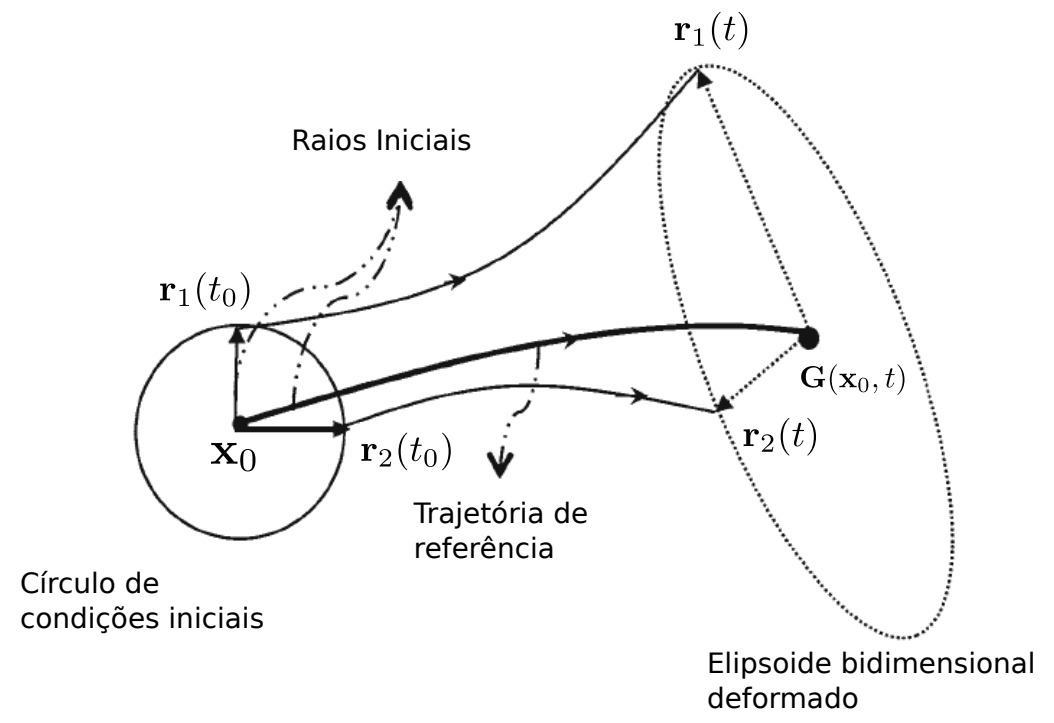

Fonte: Autor "adaptado de" Sadri e Wu, 2013

Assumindo que os raios iniciais variam exponencialmente com o tempo, o valor do raio no instante $t$ pode ser escrito como

$$
r_{i}(t)=r_{i}\left(t_{0}\right) \mathrm{b}^{\lambda_{i}\left(t-t_{0}\right)},(i=1,2, \ldots, n)
$$


onde típicamente os valores da base exponencial são dados por $\mathrm{b}=e$ e b $=2$ (SAVI, 2006). Além disso, $\lambda_{i}$ são chamados de expoentes de Lyapunov. A expressão 67 pode ser reescrita em função dos expoentes como

$$
\lambda_{i}=\frac{1}{t-t_{0}} \log _{\mathrm{b}}\left[\frac{r_{i}}{r_{i 0}}\right]
$$

onde $r_{i 0}=r_{i}\left(t_{0}\right)$ e $r_{i}=r_{i}(t)$. Se o expoente é positivo as trajetórias vizinhas divergem entre si. Caso contrário, elas convergem. Entretanto, a definição matemática dos expoentes consiste no cálculo da equação (68) para um longo período de tempo e distâncias iniciais, $r_{i}\left(t_{0}\right)$, pequenas (SAVI, 2006). Logo,

$$
\lambda_{i}=\lim _{t \rightarrow+\infty} \lim _{r_{i 0} \rightarrow 0} \frac{1}{t-t_{0}} \log _{\mathrm{b}}\left[\frac{r_{i}}{r_{i 0}}\right] .
$$

Isto é, os expoentes de Lyapunov quantificam o quanto, na média, trajetórias vizinhas se aproximam ou se afastam num longo período de tempo. O conjunto de expoentes de Lyapunov define o espectro de Lyapunov do sistema.

A razão $r_{i} / r_{i 0}$ presente na equação (69) pode ser calculada seguindo um desenvolvimento semelhante ao apresentado por Alligood, Sauer e Yorke (1997). Primeiramente, utilizase o mapa $\mathbf{G}\left(\mathbf{x}_{0}, t\right)$ que define o ponto que a órbita com condição inicial $\mathbf{x}_{0}$ atinge após o tempo $t$. Portanto, $\mathbf{G}\left(\mathbf{x}_{0}, t\right)$ é a solução da equação (66) com condição inicial $\mathbf{x}_{0}$ em função do tempo $t$.

Logo, o vetor posição $\mathbf{r}_{i}(t)$ pode ser escrito, alternativamente, como

$$
\mathbf{r}_{i}(t)=\mathbf{G}\left(\mathbf{x}_{0}+\mathbf{r}_{i}\left(t_{0}\right), t\right)-\mathbf{G}\left(\mathbf{x}_{0}, t\right)
$$

Desta forma, utilizando a equação (70) as distâncias presentes na equação (69) são dadas por

$$
\begin{aligned}
r_{i 0} & =\left|\mathbf{r}_{i}\left(t_{0}\right)\right| \\
r_{i} & =\left|\mathbf{G}\left(\mathbf{x}_{0}+\mathbf{r}_{i}\left(t_{0}\right), t\right)-\mathbf{G}\left(\mathbf{x}_{0}, t\right)\right|
\end{aligned}
$$

Substituindo as equações presentes em (71) na equação (69) temos 


$$
\lambda_{i}=\lim _{t \rightarrow+\infty} \lim _{r_{i 0} \rightarrow 0} \frac{1}{t-t_{0}} \log _{\mathrm{b}} \frac{\left|\mathbf{G}\left(\mathbf{x}_{0}+\mathbf{r}_{i}\left(t_{0}\right), t\right)-\mathbf{G}\left(\mathbf{x}_{0}, t\right)\right|}{\left|\mathbf{r}_{i}\left(t_{0}\right)\right|} .
$$

A equação (72) pode ser reescrita como

$$
\lambda_{i}=\lim _{t \rightarrow+\infty} \frac{1}{t-t_{0}} \log _{\mathrm{b}}\left|\lim _{r_{i 0} \rightarrow 0} \frac{\mathbf{G}\left(\mathbf{x}_{0}+\mathbf{r}_{i}\left(t_{0}\right), t\right)-\mathbf{G}\left(\mathbf{x}_{0}, t\right)}{\left|\mathbf{r}_{i}\left(t_{0}\right)\right|}\right| .
$$

Ou seja, para $r_{i 0}$ infinitesimalmente pequeno o argumento do logaritmo na equação (73) é dado pelo módulo da derivada do mapa $\mathrm{G}\left(\mathrm{x}_{0}, t\right)$ em relação à condição inicial $\mathrm{x}_{0}$ na direção $\mathbf{r}_{i}\left(t_{0}\right)$ :

$$
\mathrm{d} \mathbf{G}_{i}\left(\mathbf{x}_{0}, t\right)=\lim _{r_{i 0} \rightarrow 0} \frac{\mathbf{G}\left(\mathbf{x}_{0}+\mathbf{r}_{i}\left(t_{0}\right), t\right)-\mathbf{G}\left(\mathbf{x}_{0}, t\right)}{\left|\mathbf{r}_{i}\left(t_{0}\right)\right|} .
$$

Logo, substituindo a equação (74) em (73), os expoentes podem ser escritos como

$$
\lambda_{i}=\lim _{t \rightarrow+\infty} \frac{1}{t-t_{0}} \log _{\mathrm{b}}\left|\mathrm{d}_{i}\left(\mathbf{x}_{0}, t\right)\right| .
$$

Alocando $n$ vetores $\mathrm{dG}_{i}\left(\mathbf{x}_{0}, t\right)$ avaliados em $n$ direções linearmente independentes como colunas de uma matriz quadrada $n \times n$ obtemos

$$
\mathrm{DG}\left(\mathbf{x}_{0}, t\right)=\left[\begin{array}{llll}
\mathrm{d} \mathbf{G}_{1}\left(\mathbf{x}_{0}, t\right)^{T} & \mathrm{~d} \mathbf{G}_{2}\left(\mathbf{x}_{0}, t\right)^{T} & \ldots & \mathrm{d} \mathbf{G}_{n}\left(\mathbf{x}_{0}, t\right)^{T}
\end{array}\right]
$$

onde $\mathrm{DG}\left(\mathbf{x}_{0}, t\right)$ é a matriz jacobiana do mapa $\mathbf{G}\left(\mathbf{x}_{0}, t\right)$ e o sobrescrito $T$ significa a transposição do vetor.

A matriz definida na equação (76) permite quantificar o quanto a solução da equação (66) se altera, no instante $t$, em função de um pequeno deslocamento $\delta \mathbf{x}_{0}$ da condição inicial em relação à $x_{0}$. Ou seja,

$$
\delta \mathbf{x}(t)=\mathrm{DG}\left(\mathbf{x}_{0}, t\right) \cdot \delta \mathbf{x}_{0}
$$

A equação (77) determina o quanto a solução $\mathbf{x}(t)$ da equação (66) se desloca, no instante $t$, por conta de uma mudança da condição inicial de $\mathbf{x}_{0}$ para $\mathbf{x}_{0}+\delta \mathbf{x}_{0}$.

Portanto, para obter as razões das distâncias, $r_{i} / r_{i 0}$, das órbitas ao longo do tempo para todos os expoentes de Lyapunov é necessário calcular a matriz $\mathrm{DG}\left(\mathrm{x}_{0}, t\right)$. Isto é alcançado, primeiramente, substituindo o mapa $\mathbf{G}\left(\mathbf{x}_{0}, t\right)$ na equação (66) e obtendo

$$
\frac{\mathrm{d}}{\mathrm{d} t} \mathbf{G}\left(\mathbf{x}_{0}, t\right)=\mathbf{f}\left(\mathbf{G}\left(\mathbf{x}_{0}, t\right)\right)
$$


Em seguida, derivando a equação (78) em relação a $\mathbf{x}_{0}$ temos

$$
\frac{\mathrm{d}}{\mathrm{d} t} \mathrm{DG}\left(\mathbf{x}_{0}, t\right)=\mathrm{D} \mathbf{f}\left(\mathbf{G}\left(\mathbf{x}_{0}, t\right)\right) \cdot \mathrm{DG}\left(\mathbf{x}_{0}, t\right)
$$

A equação (79) é chamada de equação variacional da equação diferencial 66 (ALLIGOOD; SAUER; YORKE, 1997). Nesta etapa, algumas simplificações podem ser realizadas. Por exemplo, a matriz jacobiana do mapa avaliado em $\mathbf{x}_{0}$ pode ser escrita como

$$
\mathbf{W}=\operatorname{DG}\left(\mathbf{x}_{0}, t\right)
$$

A matriz jacobiana do sistema pode ser escrita como

$$
\mathbf{J}=\operatorname{Df}\left(\mathbf{G}\left(\mathbf{x}_{0}, t\right)\right)
$$

onde cada elemento da matriz $\mathbf{J}$ é dado pelas derivadas parciais do sistema de equações diferenciais em 66 em relação às variáveis de estado:

$$
J_{i j}=\left.\frac{\partial f_{i}}{\partial x_{j}}\right|_{x_{i}=x_{i}(t)},
$$

onde $J_{i j}$ é o elemento da linha $i$ e coluna $j$ da matriz $\mathbf{J}$ e $\partial f_{i} / \partial x_{j}$ é a derivada parcial da equação na posição $i$ da função vetorial $\mathbf{f}$ em relação ao estado na posição $j$ do vetor de estados $\mathrm{x}$.

Substituindo as equações (80) e (81) na equação (79) temos

$$
\dot{\mathbf{W}}=\mathbf{J W} \text {. }
$$

Integrando a equação (83) é possível obter os valores numéricos da matriz $\mathbf{W}$. As colunas desta matriz são iguais ao vetor $\mathrm{d}_{i}\left(\mathbf{x}_{0}, t\right)$ como visto na equação (76). Além disso, o módulo destes vetores é igual à razão das distâncias $r_{i} / r_{i 0}$ utilizadas na definição dos expoentes na equação (69). Portanto, para se calcular os expoentes de Lyapunov basta integrar a equação (83) e calcular os módulos dos vetores que compõem as colunas da matriz $\mathbf{W}$ naquele instante. Entretanto, é importante lembrar que a matriz J, normalmente, depende dos estados do sistema, logo as expressões (66) e (83) devem ser integradas simultaneamente. 


\subsection{CÁLCULO}

Em sistemas não lineares, normalmente, não é possível obter uma solução analítica que determine o valor dos expoentes de Lyapunov, sendo necessária a utilização de métodos numéricos. Nesta dissertação, para o cálculo dos expoentes é utilizado o algoritmo proposto por Wolf et al. (1985), assim como feito por Sadri e Wu (2013).

Para a realização do algoritmo é necessário integrar as equações (66) e (83) simultaneamente. Logo, elas são agrupadas da seguinte maneira:

$$
\left[\begin{array}{c}
\dot{\mathbf{x}} \\
\dot{\mathbf{W}}
\end{array}\right]=\left[\begin{array}{c}
\mathbf{f}(\mathbf{x}) \\
\mathbf{J W}
\end{array}\right] \text {. }
$$

A condição inicial da equação (84) é dada por

$$
\left[\begin{array}{c}
\mathbf{x}(0) \\
\mathbf{W}(0)
\end{array}\right]=\left[\begin{array}{c}
\mathbf{x}_{0} \\
\mathbf{W}_{0}
\end{array}\right],
$$

onde $\mathbf{x}_{0}$ é o vetor de condições iniciais do sistema dado pela equação (66) e $\mathbf{W}_{0}$ é a matriz de condições iniciais da equação (83).

A escolha dos raios iniciais é dada pelos vetores ortonormais definidos por

$$
\begin{aligned}
\overline{\mathbf{p}}_{1} & =(1,0, \ldots, 0) \\
\overline{\mathbf{p}}_{2} & =(0,1, \ldots, 0) \\
\vdots & =\vdots \\
\overline{\mathbf{p}}_{n} & =(0,0, \ldots, 1) .
\end{aligned}
$$

Os vetores da base ortonormal definidos nas equações em (86) compõem a matriz de condições iniciais $\mathbf{W}_{0}$ da seguinte forma:

$$
\mathbf{W}_{0}=\left[\begin{array}{cccc}
\overline{\mathbf{p}}_{1}^{T} & \overline{\mathbf{p}}_{2}^{T} & \ldots & \overline{\mathbf{p}}_{n}^{T}
\end{array}\right]_{n \times n}
$$

Ou seja,

$$
\mathbf{W}_{0}=\mathbf{I}_{n \times n}
$$


onde I é a matriz identidade de ordem $n$.

No caso de sistemas em que uma trajetória vizinha se afasta e a outra se aproxima, erros numéricos podem ocorrer devido à diferença de magnitude dos valores envolvidos. $\mathrm{O}$ algoritmo contorna esta limitação integrando o sistema em iterações de período $\tau$ e ortonormalizando os raios a cada iteração. Este procedimento é descrito a seguir.

A equação (84) é integrada a partir das condições iniciais dadas pela equação (85) no intervalo de tempo $\tau$. Após a integração a matriz $\mathbf{W}$ passa a ser composta por

$$
\mathbf{W}(\tau)=\left(\begin{array}{llll}
\mathbf{w}_{1}^{T}(\tau) & \mathbf{w}_{2}^{T}(\tau) & \ldots & \mathbf{w}_{n}^{T}(\tau)
\end{array}\right)_{n \times n}
$$

onde $\left\{\mathbf{w}_{1}, \mathbf{w}_{2}, \ldots, \mathbf{w}_{n}\right\}$ é o novo conjunto de vetores que compõem a matriz jacobiana após a primeira iteração. Esses vetores variam em direção e magnitude a cada instante. Logo, para gerar uma base linearmente independente para a próxima iteração utiliza-se o método de ortonormalização de Gram-Schmidt (APOSTOL, 1969). Este processo permite produzir o conjunto de vetores ortonormais $\left\{\overline{\mathbf{w}}_{1}, \overline{\mathbf{w}}_{2}, \ldots, \overline{\mathbf{w}}_{n}\right\}$ a partir do conjunto $\left\{\mathbf{w}_{1}, \mathbf{w}_{2}, \ldots, \mathbf{w}_{n}\right\}$ obtido na integração da equação (84). A operação é realizada conforme os seguintes cálculos:

$$
\begin{aligned}
\overline{\mathbf{w}}_{1} & =\frac{\mathbf{w}_{1}}{\left|\mathbf{w}_{1}\right|} \\
\overline{\mathbf{w}}_{2} & =\frac{\mathbf{w}_{2}-\left(\mathbf{w}_{2} \cdot \overline{\mathbf{w}}_{1}\right) \overline{\mathbf{w}}_{1}}{\left|\mathbf{w}_{2}-\left(\mathbf{w}_{2} \cdot \overline{\mathbf{w}}_{1}\right) \overline{\mathbf{w}}_{1}\right|} \\
\vdots & =\vdots \\
\overline{\mathbf{w}}_{n} & =\frac{\mathbf{w}_{n}-\left(\mathbf{w}_{n} \cdot \overline{\mathbf{w}}_{n-1}\right) \overline{\mathbf{w}}_{n-1}-\ldots-\left(\mathbf{w}_{n} \cdot \overline{\mathbf{w}}_{1}\right) \overline{\mathbf{w}}_{1}}{\left|\mathbf{w}_{n}-\left(\mathbf{w}_{n} \cdot \overline{\mathbf{w}}_{n-1}\right) \overline{\mathbf{w}}_{n-1}-\ldots-\left(\mathbf{w}_{n} \cdot \overline{\mathbf{w}}_{1}\right) \overline{\mathbf{w}}_{1}\right|},
\end{aligned}
$$

onde $\mathbf{w}_{i} \cdot \mathbf{w}_{j}$ é o produto interno entre $\mathbf{w}_{i}$ e $\mathbf{w}_{j}$ e $\left|\mathbf{w}_{i}\right|$ representa a norma euclidiana de $\mathbf{w}_{i}$. A interpretação geométrica do processo de ortonormalização de Gram-Schmidt para um sistema bidimensional pode ser observada na figura 11.

As razões $r_{i} / r_{i 0}$ contidas na expressão 69 são aproximadas pelos valores dos denominadores das expressões em 90. A cada iteração, $s$, estes denominadores são armazenados em vetores $P_{i}(s)$, onde o índice $i$ se refere ao vetor $\overline{\mathbf{w}}_{i}$ associado. 
Figura 11 - Ortonormalização de Gram-Schmidt para um sistema bidimensional

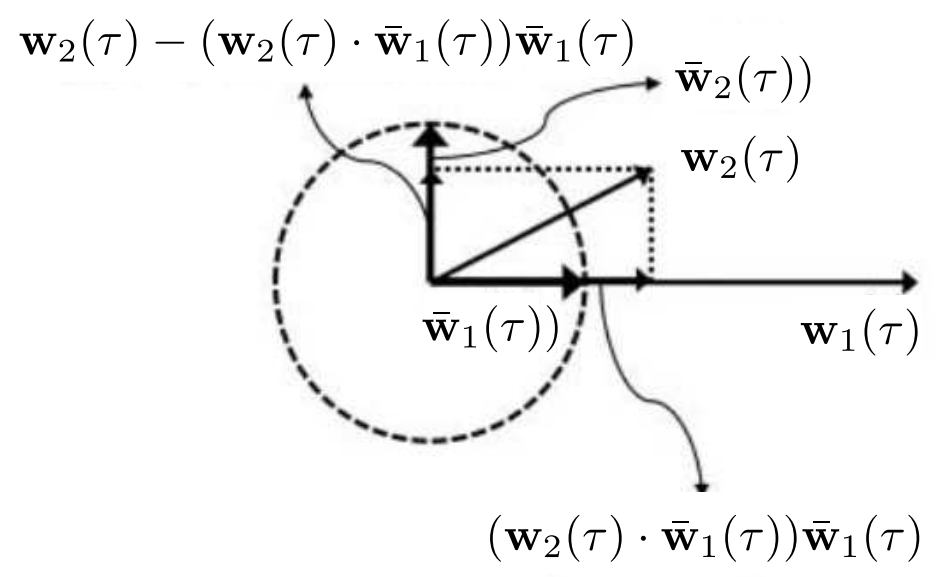

Fonte: Autor "adaptado de" Sadri e Wu, 2013

$$
\begin{aligned}
P_{1}(s) & =\left|\mathbf{w}_{1}\right| \\
P_{2}(s) & =\left|\mathbf{w}_{2}-\left(\mathbf{w}_{2} \cdot \overline{\mathbf{w}}_{1}\right) \overline{\mathbf{w}}_{1}\right| \\
\vdots & =\vdots \\
P_{n}(s) & =\left|\mathbf{w}_{n}-\left(\mathbf{w}_{n} \cdot \overline{\mathbf{w}}_{n-1}\right) \overline{\mathbf{w}}_{n-1}-\ldots-\left(\mathbf{w}_{n} \cdot \overline{\mathbf{w}}_{1}\right) \overline{\mathbf{w}}_{1}\right|
\end{aligned}
$$

A próxima iteração do algoritmo utiliza o ponto final da trajetória de referência como condição inicial das equações diferenciais do sistema e os vetores em 90 como condição inicial da equação variacional. Este procedimento é repetido seguidas vezes. Após $s$ iterações, integrando a equação (84) em intervalos de tempo $\tau$ os coeficientes de Lyapunov podem ser calculados aproximadamente por

$$
\lambda_{i} \approx \frac{\sum_{j=1}^{s} \log _{2} P_{i}(j)}{s \tau},(i=1, \ldots, n) .
$$

É possível observar que a equação (69) definida na seção anterior é aproximada pela equação (92) com base logarítmica $\mathrm{b}=2$. Conforme o número de iterações, $s$, cresce, os valores dos expoentes convergem para o seu valor definitivo.

É importante salientar que, como visto nesta seção, o número de expoentes de Lyapunov é igual à dimensão do sistema. Porém, como as direções dos raios variam constantemente, os expoentes não estão associados à uma direção ou estado específico. Além disso, o teorema de 
Oseledec (1968) afirma que os expoentes de Lyapunov são propriedades invariantes de um determinado atrator. Ou seja, se tratando de pontos fixos estáveis, as condições iniciais contidas na bacia de atração apresentam valores de expoentes de Lyapunov iguais. Estas duas propriedades são levadas em consideração nas análises de estabilidade apresentadas adiante.

Após o cálculo dos expoentes de Lyapunov, uma série de conclusões podem ser obtidas a respeito do comportamento do sistema e propriedades da condição inicial, $\mathbf{x}_{0}$, escolhida. Para condições iniciais instáveis, o algoritmo falha em obter os valores dos expoentes, pois os estados tendem ao infinito. Para situações em que o algoritmo converge para um determinado valor, o sinal e a magnitude dos expoentes fornecem informações relevantes sobre as características do sistema. Se, em sistemas tridimensionais, todos os três expoentes forem negativos a condição inicial é estável e as órbitas convergem para um ponto de equilíbrio. Se um dos expoentes for zero e os outros dois forem negativos a taxa de expansão e contração de um dos raios é considerada pequena e as órbitas convergem para um ciclo-limite. Além disso, caso um dos expoentes seja positivo o comportamento é caótico. Para a correta interpretação do comportamento das órbitas do sistema é necessário avaliar todas as ocorrências de expoentes positivos, negativos e nulos. Análises mais detalhadas de sistemas de terceira ordem podem ser encontradas em Monteiro (2006) e Viana (2009).

As magnitudes dos valores dos expoentes de Lyapunov podem ser interpretadas como indicadores do quanto as trajetórias vizinhas se aproximam ou se afastam da trajetória de referência. Isto é, o sinal determina o tipo de comportamento, e a magnitude do expoente determina a intensidade com que a convergência/divergência ocorre. Em situações em que todos os expoentes são negativos, o maior deles, neste caso, o menos negativo, indica a máxima taxa de estabilização, isto é, o menor período transitório (WU et al., 2005). Tirando proveito desta propriedade, Sadri e Wu (2013) propõem utilizar o maior expoente de Lyapunov como um índice da taxa de convergência da bacia de atração de um determinado ponto fixo. Portanto, esta técnica permite quantificar o quão rápido as órbitas na bacia de atração se aproximam do ponto fixo estável.

\subsection{EXEMPLO LINEAR}

A seguir, é apresentado um exemplo que mostra a relação entre os expoentes de Lyapunov $\lambda_{i}$ e os autovalores $\Lambda_{i}$ de um sistema dinâmico linear. Este exemplo tem como objetivo aumentar a compreensão do significado físico do valor dos expoentes de Lyapunov associados 
à dinâmica que o sistema apresenta. Por fim, são feitas considerações a respeito do caso geral e sistemas não lineares.

Supondo um sistema dinâmico linear escrito na forma matricial como

$$
\dot{\mathbf{x}}=\mathbf{A x}+\mathbf{B u}
$$

O sistema da equação (93) para $\mathbf{u}(t)=0$ e a partir de uma condição inicial $\mathbf{x}_{0}$ é dado pelas equações diferenciais homogêneas

$$
\dot{\mathbf{x}}=\mathbf{A x}
$$

A solução da equação (94) é dada por

$$
\mathbf{x}_{h}(t)=\mathbf{G}\left(\mathbf{x}_{0}, t\right)=e^{\mathbf{A} t} \mathbf{x}_{0},
$$

onde $\mathbf{x}_{h}$ é a solução homogênea e $\mathbf{G}$ é o mapa que determina o valor de $\mathbf{x}_{h}$ para uma dada condição inicial $\mathbf{x}_{0}$ no instante $t$.

Para uma matriz dinâmica $\mathbf{A}$ com autovalores dados por $\Lambda_{1}, \Lambda_{2}, \ldots, \Lambda_{n}$ e autovetores dados por $\overline{\mathbf{q}}_{1}, \overline{\mathbf{q}}_{2}, \ldots, \overline{\mathbf{q}}_{n}$ a equação (95) pode ser escrita como (ROWELL, 2002)

$$
\mathbf{x}_{h}(t)=\boldsymbol{\Phi}(t) \mathbf{x}_{0}
$$

onde $\Phi$ é a matriz de transição de estado do sistema dada por

$$
\boldsymbol{\Phi}(t)=\mathbf{H} e^{\mathbf{\Lambda} t} \mathbf{H}^{-1},
$$

onde a matriz modal $\mathbf{H}$ é composta pelos autovetores da matriz $\mathbf{A}$ da seguinte forma:

$$
\mathbf{H}=\left[\begin{array}{llll}
\overline{\mathbf{q}}_{1}^{T} & \overline{\mathbf{q}}_{2}^{T} & \ldots & \overline{\mathbf{q}}_{n}^{T}
\end{array}\right]
$$

A matriz $e^{\Lambda t}$ possui os componentes modais $e^{\Lambda_{i} t}$ dispostos na diagonal principal como

$$
e^{\boldsymbol{\Lambda} t}=\left[\begin{array}{cccc}
e^{\Lambda_{1} t} & 0 & \ldots & 0 \\
0 & e^{\Lambda_{2} t} & \ldots & 0 \\
\vdots & \vdots & \ddots & \vdots \\
0 & 0 & \ldots & e^{\Lambda_{n} t}
\end{array}\right]
$$


Ou seja, a resposta homogênea de um sistema dinâmico linear é obtida a partir dos autovalores e autovetores da matriz $\mathbf{A}$. Os autovetores $\overline{\mathbf{q}}_{i}$ fornecem a informação de como os componentes modais $e^{\Lambda_{i} t}$ são combinados linearmente para gerar as respostas de cada estado no tempo. Em contrapartida, os autovalores fornecem informações sobre a estabilidade do sistema e a rapidez de convergência para condições estacionárias. Sistemas com todos os autovalores reais e negativos são assintóticamente estáveis, pois todos os componentes modais tendem a zero conforme o tempo cresce. Porém, basta que apenas um autovalor seja positivo para que pelo menos um dos estados cresca exponencialmente, caracterizando a instabilidade. Para sistemas que apresentam autovalores em forma de pares complexos conjugados $\left(\Lambda_{i, i+1}=\sigma \pm i \omega\right)$ a análise de estabilidade deve ser feita verificando o sinal da parte real $\sigma$. Caso a parte real seja igual à zero $(\sigma=0)$ o sistema apresenta comportamento oscilatório não amortecido e é considerado marginalmente estável. Por fim, é importante lembrar que o método discutido aqui não considera a ocorrência de autovalores repetidos. Neste caso um desenvolvimento específico deve ser realizado.

Os expoentes de Lyapunov a partir de um sistema dinâmico linear dado pela equação (94) pode ser calculado seguindo o desenvolvimento a seguir. Primeiramente, deriva-se a equação (95) em relação a condição inicial obtendo

$$
\operatorname{DG}\left(\mathbf{x}_{0}, t\right)=e^{\mathbf{A} t}
$$

Multiplicando a equação (100) em ambos os lados por um dos autovetores temos

$$
\operatorname{DG}\left(\mathbf{x}_{0}, t\right) \overline{\mathbf{q}}_{i}=e^{\mathbf{A} t} \overline{\mathbf{q}}_{i}
$$

Substituindo a equação (97) na equação (101) temos

$$
\operatorname{DG}\left(\mathbf{x}_{0}, t\right) \overline{\mathbf{q}}_{i}=\left(\mathbf{H} e^{\mathbf{\Lambda} t} \mathbf{H}^{-1}\right) \overline{\mathbf{q}}_{i} .
$$

Como $\overline{\mathbf{q}}_{i}$ é uma das colunas de $\mathbf{H}$, a equação (102) pode ser reescrita como

$$
\mathrm{DG}\left(\mathbf{x}_{0}, t\right) \overline{\mathbf{q}}_{i}=e^{\Lambda_{i} t} \overline{\mathbf{q}}_{i}
$$

Das equações (75) e (77), a definição dos expoentes de Lyapunov pode ser reescrita como

$$
\lambda_{i}=\lim _{t \rightarrow+\infty} \frac{1}{t-t_{0}} \log _{\mathrm{b}}\left|\mathrm{DG}\left(\mathbf{x}_{0}, t\right) \mathbf{r}_{i}\right|
$$


onde $\mathbf{r}_{i}$ é a direção considerada para a derivada do mapa $\mathbf{G}\left(\mathbf{x}_{0}, t\right)$ em relação à condição inicial.

Assumindo o tempo inicial $t_{0}=0$, a base logarítmica $\mathrm{b}=e$ e a direção $\mathbf{r}_{i}=\overline{\mathbf{q}}_{i} \mathrm{a}$ expressão 104 pode ser escrita como

$$
\lambda_{i}=\lim _{t \rightarrow+\infty} \frac{1}{t} \ln \left|\mathrm{DG}\left(\mathbf{x}_{0}, t\right) \overline{\mathbf{q}}_{i}\right| .
$$

Substituindo a equação (103) na equação (105) temos

$$
\lambda_{i}=\lim _{t \rightarrow+\infty} \frac{1}{t} \ln \left|e^{\Lambda_{i} t} \overline{\mathbf{q}}_{i}\right| .
$$

Para $\left|\overline{\mathbf{q}}_{i}\right|=1$ a equação (106) se reduz a

$$
\lambda_{i}=\lim _{t \rightarrow+\infty} \frac{1}{t} \ln \left|e^{\Lambda_{i} t}\right|
$$

Logo,

$$
\lambda_{i}=\Lambda_{i}
$$

Ou seja, para sistemas dinâmicos lineares os expoentes de Lyapunov, $\lambda_{i}$, quando calculados através da equação (106), são iguais aos autovalores, $\Lambda_{i}$, da matriz $\mathbf{A}$ do sistema dado pela equação (94). Esta afirmação é válida para qualquer condição inicial, excluindo a origem, e com a direção da derivada do mapa coincidente com a direção de um dos autovetores do sistema $\left(\mathbf{r}_{i}=\overline{\mathbf{q}}_{i}\right)$.

Para sistemas não lineares esta relação, obviamente, se altera, pois, primeiramente, o modelo deixa de ser caracterizado por uma matriz dinâmica constante. Entretanto, ainda é possível considerar, por exemplo, a utilização do sistema linearizado localmente e aplicar um procedimento de cálculo que leve em consideração a variação dos autovalores do sistema ao longo do tempo. Além disso, as direções das derivadas do mapa não são, necessariamente, dadas pelos autovetores da matriz dinâmica. Apesar destes desvios a dependência dos expoentes com relação aos autovalores do modelo linearizado é evidente. Porém, a relação exata se torna complexa e não será explorada nesta dissertação.

\subsection{EXEMPLO NÃO LINEAR}

Um estudo em que ocorre a aplicação do conceito de expoentes de Lyapunov na análise de estabilidade de sistemas não lineares é realizado por Sadri e Wu (2013). O modelo de veículo 
utilizado pelos autores é simples, sem articulação, e se encontra ilustrado na figura 12 com os símbolos adaptados à nomenclatura utilizada nesta dissertação.

O método descrito no artigo permite apresentar as regiões de estabilidade, os efeitos da variação paramétrica e os valores do índice de convergência conforme a configuração do sistema. Ou seja, é possível, segundo o autor, determinar a região de estabilidade de maneira formal e obter informações sobre com que velocidade as condições iniciais são atraídas para o ponto de equilíbrio.

Figura 12 - Modelo bicicleta sem articulação e com dois graus de liberdade

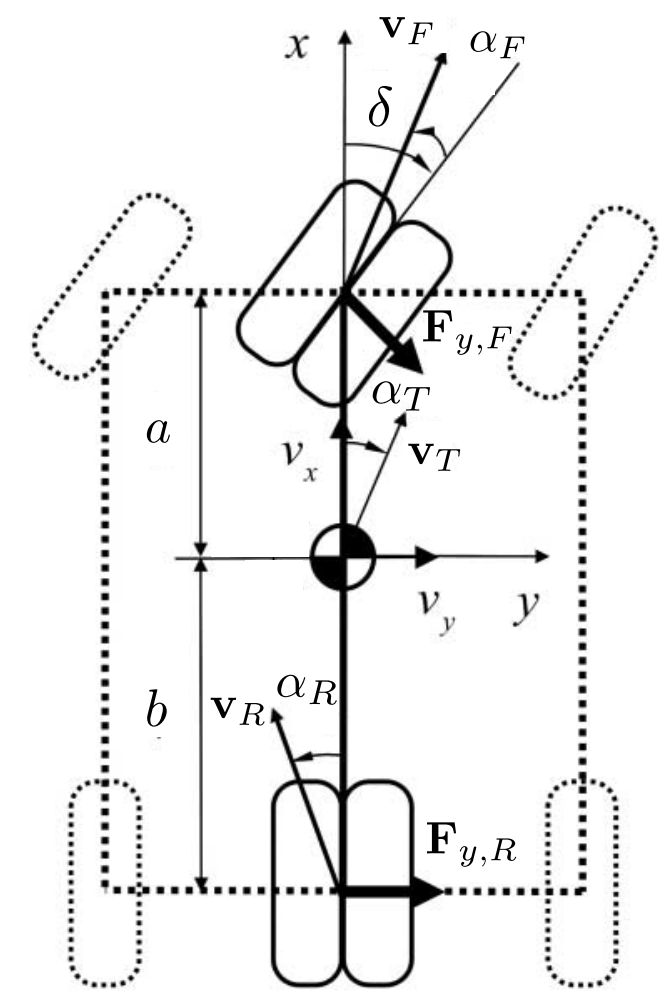

Fonte: Autor "adaptado de" Sadri e Wu, 2013

O modelo é do tipo bicicleta, não linear e com 2 graus de liberdade, velocidade angular $\dot{\psi}$ e velocidade transversal do centro de massa $v_{y}$. Este modelo pode ser interpretado como um caso particular do modelo de veículo articulado apresentado na seção 3.2. A interação com o semirreboque é desprezada, eliminando o estado $\phi$, e a velocidade longitudinal do centro de massa $v_{x}$ é constante, tornando possível a eliminação do estado $v$. Além disso, a caracterização da orientação do vetor velocidade do centro de massa é dada por sua componente transversal $v_{y}$ e não pelo ângulo de deriva $\alpha_{T}$. A relação entre estas duas grandezas é dada por

$$
v_{y}=v_{T} \sin \alpha_{T} .
$$


Logo, a equação de movimento de veículo simples na forma matricial é dada por

$$
\left[\begin{array}{c}
\dot{v}_{y} \\
\ddot{\psi}
\end{array}\right]=\mathbf{f}\left(v_{y}, \dot{\psi}\right)=\left[\begin{array}{c}
\left(F_{y, F} \cos \delta+F_{y, R}\right) / m-\dot{\psi} v_{x} \\
\left(a F_{y, F} \cos \delta-b F_{y, R}\right) / I
\end{array}\right],
$$

onde a distância $a$ mede o afastamento entre o eixo dianteiro e o centro de massa do veículo e a distância $b$ mede o afastamento entre o centro de massa do veículo e o eixo traseiro. A constante $m$ representa a massa e $I$ o momento de inércia do veículo. $\mathrm{O}$ ângulo $\delta$ define o esterçamento do eixo dianteiro. As forças $F_{y, F}$ e $F_{y, R}$ são as forças transversais no eixo dianteiro e traseiro, respectivamente. Estas forças são obtidas através do modelo polinomial descrito pela equação (2). Portanto, as forças transversais nos eixos dianteiro e traseiro são dadas por

$$
\begin{gathered}
F_{y, F}=k_{1, F} \alpha_{F}-k_{2, F} \alpha_{F}^{3} \\
F_{y, R}=k_{1, R} \alpha_{R}-k_{2, R} \alpha_{R}^{3},
\end{gathered}
$$

onde $k_{1, F}$ e $k_{2, F}$ são os coeficientes do eixo dianteiro e $k_{1, R}$ e $k_{2, R}$ são os coeficientes do eixo traseiro. Os ângulos de deriva nos eixos dianteiro e traseiro são obtidos linearizando as expressões de $\alpha_{F}$ e $\alpha_{R}$ nas equações (25) e (26) resultando nas expressões

$$
\begin{aligned}
\alpha_{F} & =\frac{v_{y}+a \dot{\psi}}{v_{x}}-\delta \\
\alpha_{R} & =\frac{v_{y}-b \dot{\psi}}{v_{x}}
\end{aligned}
$$

Importante notar que esta aproximação é válida apenas para $v_{y} \mathrm{e} \dot{\psi}$ pequenos.

Para o cálculo dos expoentes de Lyapunov é necessário obter a matriz Jacobiana do sistema definida como

$$
\mathbf{J}=\left[\begin{array}{ll}
\partial f_{1} / \partial v_{y} & \partial f_{1} / \partial \dot{\psi} \\
\partial f_{2} / \partial v_{y} & \partial f_{2} / \partial \dot{\psi}
\end{array}\right]
$$

onde os elementos da matriz $\mathbf{J}$ são dados por 


$$
\begin{aligned}
\frac{\partial f_{1}}{\partial v_{y}} & =\frac{\cos \delta\left(-k_{1, F}+3 k_{2, F} \alpha_{F}^{2}\right)+\left(-k_{1, R}+3 k_{2, R} \alpha_{R}^{2}\right)}{m v_{x}} \\
\frac{\partial f_{1}}{\partial \dot{\psi}} & =\frac{a \cos \delta\left(-k_{1, F}+3 k_{2, F} \alpha_{F}^{2}\right)-\operatorname{lr}\left(-k_{1, R}+3 k_{2, R} \alpha_{R}^{2}\right)-m v_{x}^{2}}{m v_{x}} \\
\frac{\partial f_{2}}{\partial v_{y}} & =\frac{a \cos \delta\left(-k_{1, F}+3 k_{2, F} \alpha_{F}^{2}\right)-\operatorname{lr}\left(-k_{1, R}+3 k_{2, R} \alpha_{R}^{2}\right)}{I v_{x}} \\
\frac{\partial f_{2}}{\partial \dot{\psi}} & =\frac{a^{2} \cos \delta\left(-k_{1, F}+3 k_{2, F} \alpha_{F}^{2}\right)+r^{2}\left(-k_{1, R}+3 k_{2, R} \alpha_{R}^{2}\right)}{I v_{x}},
\end{aligned}
$$

onde $f_{1}$ e $f_{2}$ são as equações de movimento na posição um e dois da função vetorial (equação (110)), respectivamente.

Os dados do modelo utilizado por Sadri e Wu (2013) estão listados na tabela 13. É possível observar que os coeficientes do modelo polinomial são os mesmos utilizados no exemplo de comparação de modelo de pneu na seção 3.1. Logo, a curva característica do modelo de pneu escolhido se encontra ilustrada na figura 4.

Tabela 13 - Dados do veículo simples, sem articulação, utilizado por Sadri e Wu (2013)

\begin{tabular}{llrr}
\hline Item & Descrição & Valor & Unidade \\
\hline$m$ & Massa do veículo & 2.527 & $\mathrm{~kg}$ \\
$I$ & Momento de inércia do veículo & 6.550 & $\mathrm{~kg} \cdot \mathrm{m}^{2}$ \\
$a$ & Distância entre o eixo dianteiro e centro de massa & 1,37 & $\mathrm{~m}$ \\
$b$ & Distância entre o centro de massa e o eixo traseiro & 1,86 & $\mathrm{~m}$ \\
$k_{1, F}$ & Coeficiente 1 do modelo polinomial no eixo dianteiro & 114.600 & $\mathrm{~N} / \mathrm{rad}$ \\
$k_{2, F}$ & Coeficiente 2 do modelo polinomial no eixo dianteiro & 558.102 & $\mathrm{~N} / \mathrm{rad}^{3}$ \\
$k_{1, R}$ & Coeficiente 1 do modelo polinomial no eixo traseiro & 114.600 & $\mathrm{~N} / \mathrm{rad}^{3}$ \\
$k_{2, R}$ & Coeficiente 2 do modelo polinomial no eixo traseiro & 558.102 & $\mathrm{~N} / \mathrm{rad}^{3}$ \\
\hline
\end{tabular}

Fonte: Autor "adaptado de" Sadri e Wu, 2013

Os cálculos adiante são realizados no equipamento, sistema operacional e programa detalhados no apêndice A.

A evolução dos estados do modelo definido pela equação (110) com os dados da tabela 13 a partir das condições iniciais $\dot{\psi}_{0}=0,1 \mathrm{rad} / \mathrm{s}$ e $v_{y, 0}=1 \mathrm{~m} / \mathrm{s}$ pode ser observada na figura 13. O tempo total de integração é cem segundos e os resultados são exibidos com uma resolução de $\Delta t=0,01 \mathrm{~s}$. Estas condições são as mesmas apresentadas em Sadri e Wu (2013). Nesta mesma manobra, os expoentes de Lyapunov são calculados a partir do algoritmo proposto por Wolf et al. (1985) apresentado na seção 4.2. 
Figura 13 - Evolução dos estados para as condições iniciais $\dot{\psi}_{0}=0,1 \mathrm{rad} / \mathrm{s}$ e $v_{y, 0}=1 \mathrm{~m} / \mathrm{s}$

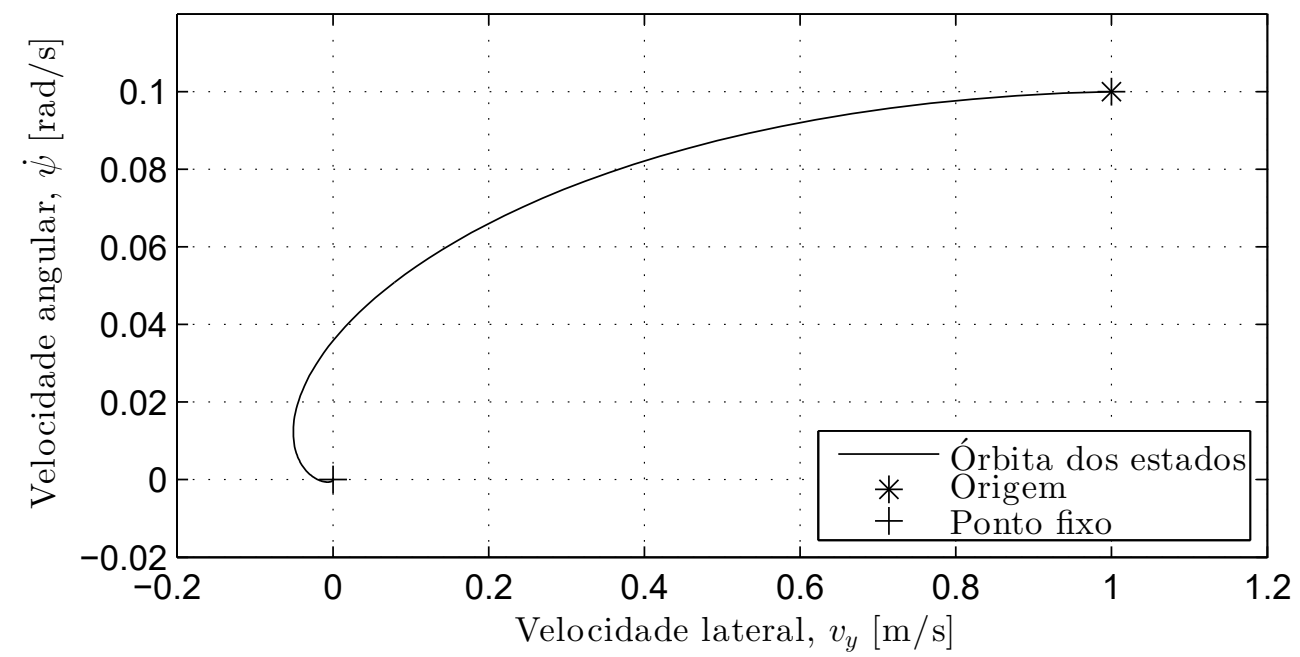

Fonte: Autor

A convergência dos expoentes de Lyapunov é ilustrada na figura 14. Nela, é possível observar que ambos os expoentes convergem para valores negativos, $\lambda_{1}=-6,616$ e $\lambda_{2}=$ $-6,661$, confirmando a estabilidade do sistema observada na figura 13. Ou seja, o sistema é estável e a órbita dos estados converge para o ponto fixo $(0,0)$. Estes resultados estão de acordo com os dados apresentados pelo autor do artigo.

Na figura 15 são mostrados três gráficos. Os dois primeiros exibem a evolução no tempo dos estados do sistema e o último apresenta a evolução da parte real dos autovalores do modelo linearizado. É possível observar que a parte real dos autovalores converge para valores negativos conforme os estados convergem para o ponto de equilíbrio. Comparando as figuras 14 e 15 é possível verificar que rapidamente (menos de um segundo) os autovalores deixam de se alterar e na maior parte do tempo de execução do algoritmo (100 segundos) as iterações são realizadas com a matriz jacobiana constante. Logo, neste caso, é possível conjecturar que a invariância dos expoentes de Lyapunov na região de convergência deste ponto fixo está associada à rápida convergência da matriz jacobiana. A partir do instante em que a matriz jacobiana se mantém constante as iterações subsequentes conduzem os expoentes de acordo com os autovalores do modelo linearizado naquele ponto fixo. Ou seja, a invariância da região de estabilidade é aparentemente obtida pelo fato da convergência ser influenciada na maior parte do tempo pelos autovalores do sistema no ponto de equilíbrio, reduzindo a contribuição do regime transiente.

A utilização do conceito de expoentes de Laypunov na obtenção da região de estabilidade é realizada verificando o sucesso da execução do algoritmo. Caso o sistema seja instável, os estados crescem exponencialmente e o algoritmo não converge devido a erros numéricos. 
Figura 14 - Expoentes de Lyapunov para as condições iniciais $\dot{\psi}_{0}=0,1 \mathrm{rad} / \mathrm{s}$ e $v_{y, 0}=1 \mathrm{~m} / \mathrm{s}$

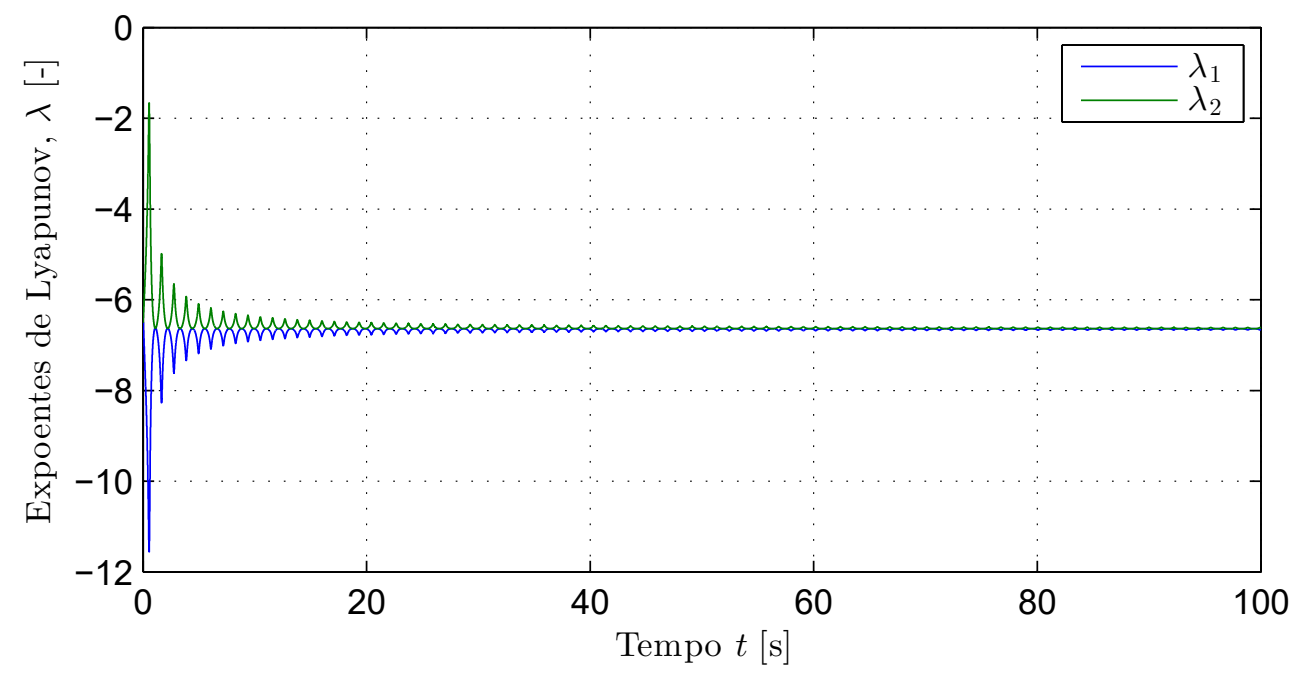

Fonte: Autor

Figura 15 - Evolução dos estados e parte real dos autovalores do modelo linearizado para as condições iniciais $\dot{\psi}_{0}=0,1 \mathrm{rad} / \mathrm{s}$ e $v_{y, 0}=1 \mathrm{~m} / \mathrm{s}$
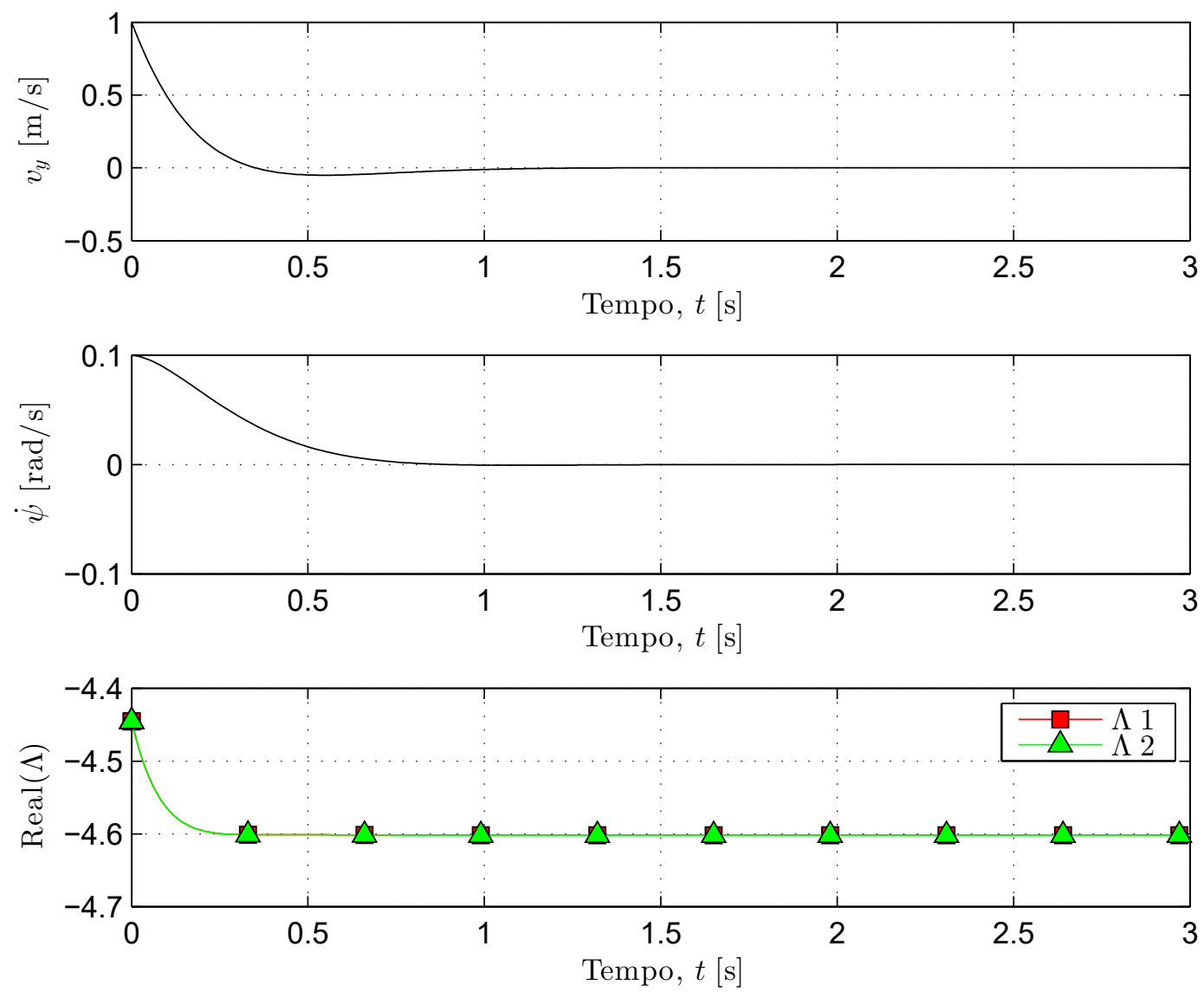
Entretanto, as condições de contorno impostas sobre o veículo sugerem um sistema dissipativo e o crescimento dos estados é uma ocorrência não intuitiva. Este fenômeno indica a introdução de energia no conjunto que pode ser fruto da curva característica do modelo de pneu adotado que após o pico de força lateral apresenta uma inclinação descrescente. Para contornar este fato o modelo de pneu polinomial deve ser subtituido por um modelo de pneu que melhor represente a curva característica típica ilustrada na figura 3.

Substituindo apenas o modelo de pneu polinomial pelo modelo de pneu Pacejka (com os parâmetros descritos na tabela 12), mantendo o modelo de veículo da equação (110), o comportamento dinâmico do veículo se manteve satisfatório para valores de condições iniciais próximas ao ponto fixo. Para condições iniciais mais afastadas da coordenada $(0,0)$ a instabilidade vista com o modelo polinomial não ocorre, porém o sistema apresenta comportamento dinâmico anormal. Isto se deve às hipóteses de linearização e à velocidade longitudinal do centro de massa prescrita. Logo, é necessário aumentar a complexidade do modelo para que o comportamento dinâmico na vizinhança das fronteiras de estabilidade seja satisfatório. De fato, isto é atingido utilizando um modelo não linear de veículo com um estado adicional, o módulo do vetor velocidade do centro de massa $v$. Este modelo alternativo de veículo simples é, então, do tipo bicicleta, não linear, com três graus de liberdade e é um caso particular, sem semirreboque, do modelo desenvolvido na seção 3.3.

Integrando o modelo alternativo para diversas condições iniciais é possível verificar que os estados convergem para $\dot{\psi}_{\text {final }}=0, v_{y, \text { final }}=0$ e $v_{\text {final }}<v_{0}$. Ou seja, o veículo volta a se movimentar em linha reta com o módulo do vetor velocidade menor que a velocidade inicial $v_{0}$. Porém, o veículo pode convergir para este regime estacionário após mudanças de orientação que resultem na movimentação de ré ou de frente após ter trafegado de ré em algum instante. Estas condições são estáveis dinâmicamente, porém não são do interesse prático. Logo, é conveniente determinar uma região de convergência em que o veículo retorne à movimentação em linha reta por trajetórias de fase satisfatórias. O critério adotado para esta região consiste em limitar as condições iniciais em que o veículo volta à trafegar em linha reta sem que ele se movimente de ré em nenhum instante. Ou seja, a componente longitudinal do vetor velocidade do caminhãotrator é sempre positiva.

Na figura 16 estão apresentadas a região de estabilidade apresentada por Sadri e Wu (2013) utilizando o conceito de expoentes de Lyapunov e a região de convergência do modelo bicicleta não linear de três graus de liberdade obtida através do método de trajetórias de fase aplicando o critério descrito no parágrafo anterior. 
Figura 16 - Comparação das regiões de estabilidade obtidas através dos expoentes de Lyapunov e método de trajetórias de fase

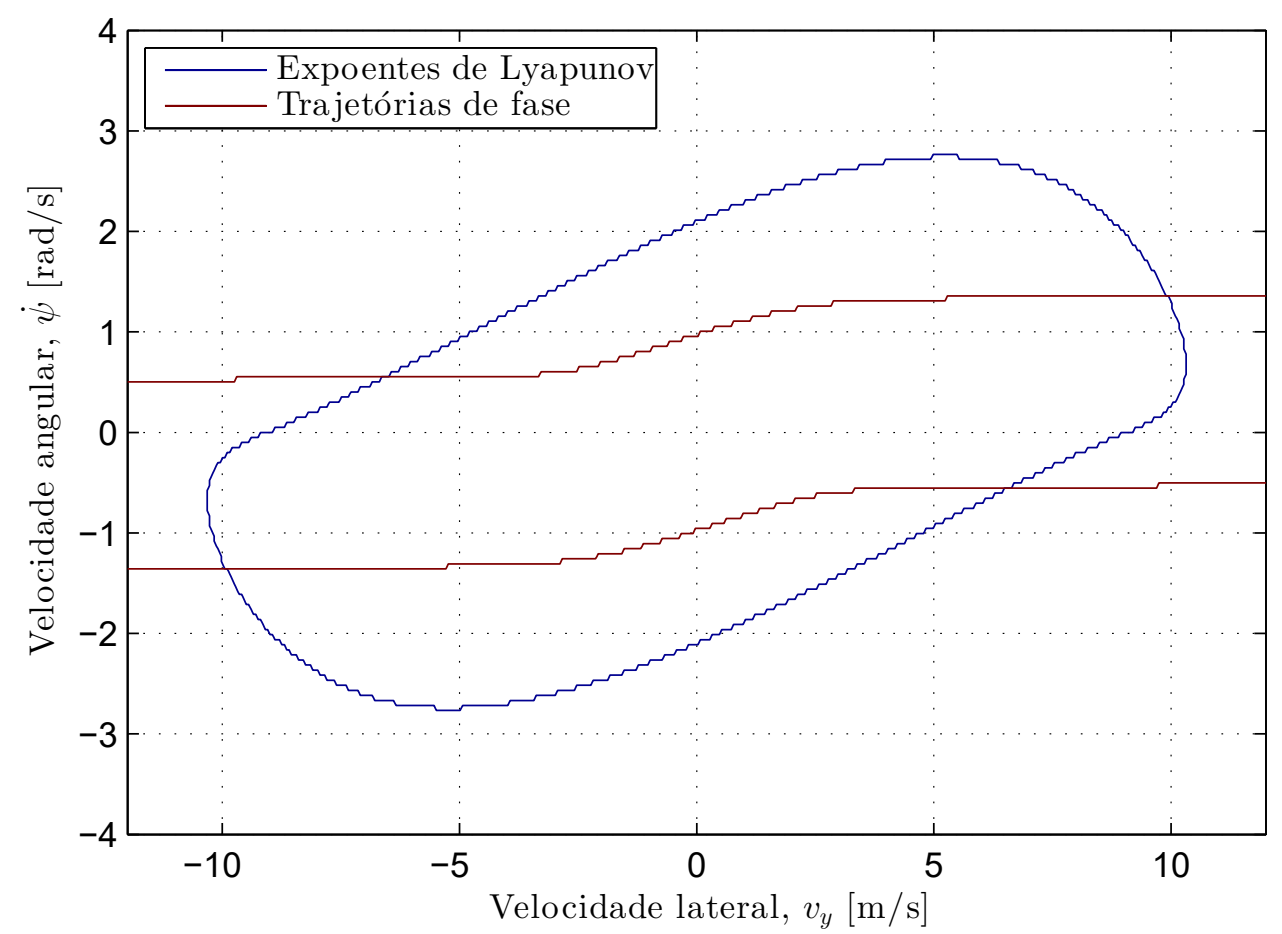

Fonte: Autor

É possível observar que a região obtida através do método de trajetórias de fase é mais estreita na direção da velocidade angular que a região obtida através do conceito de expoentes de Lyapunov. Além disso, ela se estende até os limites de análise de $v_{y}= \pm 12 \mathrm{~m} / \mathrm{s}$. Importante lembrar que além da mudança do método os modelos utilizados são distintos.

O modelo linear de dois graus de liberdade apresenta limitações para representar o veículo em condições dinâmicas distantes do ponto fixo, uma vez que os estados crescem indefinidamente. Este não é o comportamento esperado. No que diz respeito ao método, os expoentes de Lyapunov não contribuem para a determinação da região de estabilidade já que o crescimento indeterminado dos estados é o que provoca a falha do algoritmo. A instabilidade pode ser verificada através da simples integração do modelo. Mais ainda, como foi apresentado na figura 15 e discutido acima, os expoentes de Lyapunov, neste caso, não fornecem muito mais informações sobre a região de estabilidade do que os autovalores do modelo linearizado no ponto fixo associado. Através do conceito de expoentes de Lyapunov não parece ser possível extrair informações relevantes sobre o sistema dinâmico em questão, tanto para a determinação da região de estabilidade quanto para a velocidade de convergência das órbitas estáveis. 


\section{VEÍCULO ARTICULADO}

Para realizar a análise de estabilidade proposta nesta dissertação são escolhidos um caminhão-trator e um semirreboque comerciais que fornecem os parâmetros contidos nas equações de movimento.

\subsection{PARÂMETROS DO PNEU}

Os parâmetros do modelo Pacejka são obtidos experimentalmente e correspondem a um pneu comercial de tamanho 295/80 R22.5. Os valores extraidos do equipamento de medição estão presentes na tabela 14.

Tabela 14 - Parâmetros do modelo de pneu comercial de tamanho 295/80 R22.5 obtidos experimentalmente

\begin{tabular}{llrr}
\hline Item & Descrição & Valor & Unidade \\
\hline $\mathrm{a}_{0}$ & Fator de forma Shape factor & 1,028 & - \\
$\mathrm{a}_{1}$ & Influência de $F_{z}$ sobre $\mu_{n}(* 1000)$ & 2,014 & $1 / k N$ \\
$\mathrm{a}_{2}$ & Nível de atrito lateral $(* 1000)$ & 710,501 & - \\
$\mathrm{a}_{3}$ & Rigidez de curva máxima (para $\gamma=0)$ & 5226,341 & $\mathrm{~N} / \mathrm{grau}$ \\
$\mathrm{a}_{4}$ & Carga vertical em que rigidez de curva é máxima & 78,877 & $k N$ \\
$\mathrm{a}_{5}$ & Influência de $\gamma$ sobre a rigidez de curva & 0,012 & $1 / \mathrm{grau}$ \\
$\mathrm{a}_{6}$ & Influência de $F_{z}$ sobre a curvatura & $-0,005$ & $1 / k N$ \\
$\mathrm{a}_{7}$ & Nível do fator de curvatura & 0,670 & - \\
\hline Autor & & &
\end{tabular}

A influência da carga vertical na curva característica é apresentada na figura 17. As curvas características para as cargas verticais $F_{z}=29.430 \mathrm{~N}(\mathrm{~m}=3.000 \mathrm{~kg}), F_{z}=24.525 \mathrm{~N}(\mathrm{~m}=$ $2.500 \mathrm{~kg})$ e $F_{z}=20.846 \mathrm{~N}(m=2.125 \mathrm{~kg})$ são comparadas. O coeficiente de atrito de operação é dado por $\mu=0.3$.

É possível perceber que, com o aumento da carga vertical, a maior força lateral possível também aumenta. Além disso, o coeficiente de rigidez lateral para ângulos de deriva próximos a zero também aumenta com o aumento da carga vertical. 
Figura 17 - Comparação da curva característica para diferentes cargas verticais

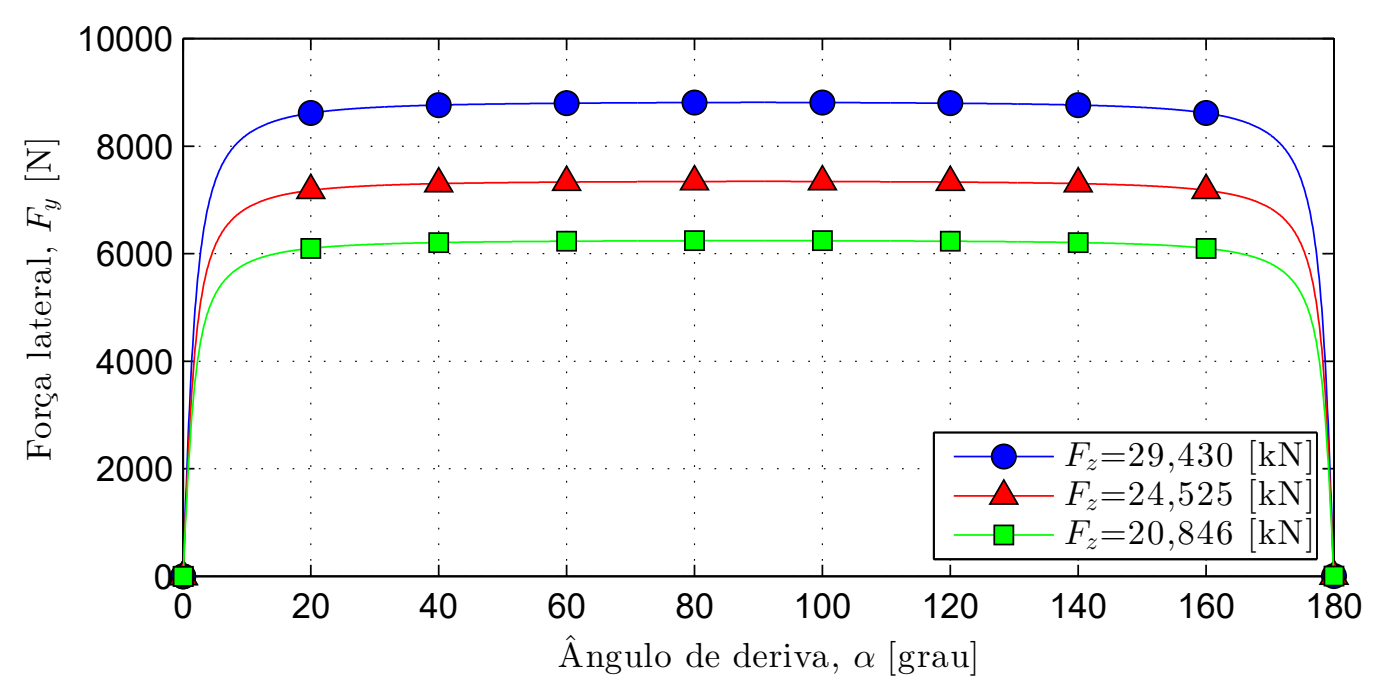

Fonte: Autor

\subsection{PARÂMETROS DO VEÍCULO}

Assim como do pneu, os parâmetros do caminhão-trator também correspondem à um veículo comercial. Além disso, os parâmetros do semirreboque assumem valores típicos encontrados no transporte rodoviário. A tabela 15 lista os parâmetros do conjunto que são típicamente obtidos através de processos diretos de medição. Os dados $m_{F, d e s}$ e $m_{R, d e s}$ correspondem às medidas da massa sobre os eixos do caminhão-trator, quando desacoplado do semirreboque. Após o acoplamento entre as duas unidades as massas dos três eixos são medidas, $m_{F}, m_{R} \mathrm{e}$ $m_{M}$. Estes valores correspondem aos limites de carga especificados pela legislação brasileira e informados na tabela 8. Os momentos de inércia das unidades $I_{T}$ e $I_{S}$ são estimados com base nos valores verificados na literatura. Todas as análises são feitas para esterçamento $\delta$ igual a zero. O posicionamento da articulação é medido através da distância $c$. A distância entre os eixos do módulo dianteiro é dada por $p$ e a distância da articulação ao eixo do semirreboque é dada por $q$. Como apresentado na seção 3.3 cada eixo apresenta uma quantidade diferente de pneus especificados por $\mathrm{n}_{F}, \mathrm{n}_{R}$ e $\mathrm{n}_{M}$.

Apesar da praticidade de ter como parâmetros de entrada os dados apresentados na tabela 15 ainda é necessário converter estes valores para os valores dos parâmetros presentes no modelo. Isto é realizado através das operações apresentadas a seguir.

A massa do caminhão-trator pode ser calculada como

$$
m_{T}=m_{F, d e s}+m_{R, d e s} .
$$


Tabela 15 - Parâmetros de medição direta da combinação caminhão-trator e semirreboque

\begin{tabular}{llrr}
\hline Item & Descrição & Valor & Unidade \\
\hline$m_{F, d e s}$ & Massa no eixo dianteiro do caminhão-trator desacoplado & 5.237 & $\mathrm{~kg}$ \\
$m_{R, d e s}$ & Massa no eixo traseiro do caminhão-trator desacoplado & 2.440 & $\mathrm{~kg}$ \\
$m_{F}$ & Massa no eixo dianteiro do caminhão-trator & 6.000 & $\mathrm{~kg}$ \\
$m_{R}$ & Massa no eixo traseiro do caminhão-trator & 10.000 & $\mathrm{~kg}$ \\
$m_{M}$ & Massa no eixo do semirreboque & 17.000 & $\mathrm{~kg}$ \\
$I_{T}$ & Momento de inércia do caminhão-trator & 46.100 & $\mathrm{~kg} \cdot \mathrm{m}^{2}$ \\
$I_{S}$ & Momento de inércia do semirreboque & 452.010 & $\mathrm{~kg} \cdot \mathrm{m}^{2}$ \\
$\delta$ & Esterçamento do eixo dianteiro & 0 & $\mathrm{rad}$ \\
$c$ & Grandeza escalar do vetor (R - A) =c t t $_{x}$ & $-0,31$ & $\mathrm{~m}$ \\
$p$ & Distância entre os eixos do caminhão-trator & 3,55 & $\mathrm{~m}$ \\
$q$ & Distância entre a articulação e o eixo do semirreboque & 7,70 & $\mathrm{~m}$ \\
$\mathrm{n}_{F}$ & Número de pneus no eixo dianteiro do caminhão-trator & 2 & - \\
$\mathrm{n}_{R}$ & Número de pneus no eixo traseiro do caminhão-trator & 4 & - \\
$\mathrm{n}_{M}$ & Número de pneus no eixo do semirreboque & 8 & - \\
\hline
\end{tabular}

Fonte: Autor

O posicionamento do centro de massa pode ser caracterizado pelas distâncias

$$
a=\frac{m_{F, d e s}}{m_{T}} p
$$

e

$$
b=p-a .
$$

A força vertical sobre o caminhão-trator no ponto de articulação é dada por

$$
F_{z, A}=\left(m_{F}+m_{R}-m_{T}\right) g
$$

A massa do semirreboque portanto é calculada como

$$
m_{S}=\frac{\left(F_{z, A}+m_{M} g\right)}{g} .
$$

As distâncias $d$ e $e$ são escritas como

$$
d=\frac{m_{M}}{m_{S}} q
$$




$$
e=q-d
$$

Portanto a lista completa dos parâmetros utilizados pelo modelo dinâmico em guinada do veículo é apresentada na tabela 16

Tabela 16 - Parâmetros do modelo de veículo articulado

\begin{tabular}{llrr}
\hline Item & Descrição & Valor & Unidade \\
\hline$m_{T}$ & Massa do caminhão-trator & 7.677 & $\mathrm{~kg}$ \\
$m_{S}$ & Massa do semirreboque & 25.323 & $\mathrm{~kg}$ \\
$I_{T}$ & Momento de inércia do caminhão-trator & 46.100 & $\mathrm{~kg} \cdot \mathrm{m}^{2}$ \\
$I_{S}$ & Momento de inércia do semirreboque & 452.010 & $\mathrm{~kg} \cdot \mathrm{m}^{2}$ \\
$\delta$ & Esterçamento do eixo dianteiro & 0 & $\mathrm{rad}$ \\
$a$ & Grandeza escalar do vetor $(\mathrm{F}-\mathrm{T})=a \mathbf{t}_{x}$ & 1,128 & $\mathrm{~m}$ \\
$b$ & Grandeza escalar do vetor $(\mathrm{T}-\mathrm{R})=b \mathbf{t}_{x}$ & 2.422 & $\mathrm{~m}$ \\
$c$ & Grandeza escalar do vetor $(\mathrm{R}-\mathrm{A})=c \mathbf{t}_{x}$ & $-0,31$ & $\mathrm{~m}$ \\
$d$ & Grandeza escalar do vetor $(\mathrm{A}-\mathrm{S})=d \mathbf{s}_{x}$ & 5.169 & $\mathrm{~m}$ \\
$e$ & Grandeza escalar do vetor $(\mathrm{S}-\mathrm{M})=e \mathbf{s}_{x}$ & 2.531 & $\mathrm{~m}$ \\
$\mathrm{n}_{F}$ & Número de pneus no eixo dianteiro do caminhão-trator & 2 & - \\
$\mathrm{n}_{R}$ & Número de pneus no eixo traseiro do caminhão-trator & 4 & - \\
$\mathrm{n}_{M}$ & Número de pneus no eixo do semirreboque & 8 & - \\
Fonte: Autor & & &
\end{tabular}

\subsection{INTEGRAÇÃO}

Em veículos simples, sem articulação, a dinâmica em guinada é caracterízada típicamente pelos estados velocidade ângular $\dot{\psi}$ e ângulo de deriva do centro de massa $\alpha_{T}$ (Supondo o mesmo modelo apresentado na figura 6, porém sem o semirreboque). Ou seja, através do monitoramento e da análise do valor de convergência destes dois estados é possível chegar à uma conclusão sobre a estabilidade em guinada do veículo. Um exemplo desta análise pode ser obervada na seção 4.4. Um procedimento semelhante pode ser realizado na análise de estabilidade de veículos articulados, em que os mesmos dois estados são verificados com o acréscimo do estado orientação do semirreboque $\phi$. Logo, $\dot{\psi}, \alpha_{T}$ e $\phi$ são os três estados usados para confirmar a capacidade do veículo em retornar para a movimentação em linha reta sem que haja acotovelamento.

Para simular o comportamento dinâmico deste modelo é utilizado o programa Matlab ${ }^{\circledR}$. Nele, o modelo descrito na seção 3 é integrado através da função ode45. Esta função permite 
simular a equação de movimento 59 a partir da função vetorial $\mathbf{f}(\mathbf{x})$ considerando a matriz de massa $\mathbf{M}(\mathbf{x})$ passada para o integrador através da opção Mass. Maiores informações podem ser obtidas em Mathworks (2015). Além disso, os detalhes computacionais estão apresentados no apêndice A. O modelo é simulado para duas condições iniciais diferentes. O primeiro exemplo (caso 1) consiste numa manobra sem acotovelamento e o segundo (caso 2) numa manobra com acotovelamento. Os parâmetros de integração de ambos os casos são arbitrários e se econtram na tabela 17.

Tabela 17 - Parâmetros de integração e condição inicial

\begin{tabular}{llrrr}
\hline Item & Descrição & Caso 1 & Caso 2 & Unidade \\
\hline$T$ & Tempo total de simulação & 14 & 15 & $\mathrm{~s}$ \\
$N$ & Número de pontos de exibição da solução & 500 & 500 & - \\
$\dot{\psi}_{0}$ & Velocidade angular caminhão-trator & 0,25 & 0,4 & $\mathrm{rad} / \mathrm{s}$ \\
$\alpha_{T, 0}$ & Ângulo de deriva em T do caminhão-trator & 0,3 & 0 & $\mathrm{rad}$ \\
$\dot{\phi}_{0}$ & Velocidade angular relativa entre o os dois módulos & 0,25 & 0,4 & $\mathrm{rad} / \mathrm{s}$ \\
$v_{0}$ & Módulo do vetor velocidade no ponto T & 20 & 20 & $\mathrm{~m} / \mathrm{s}$ \\
$\phi_{0}$ & Ângulo entre o caminhão-trator e o semirreboque & 0 & 0 & $\mathrm{rad}$ \\
$\psi_{0}$ & Ângulo de orientação do caminhão-trator & 0 & 0 & $\mathrm{rad}$ \\
$X_{0}$ & Deslocamento na direção longitudinal & 0 & 0 & $\mathrm{~m}$ \\
$Y_{0}$ & Deslocamento na direção transversal & 0 & 0 & $\mathrm{~m}$ \\
\hline Fonte: Autor & & &
\end{tabular}

A figura 18 mostra a evolução em relação ao tempo dos estados relevantes para a análise da dinâmica em guinada. No canto superior esquerdo é possível observar a velocidade angular do caminhão-trator $\dot{\psi}$. No canto superior direito encontra-se o ângulo de deriva do caminhãotrator $\alpha_{T}$. A evolução do ângulo da articulação $\phi$ é observada no gráfico localizado no canto inferior esquerdo e a velocidade $v$ encontra-se no canto inferior direito. É possível observar que os estados $\dot{\psi}, \alpha_{T}$ e $\phi$ oscilam com amplitude decrescente e convergem para zero. Enquanto isso a velocidade $v$ converge para o valor $v=17.97 \mathrm{~m} / \mathrm{s}$. Não há ocorrência de acotovelamento, pois após a convergência do sistema os valores de $\phi$ não chegam à $\pi \approx 3,14 \mathrm{rad}$. Além disso, os ângulos $\alpha_{T}$ e $\phi$ se mantêm abaixo de $\pi / 2 \approx 1,57 \mathrm{rad}$ ao longo de toda a manobra, ou seja, em nenhum instante a componente longitudinal do vetor velocidade do centro de massa do caminhão-trator $\mathbf{v}_{T}$ é negativa. Logo, o veículo converge para a movimentação em linha reta porém com uma velocidade do centro de massa do caminhão-trator reduzida.

A figura 19 mostra a evolução dos ângulos de deriva em cada eixo. É possível observar que os valores dos ângulos se iniciam próximos de 20 graus e oscilam com amplitude decrescente convergindo para zero. Verificando a curva característica da figura 17 é possível confirmar 
Figura 18 - Evolução dos estados em função do tempo
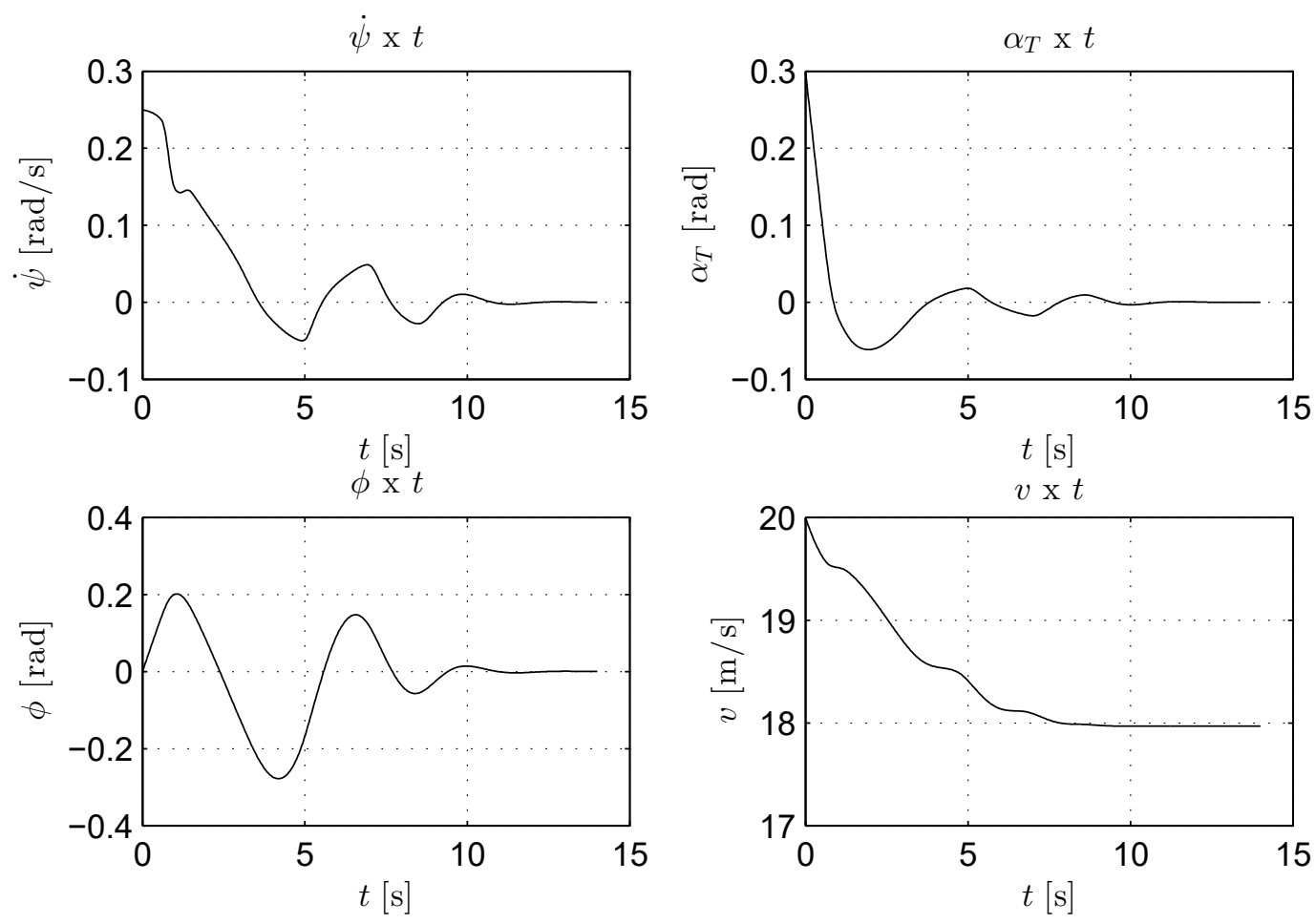

Fonte: Autor

a necessidade de aplicação do modelo de pneu não linear devido à faixa de ângulos de deriva obtidos ao longo da manobra.

Como discutido na modelagem do veículo as acelerações laterais do centro de massa das unidades devem se manter abaixo do limiar de tombamento. Logo, na figura 20, é possível observar os valores da aceleração lateral em função do tempo. Nesta dissertação, o limiar de aceleração lateral é arbitrariamente escolhida como $A_{y, l i m}=0,35 \mathrm{~g}$, onde $g=9,81 \mathrm{~m} / \mathrm{s}^{2}$ é a aceleração da gravidade. Nesta manobra estável a aceleração lateral não excedeu em nenhum instante a aceleração lateral máxima estipulada.

Nas figuras 21 e 22 a evolução das variáveis de estado são mostradas numa representação em três dimensões junto com três projeções em duas dimensões. Os estados de maior relevância nas análises de estabilidade, $\dot{\psi}$ e $\alpha_{T}$, são mantidos nas duas figuras. Na figura 21 os estados $\dot{\psi}$ e $\alpha_{T}$ são apresentados em conjunto com o estado $v$. Nesta figura é possível observar por uma outra perspectiva o que ja foi concluido acima, porém, agora a reta de velocidades finais está presente. Esta reta representa os valores finais em que a velocidade $v$ pode convergir e ainda satisfazer a convergência dos outros estados para zero. Na figura 22 o estado $\phi$ é usada como a terceira dimensão. Neste caso todos os estados presentes na ilustração convergem para zero. 
Figura 19 - Evolução dos ângulos de deriva dos três eixos em função do tempo

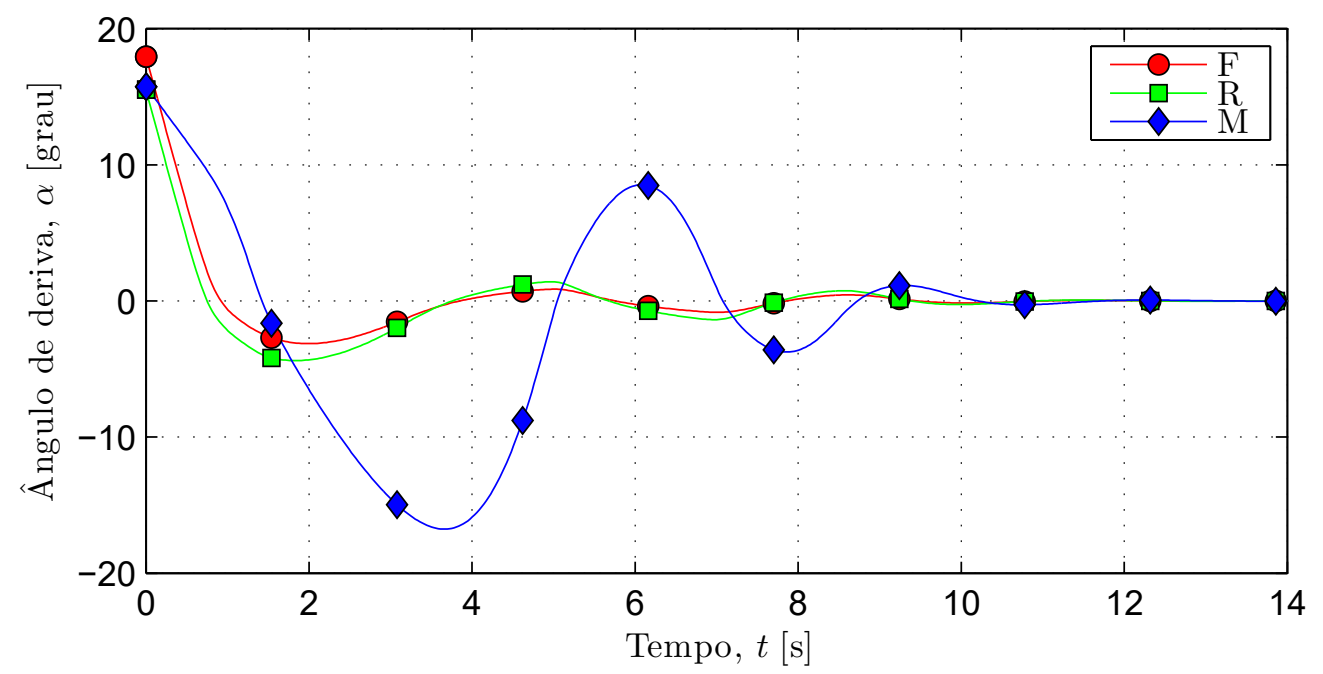

Fonte: Autor

O símbolo $*$ indica o posicionamento da condição inicial e o símbolo + indica o ponto para o qual a órbita convergiu.

A verificação das ilustrações apresentadas até aqui pode não transmitir com clareza a real movimentação do veículo articulado no espaço. Para solucionar este problema a figura 23 exibe o posicionamento do conjunto caminhão-trator e semirreboque em diversos instantes igualmente espaçados da manobra. O módulo dianteiro é representado pelo retângulo menor e o módulo traseiro pelo retângulo maior. As trajetórias de cada eixo são também mostradas. Com esta figura é possível observar o significado físico da condição inicial imposta na integração. O veículo se movimenta na direção tranversal e o ângulo da articulação aumenta e depois retorna a zero. Por fim, o veículo se movimenta em linha reta porém numa orientação diferente da inicial.

A dinâmica apresentada nas figuras 18, 19, 20, 21, 22 e 23 é considerada nesta dissertação como de interesse prático, pois para a dada condição inicial, o veículo, sem ser atuado por esterçamento ou tração nos pneus, retorna à movimentação em linha reta sem a ocorrência de acotovelamento.

Para ilustrar o caso em que há a ocorrência de acotovelamento as condições iniciais são alteradas conforme já apresentado na tabela 17. O estado ângulo de deriva passa a ser zero e a velocidade angular inicial do caminhão-trator passa a ser $0,4 \mathrm{rad} / \mathrm{s}$ enquanto todos os outros estados se mantém inalterados. Além disso, o tempo de integração passa de 14 segundos para 15 segundos.

A evolução dos estados se encontra ilustrada na figura 24. A disposição dos gráficos se mantém como realizado na figura 18. Na parte superior estão os estados $\dot{\psi}$ e $\alpha_{T}$ (lado es- 
Figura 20 - Evolução da aceleração lateral do centro de massa dos módulos em função do tempo

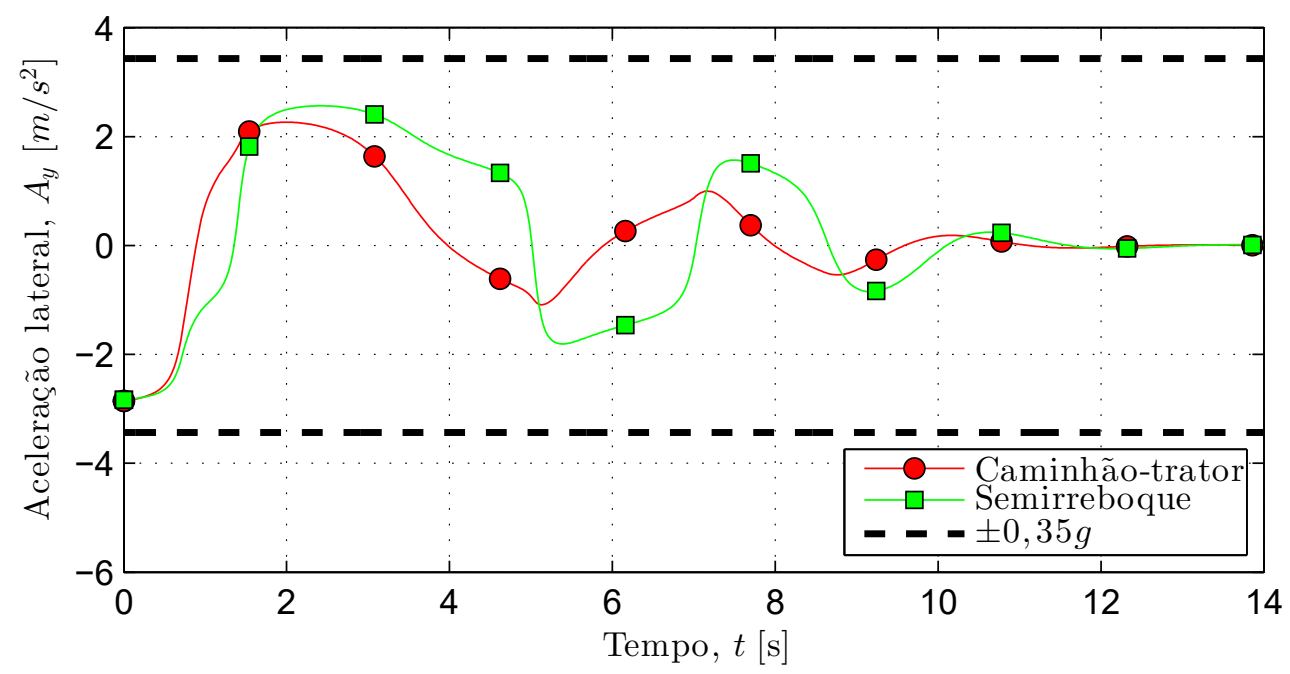

Fonte: Autor

Figura 21 - Representação em três dimensões da evolução dos estados. Terceira dimensão dada pelo módulo do vetor velocidade do centro de massa do caminhão-trator $v$

. Reta de velocidades finais visível no gráfico em três dimensões
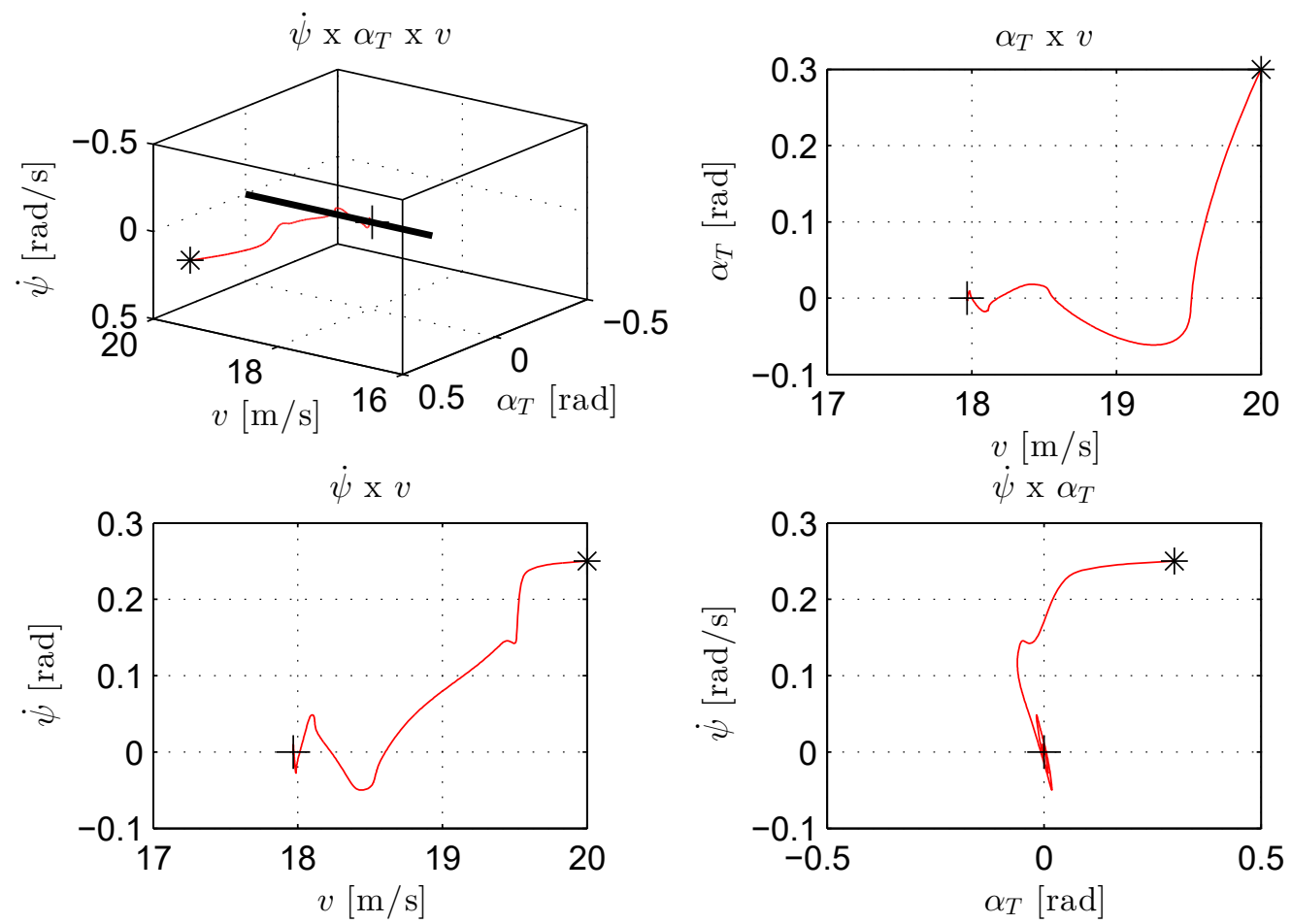

Fonte: Autor 
Figura 22 - Representação em três dimensões da evolução dos estados. Terceira dimensão dada pelo ângulo relativo entre os módulos $\phi$
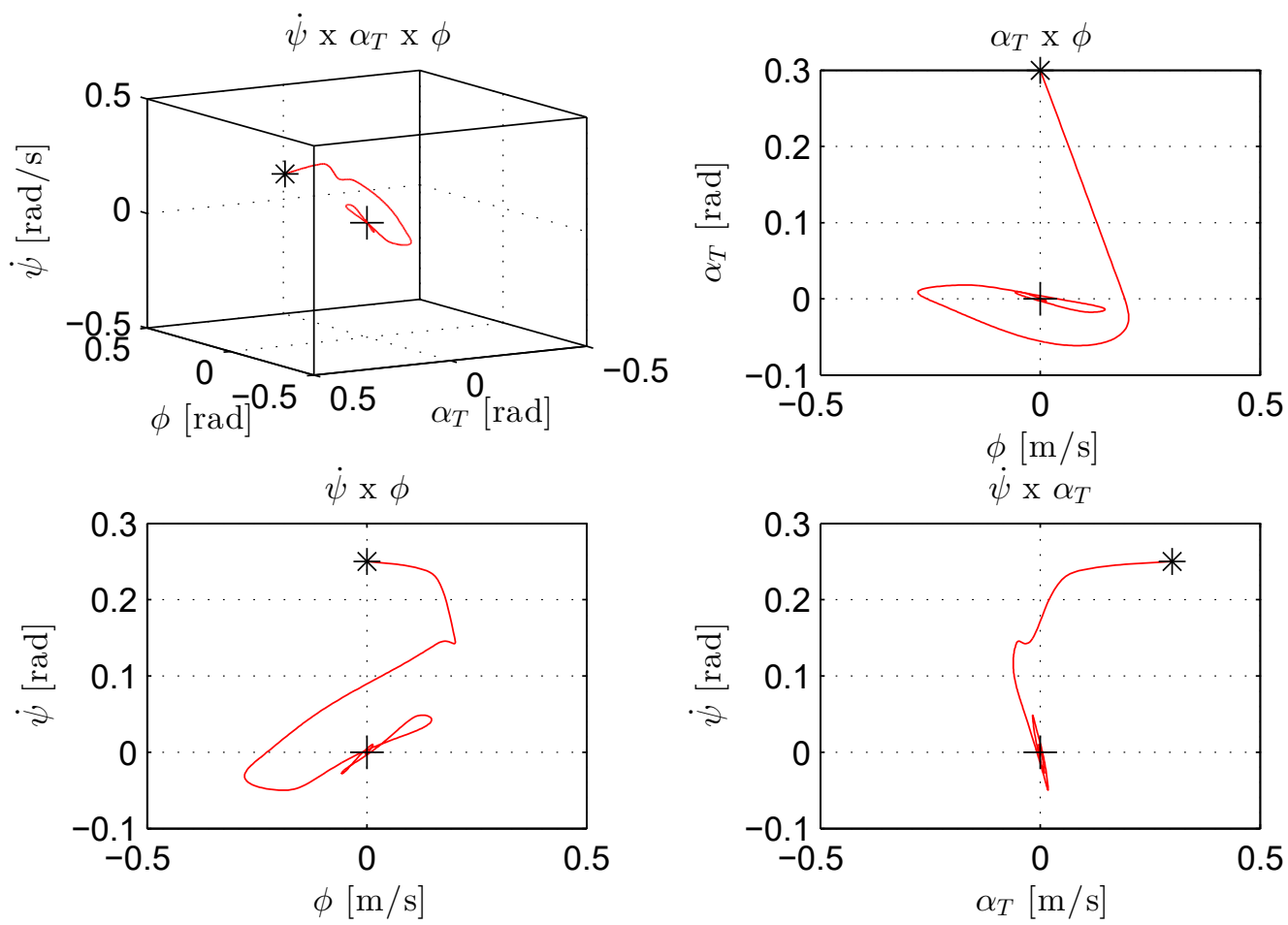

Fonte: Autor

Figura 23 - Trajetória do veículo articulado

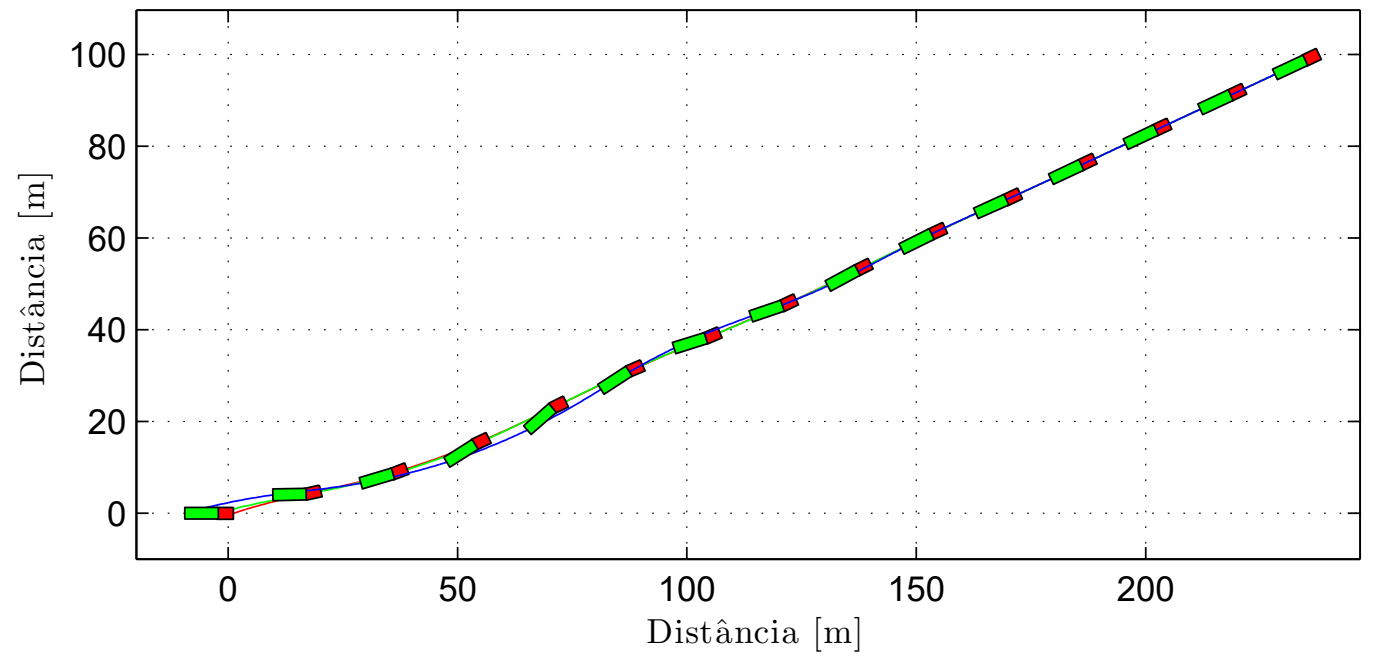

Fonte: Autor 
querdo e direito, respectivamente). Na parte inferior os estados $\phi$ e $v$ (lado esquerdo e direito, respectivamente).

Figura 24 - Evolução dos estados em função do tempo
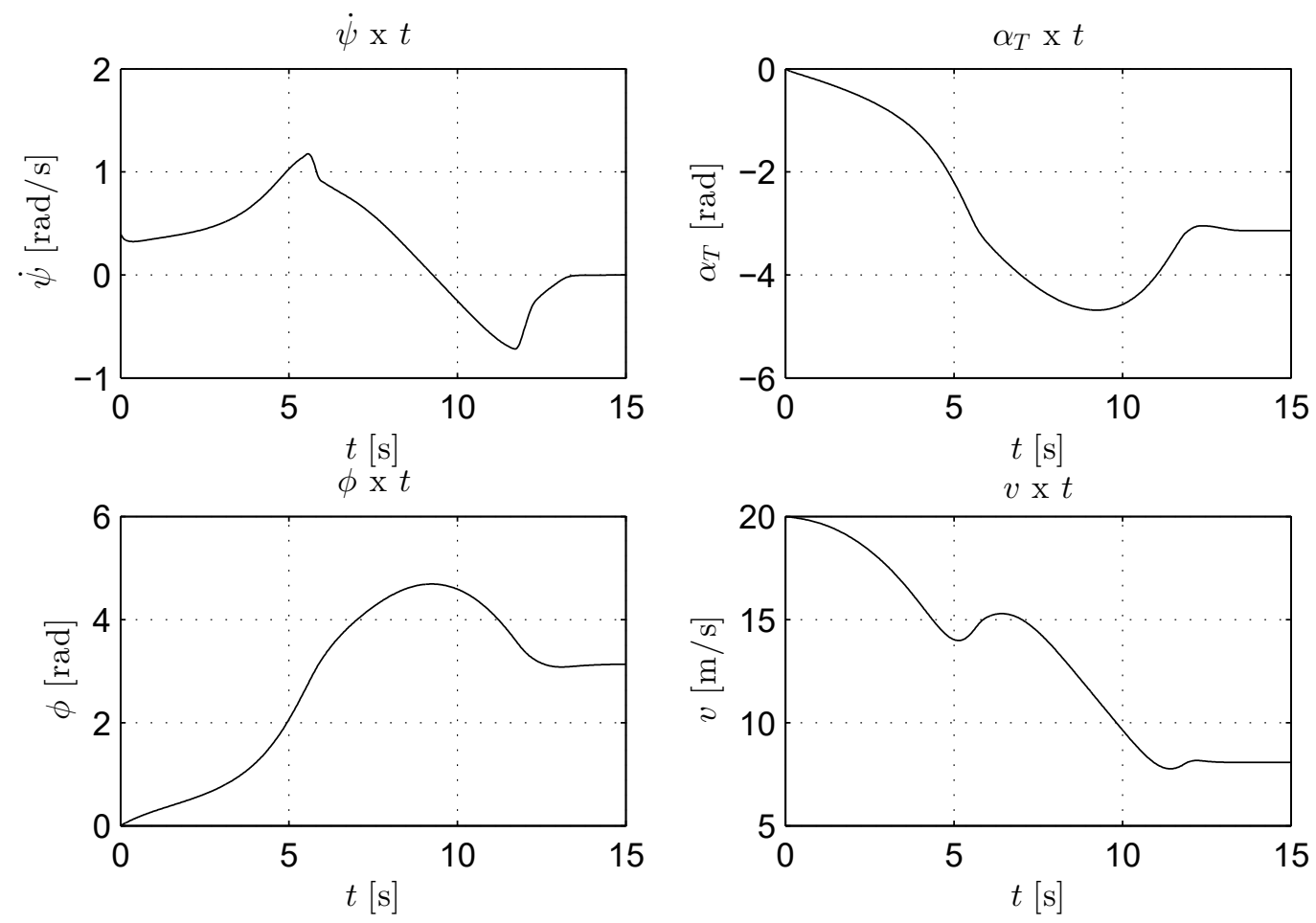

Fonte: Autor

Assim como no caso anterior, o estado $\dot{\psi}$ converge para zero. Entretanto, os estados $\alpha_{T}$ e $\phi$ convergem para $-\pi$ e $+\pi \mathrm{rad}$, respectivamente. Ou seja, o veículo volta a se movimentar em linha reta, porém apenas o caminhão-trator trafega de ré. Apesar desta configuração ser impossibilitada na realidade devido às características contrutivas do veículo este é um cenário possível matematicamente pois estes fatores limitantes não são incorporados no modelo.

Os ângulos de deriva nos três eixos podem ser observados na figura 25. Como, neste caso, a manobra é mais severa, os ângulos de deriva nos pneus atingem valores contidos em toda a faixa considerada no modelo de pneu escolhido ( -180 a 180 graus). Por este motivo ocorre a descontinuidade que pode ser vista por volta dos instantes 5,5, 12,0 e 13,0 segundos. Além disso, é possível notar a relativamente baixa amplitude do ângulo de deriva do eixo do semirreboque.

A aceleração lateral dos dois módulos para esta nova condição inicial se encontra na figura 26. Interessante perceber que mesmo a manobra sendo mais intensa e com ângulos de deriva maiores nos eixos do conjunto a aceleração lateral máxima nos dois centros de massa se 
Figura 25 - Evolução dos ângulos de deriva dos três eixos em função do tempo

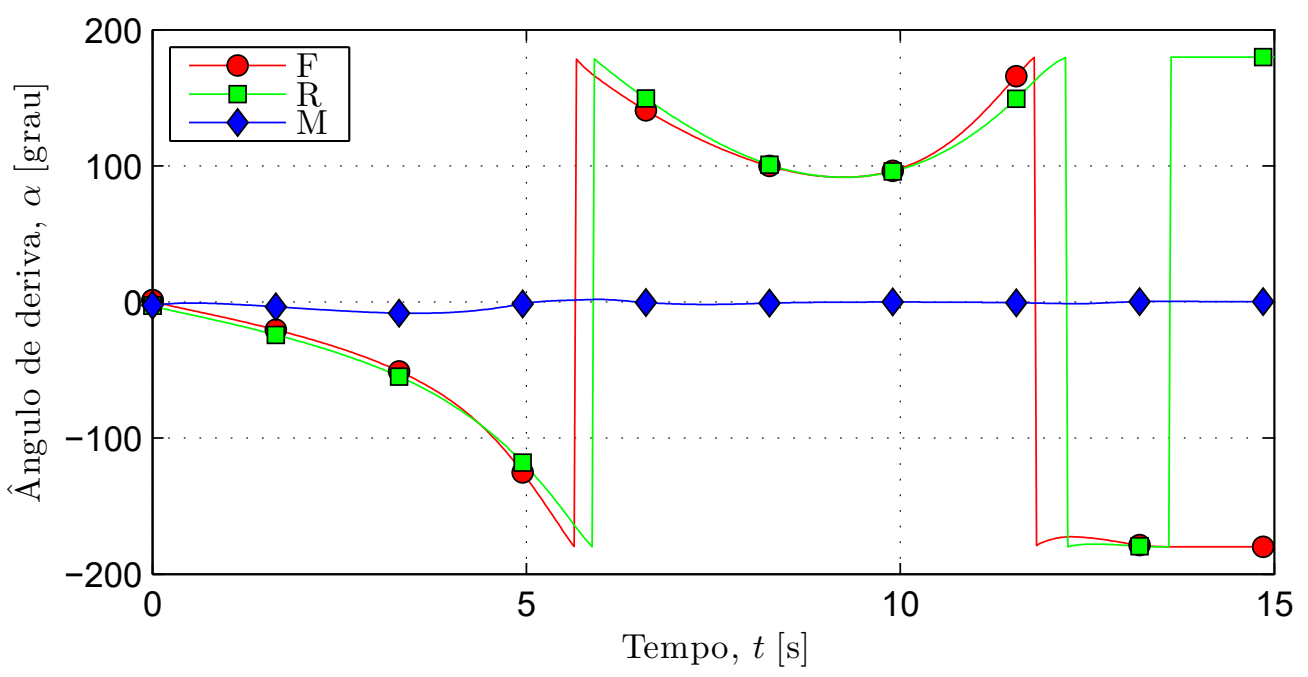

Fonte: Autor

manteve abaixo do limiar de tombamento. Logo, ocorre o acotovelamento com baixa probabilidade de ocorrência de tombamento.

Figura 26 - Evolução da aceleração lateral do centro de massa em função do tempo

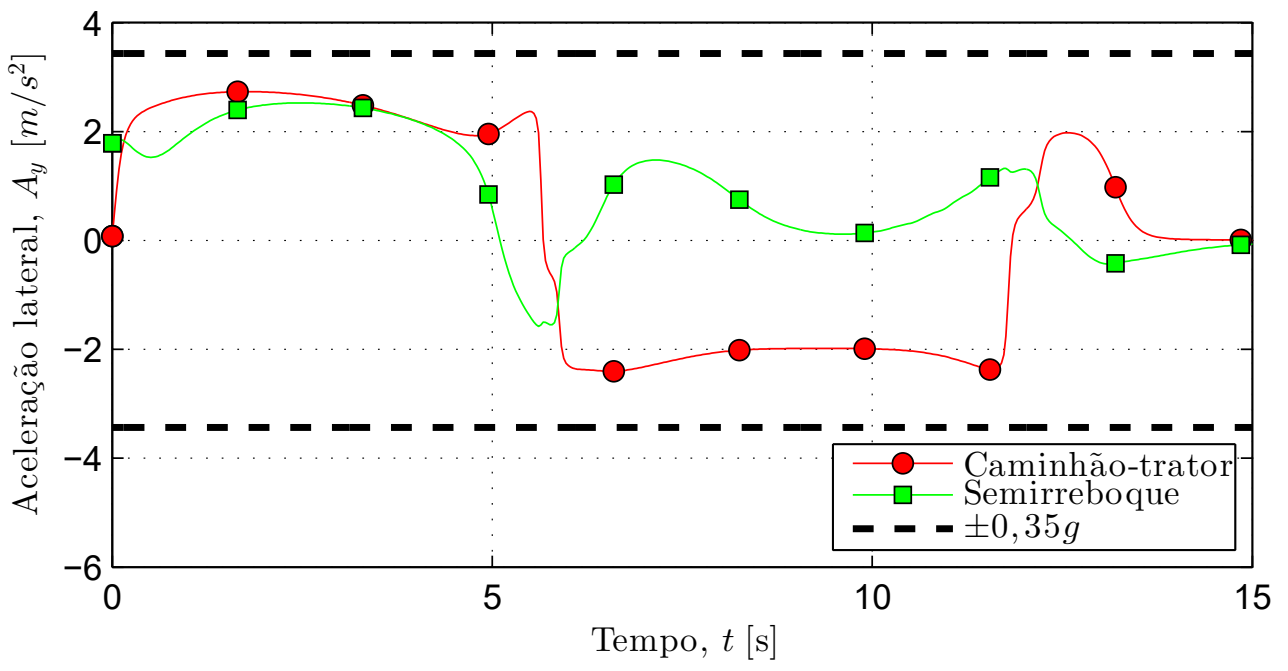

Fonte: Autor

A dupla de figuras 27 e 28 apresentam gráficos com as órbitas dos estados num espaço de fase de três dimensões. Na figura 27 a reta de velocidades finais está presente. Em ambas as figuras é possível verificar a nova coordenada de convergência dos estados $\alpha_{T}$ e $\phi,(-\pi,+\pi)$. Novamente, os símbolos $* \mathrm{e}+$ indicam os pontos de condição inicial e convergência, respectivamente. 
Figura 27 - Representação em três dimensões da evolução dos estados. Terceira dimensão dada pelo módulo do vetor velocidade do centro de massa do caminhão-trator $v$

. Reta de velocidades finais visível no gráfico em três dimensões
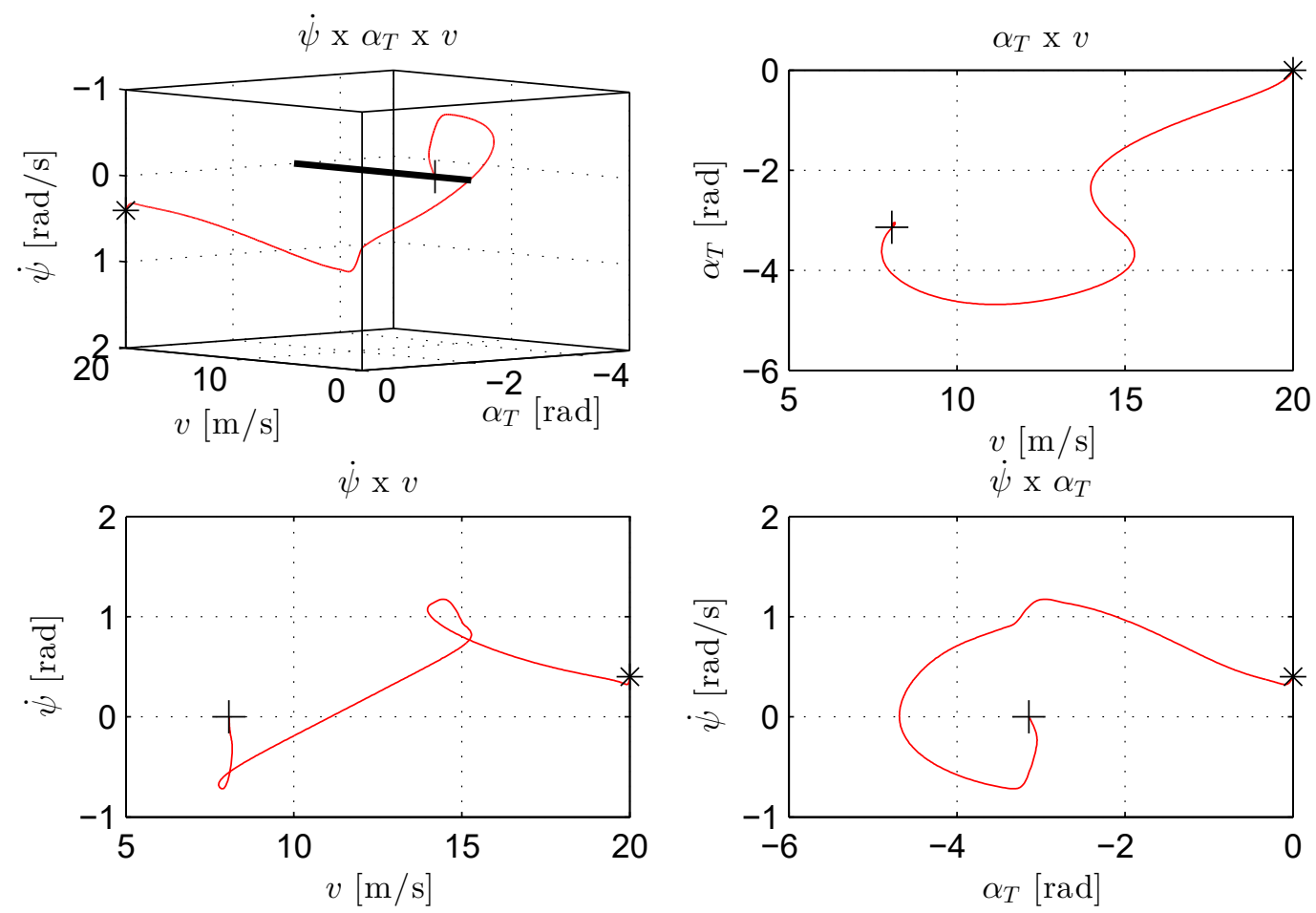

Fonte: Autor

Para aumentar a compreensão sobre a manobra realizada a figura 29 mostra a trajetória do veículo. É possível observar a ocorrência de acotovelamento como definido na figura 2. O veículo encontra um ponto de equilíbrio dado pela coordenada $\left(\dot{\psi}, \alpha_{T}, \dot{\phi}, \phi, v\right)=$ $(0,-\pi, 0, \pi, 8,07)$. No início da manobra o veículo apresenta apenas uma movimentação angular sem translação lateral. O acotovelamento ocorre aumentando gradualmente o ângulo formado pelos dois módulos. Este ângulo ultrapassa o valor de $\pi \mathrm{rad}$ e se aproximando de $5 \mathrm{rad}$ e depois retornando novamente para $\pi \mathrm{rad}$. 
Figura 28 - Representação em três dimensões da evolução dos estados. Terceira dimensão dada pelo ângulo relativo entre os módulos $\phi$
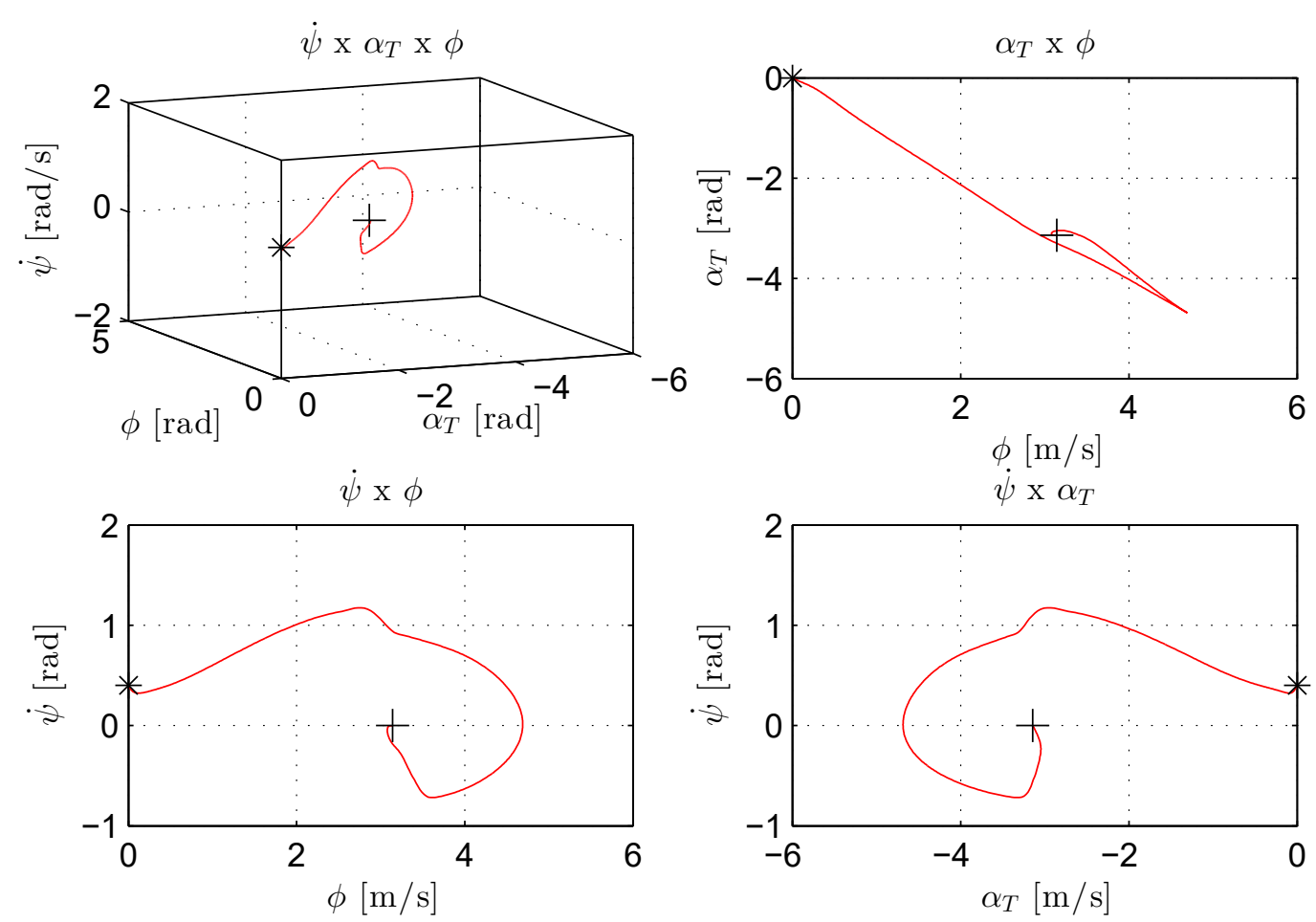

Fonte: Autor

Figura 29 - Trajetória do veículo articulado

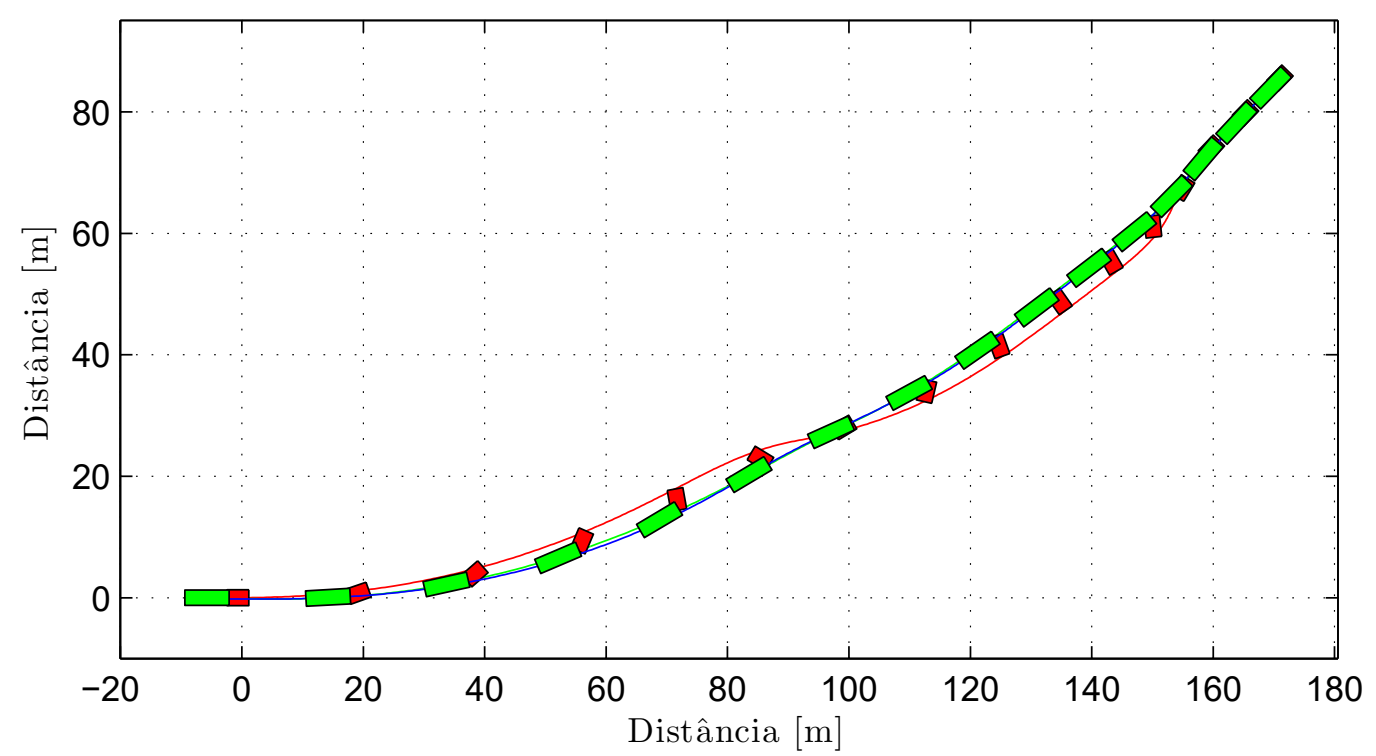

Fonte: Autor 


\section{ANÁLISE DE ESTABILIDADE}

Como discutido até aqui, o regime final de interesse consiste em todos os estados iguais a zero para uma determinada velocidade final. A convergência para qualquer outro ponto implica que o veículo trafegou de ré em algum instante, não sendo do interesse prático. Portanto, faz parte do objetivo desta pesquisa traçar no plano de fase a região de convergência em que todas as condições iniciais convergem para a movimentação em linha reta sem que haja a ocorrência de acotovelamento. Apesar do sistema utilizado (descrito na seção 3) apresentar quatro graus de liberdade é possível obter uma região de convergência num plano de fase composto pelos estados mais representativos em guinada e monitorando os outros estados e grandezas relevantes para a avaliação da condição inicial. Região semelhante é apresentada na figura 16.

\subsection{REGIÃO DE CONVERGÊNCIA}

O veículo apresentado na seção 5 converge para diferentes configurações dos estados de acordo com a condição inicial que foi imposta ao sistema. O plano de fase usado para representar a região de estabilidade é composto pelos estados $\dot{\psi}$ e $\alpha_{T}$. A utilização do estado $\alpha_{T}$ é conveniente devido à associação de seu valor com o significado físico da manobra. Se $\alpha_{T}$ converge, por exemplo, para - $\pi$ rad é evidente que o caminhão-trator está se movimentando de ré. Caso o estado escolhido fosse $v_{y}$ (outra forma de representar a orientação do vetor velocidade do centro de massa do caminhão-trator) seu valor seria zero e a informação da orientação do veículo deveria ser monitorada de forma alternativa. Importante ressaltar que os outros estados continuam sendo verificados. Além disso, o estado $\phi$, mesmo convergindo para zero não pode assumir valores maiores que 90 graus devido às características construtivas do veículo. Importante salientar, também, que a condição inicial do estado $\phi$ em toda a varredura do plano de fase recebe o mesmo valor atribuido para a condição inicial de $\dot{\psi}$. Este recurso garante a rotação relativa entre os dois módulos e já foi usado na seção 5 (ver tabela 17).

Na figura 30 é possível observar a região que limita as condições iniciais a partir das quais o veículo articulado converge para o ponto fixo com ausência de acotovelamento. A região central em vermelho indica as condições iniciais que convergem para a configuração final dos estados de interesse. Na região superior o estado $\alpha_{T}$ converge para valores inferiores ou iguais a $-\pi \mathrm{rad}$. De maneira semelhante, na região inferior o estado $\alpha_{T}$ converge para valores superiores ou iguais a $\pi$ rad. Em todos os casos o estado $\dot{\psi}$ converge para zero. Nestas regiões 
adjacentes, é possível demonstrar, que o caminhão-trator conclui o movimento trafegando por fim de ré ou de frente após ter trafegado de ré em algum instante.

O plano de fase foi discretizado na direção vertical do ponto $\dot{\psi}=-1,395 \mathrm{rad} / \mathrm{s}$ ao ponto $\dot{\psi}=1,395 \mathrm{rad} / \mathrm{s}$ em passos de $\Delta \dot{\psi}=0,015 \mathrm{rad} / \mathrm{s}$ e na direção horizontal do ponto $\alpha_{T}=-1,560 \mathrm{rad}$ ao ponto $\alpha_{T}=1,560 \mathrm{rad}$ em passos de $\Delta \alpha_{T}=0,015 \mathrm{rad}$. O sistema é integrado para cada condição inicial com os dados de veículo apresentados na tabela 16 . O tempo de integração é de 20 segundos com resolução de 0,1 segundos. O tempo de simulação para a integraçao de todas as condições iniciais foi de 4 horas e 18 minutos com os dados computacionais detalhados no apêndice A. A configuração dos estados para a qual o sistema converge é verificada e a condição inicial é demarcada apropriadamente, verificando também o valor máximo do ângulo formado entre os dois módulos e o valor máximo das acelerações laterais dos centros de massa, que não devem exceder o limiar de $0,35 g$ discutido na seção 5.3. Se o sistema converge para o par $\left(\dot{\psi}_{\text {final }}=0, \alpha_{T, \text { final }}=0\right)$ com $\left|\phi_{\text {final }}\right|<\pi$ rad a condição inicial faz parte da região de interesse. Caso contrário ela é atribuida à região adjacente.

Figura 30 - Região de convergência e as condições iniciais dos casos 1 e 2 da seção 5.3

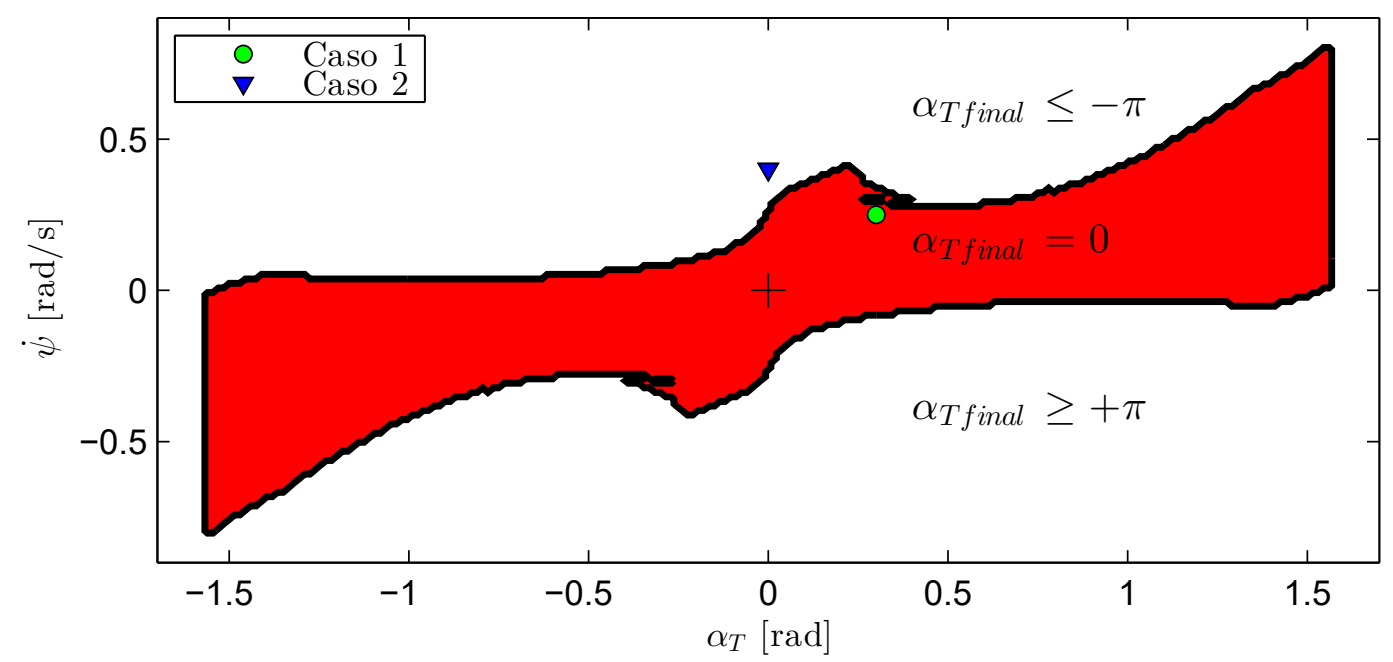

Fonte: Autor

Interessante observar que as condições iniciais utilizadas na seção 5.3 estão de acordo com a região obtida na figura 30 , pois o caso $1 \mathrm{com}$ a condição inicial $\dot{\psi}_{0}=0,25 \mathrm{rad} / \mathrm{s}$ e $\alpha_{T, 0}=0,3 \mathrm{rad}$ converge para $\alpha_{T, \text { final }}=0$ (exemplo sem acotovelamento) e o caso 2 com a condição inicial $\dot{\psi}_{0}=0,4 \mathrm{rad} / \mathrm{s}$ e $\alpha_{T, 0}=0$ converge para $\alpha_{T, \text { final }}=-\pi \mathrm{rad}$.

É possível detalhar ainda mais as regiões adjacentes adicionando mais pontos de convergência. Na figura 31 é possível ver as regiões em que $\alpha_{T}$ converge para $-\pi$ e $\pi \mathrm{rad}$ enquanto que o estado $\dot{\psi}$ converge para zero. As regiões mais externas, na parte superior e inferior do 
gráfico, neste caso, delimitam condições iniciais em que o valor de $\alpha_{T}$ converge para valores em módulo maiores ou iguais a $2 \pi \mathrm{rad}$.

Figura 31 - Regiões de convergência para diferentes valores de $\alpha_{T, \text { final }}$

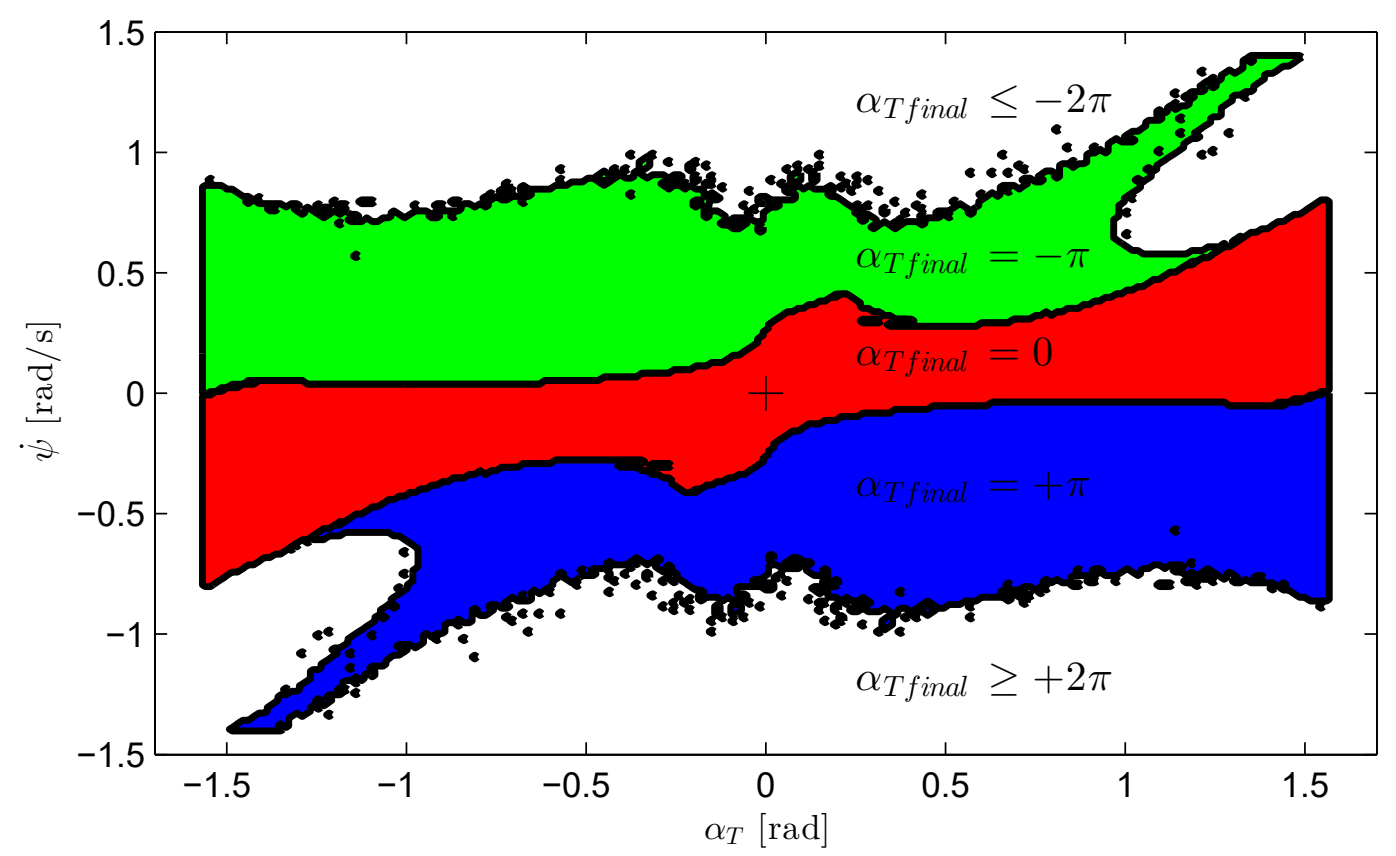

Fonte: Autor

A comparação entre as acelerações laterais máximas dos módulos são apresentadas na figura 32 através das curvas de nível indicando a aceleração máxima na trajetória que teve origem na coordenada demarcada. O maior valor de aceleração lateral máxima no caminhão-trator é dado por $A_{T, y, \max }=4,077 \mathrm{~m} / \mathrm{s}^{2}$, enquanto que no semirreboque é $A_{S, y, \max }=3,228 \mathrm{~m} / \mathrm{s}^{2}$. Logo, o semirreboque nas manobras a partir de todas as condições iniciais simuladas apresenta aceleração lateral máxima inferior ao limiar de tombamento adotado, $0,35 \mathrm{~g}=3,4335 \mathrm{~m} / \mathrm{s}^{2}$. Entretanto, algumas condições iniciais provocam acelerações laterais máximas no caminhãotrator acima deste valor.

No canto superior direito e no canto inferior esquerdo da figura 31 é possível observar a influência da aceleração lateral máxima nas regiões de $\alpha_{T, \text { final }}=-\pi \mathrm{rad}$ e $\alpha_{T, \text { final }}=\pi \mathrm{rad}$. Nestes cantos a região apresenta uma fronteira aproximadamente elíptica que coincide com a mesma forma elíptica do conjunto de acelerações laterais máximas observáveis nas curvas de nível da figura 32. Isto indica que o critério discutido acima é então aplicado limitando a região não apenas com relação ao ponto de convergência mas também com relação ao limiar de tombamento. 
Figura 32 - Curvas de nível do módulo da aceleração lateral máxima no plano de fase para o caminhão-trator e semirreboque
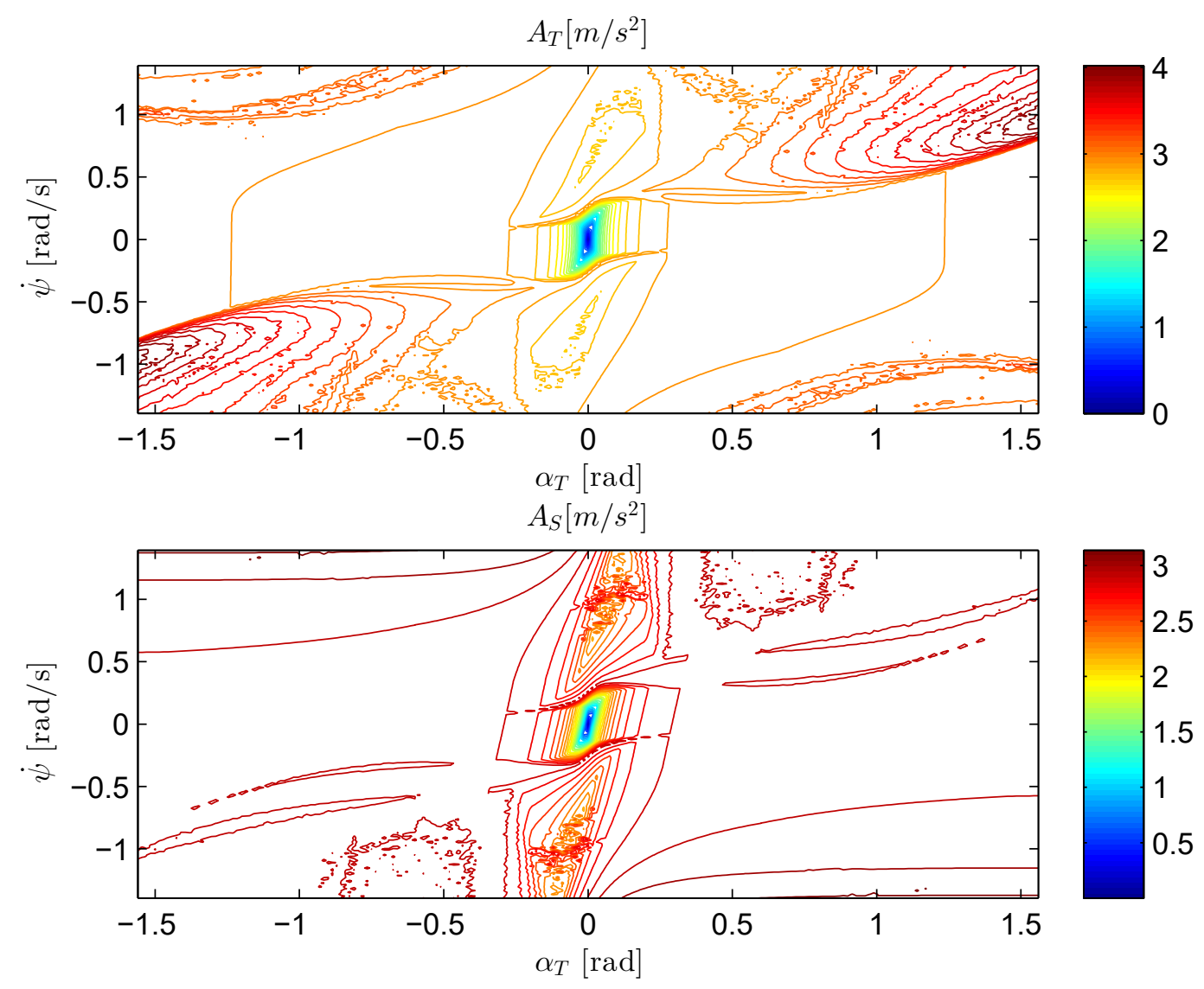

Fonte: Autor

A figura 33 ilustra as mesmas regiões presentes na figura 31 porém estendendo o detalhamento com as trajetórias dos estados. É possível observar as trajetórias da região central convergindo para a coordenada $\left(\dot{\psi}_{\text {final }}=0, \alpha_{T, \text { final }}=0\right)$. Além disso, as trajetórias das condições iniciais das regiões adjacentes convergem para coordenadas finais distintas. A região acima converge para a coordenada $\left(\dot{\psi}_{\text {final }}=0, \alpha_{T, \text { final }}=-\pi \mathrm{rad}\right)$ e a região abaixo converge para a coordenada $\left(\dot{\psi}_{\text {final }}=0, \alpha_{T, \text { final }}=\pi \mathrm{rad}\right)$.

Na figura 34 é apresentada a evolução das trajetórias da região de convergência central apresentada na figura 33, porém num espaço de estados em três dimensões composto pelos estados $\dot{\psi}, \alpha_{T}$ e $v$. Um eixo de velocidades finais é posicionado interceptando o plano formado pelos eixos de $\dot{\psi}$ e $\alpha_{T}$ no ponto $\left(\dot{\psi}=0, \alpha_{T}=0\right)$. Após os 20 segundos de integração, todas as órbitas convergem para a coordenada $\left(\dot{\psi}_{\text {final }}=0, \alpha_{T, \text { final }}=0, v_{\text {final }}<v_{0}\right)$. Ou seja, o módulo do vetor velocidade converge para valores diferentes para cada condição inicial. Isto está associado ao nível de dissipação de energia da manobra executada. Importante notar a 
Figura 33 - Regiões de estabilidade com trajetória dos estados estendido

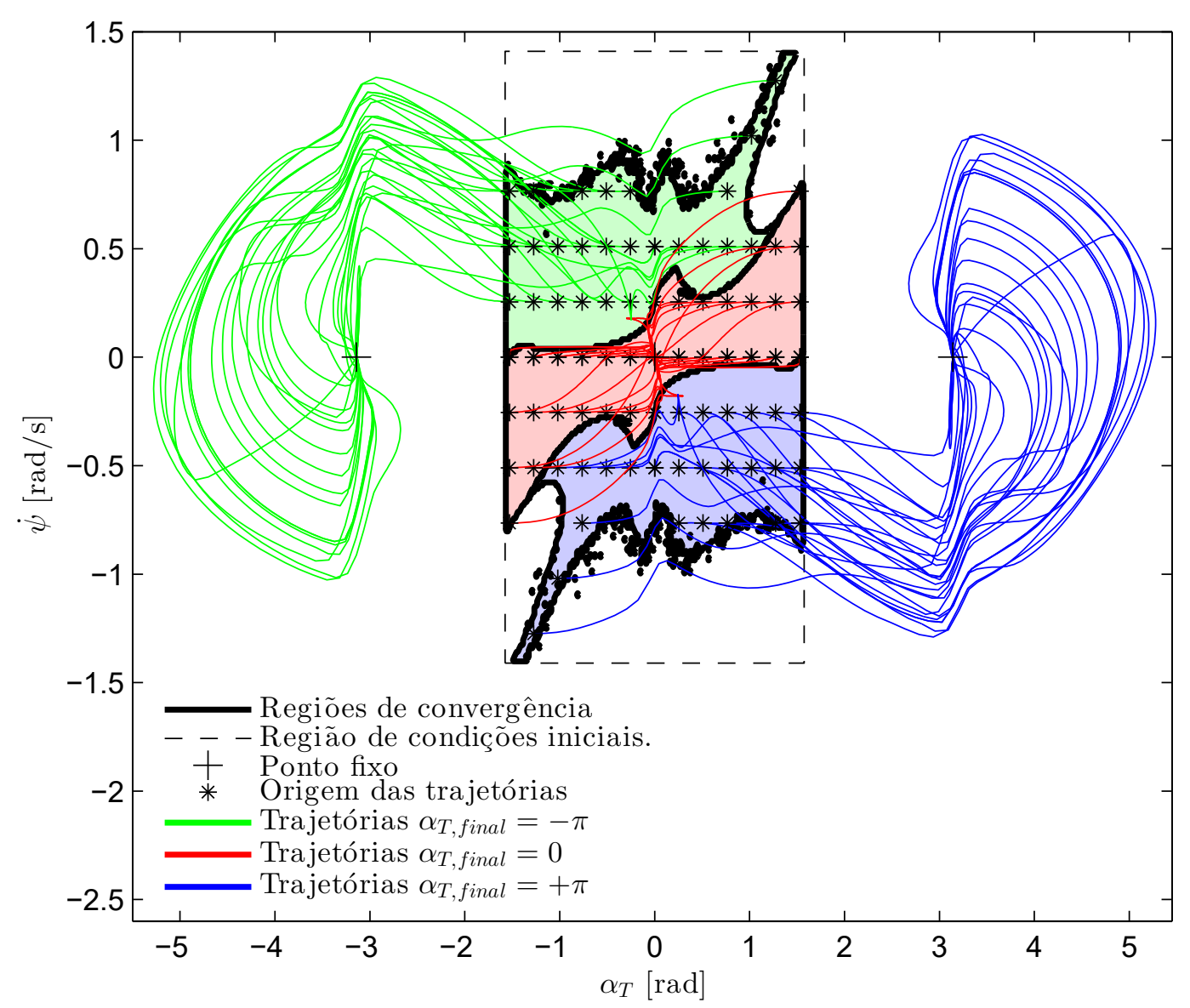

Fonte: Autor

simetria axial existente entre as órbitas dos estados em relação ao eixo de velocidades finais nos gráficos de $\alpha_{T}$ em função de $v$ e $\dot{\psi}$ em função de $v$. Cada órbita possui um par espelhado em relação ao eixo de velocidades finais. No plano formado pelos eixos de $\dot{\psi}$ e $\alpha_{T}$ é possível observar a simetria rotacional das óbritas com relação à origem. Neste plano, cada órbita possui um par idêntico rotacionado em 180 graus com relação à origem.

De maneira semelhante a figura 35 apresenta a evolução das trajetórias dos estados $\dot{\psi}$, $\alpha_{T}$ e $\phi$. É possível observar que todos os estados presentes convergem para zero como já comentado acima. Simetria está também presente nas projeções das órbitas nos três planos. Em todos eles as óbitas se apresentam em pares rotacionados em 180 graus em relação à origem. 
Figura 34 - Trajetória dos estados no espaço de fase formado pelos estados $\dot{\psi}, \alpha_{T}$ e $v$.
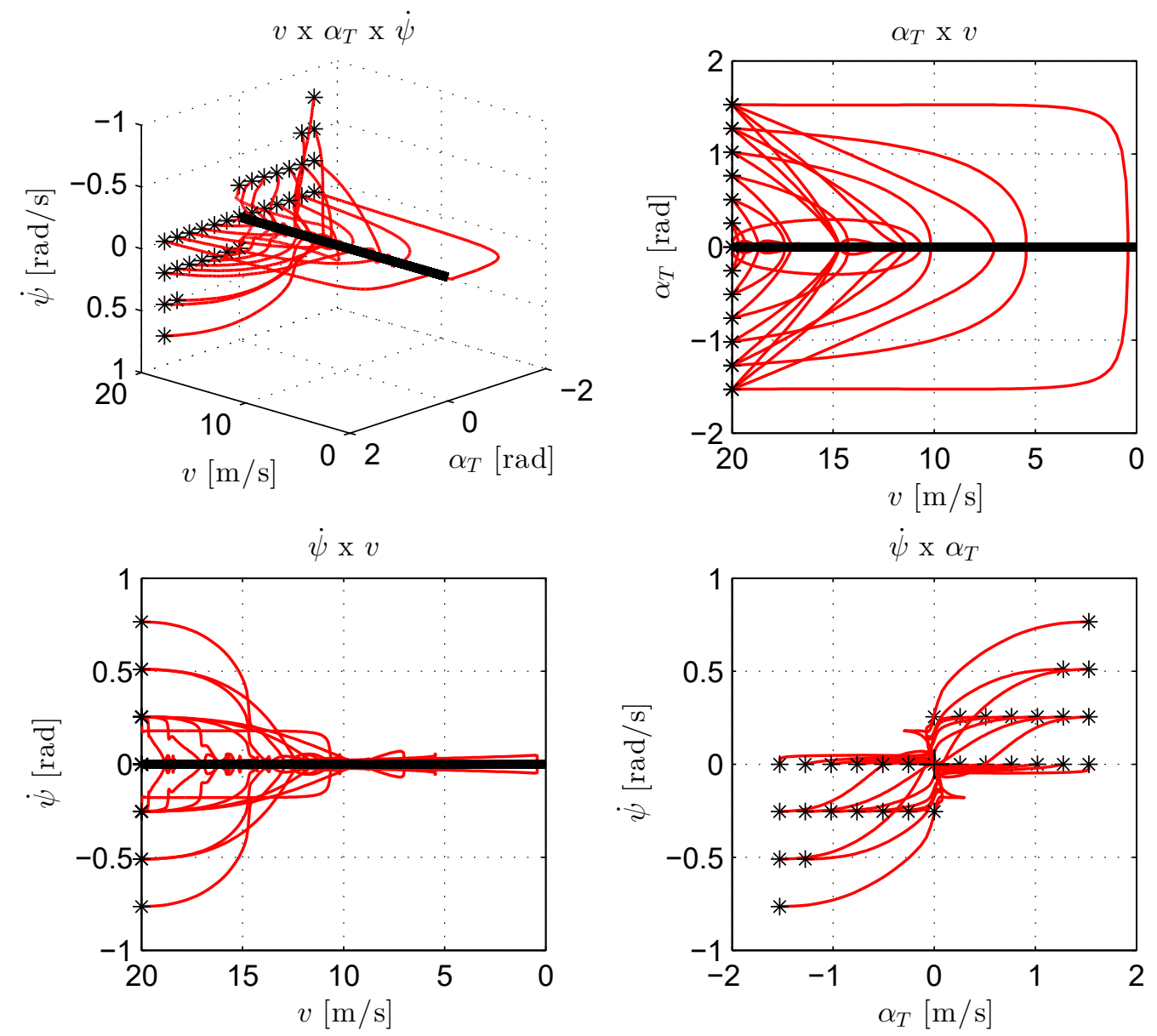

Fonte: Autor

\subsection{INFLUÊNCIA DO MÓDULO DA VELOCIDADE}

Os resultados apresentados na seção 6.1 mostram a região de convergência de um veículo articulado com os parâmetros listados na tabela 16. Em seguida, é investigada a influência da região de convergência em função do módulo do vetor velocidade inicial do centro de massa do caminhão-trator $v_{0}$. Os parâmetros do veículo são os mesmos apresentados na tabela 16 e novamente a varredura do plano de fase é realizada para diversos valores da velocidade inicial. A discretização do espaço de estados é feito na mesma resolução utilizada na seção anterior, na direção vertical de $\dot{\psi}=-1,395 \mathrm{rad} / \mathrm{s}$ a $\dot{\psi}=1,395 \mathrm{rad} / \mathrm{s}$ em passos de $\Delta \dot{\psi}=0,015 \mathrm{rad} / \mathrm{s}$ e na direção horizontal de $\alpha_{T}=-1,560 \mathrm{rad}$ a $\alpha_{T}=1,560 \mathrm{rad}$ em passos de $\Delta \alpha_{T}=0,015 \mathrm{rad}$. 
Figura 35 - Trajetória dos estados no espaço de fase formado pelos estados $\dot{\psi}, \alpha_{T}$ e $\phi$
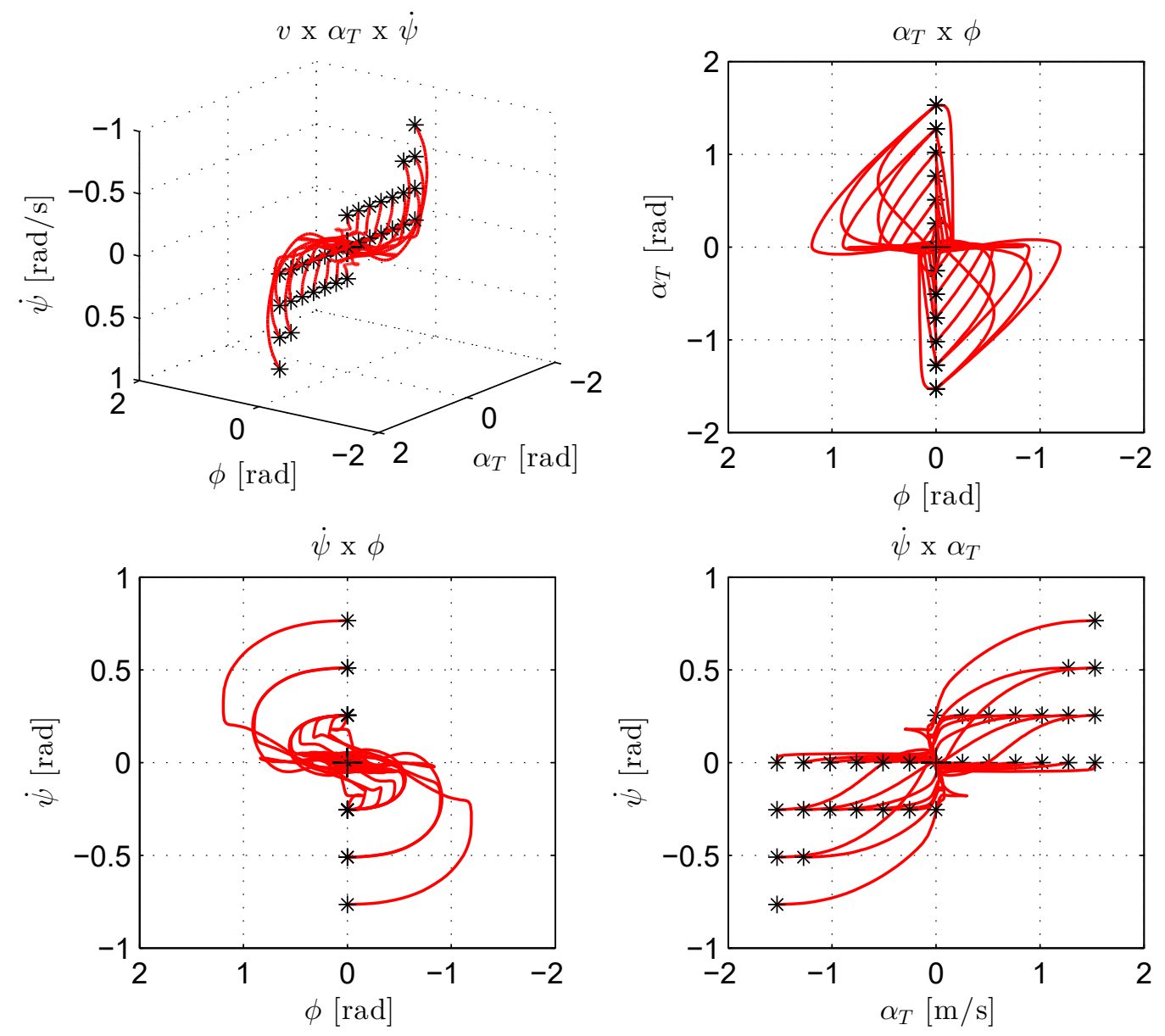

Fonte: Autor

A velocidade inicial do centro de massa do caminhão-trator é um indicativo de quanta energia está presente no sistema. As velocidades analisadas vão de $v_{0}=10 \mathrm{~m} / \mathrm{s}$ a $v_{0}=30 \mathrm{~m} / \mathrm{s}$ em passos de $\Delta v_{0}=2 \mathrm{~m} / \mathrm{s}$, totalizando onze velocidades iniciais.

Na figura 36 é possível observar a alteração na região de convergência conforme a variação do módulo da velocidade inicial do caminhão-trator no plano de fase.

A área total da região de convergência diminui conforme o aumento da velocidade inicial do caminhão-trator. Para valores de $\alpha_{T}$ positivos (componente transversal do vetor $\mathbf{v}_{T}$ apontando para a esquerda do veículo) a região de convergência é, para todas as velocidades, maior quando a velocidade angular é positiva (veículo girando no sentido anti-horário) do que quando a velocidade angular é negativa (veículo girando no sentido horário). Isto implica que para $\alpha_{T}>0$ uma pequena velocidade angular negativa coloca o sistema fora da região de convergência. Entretanto, a região do primeiro quadrante que é maior para velocidades inici- 
Figura 36 - Regiões de convergência em função da velocidade inicial do centro de massa do caminhão-trator (No plano de fase em duas dimensões)

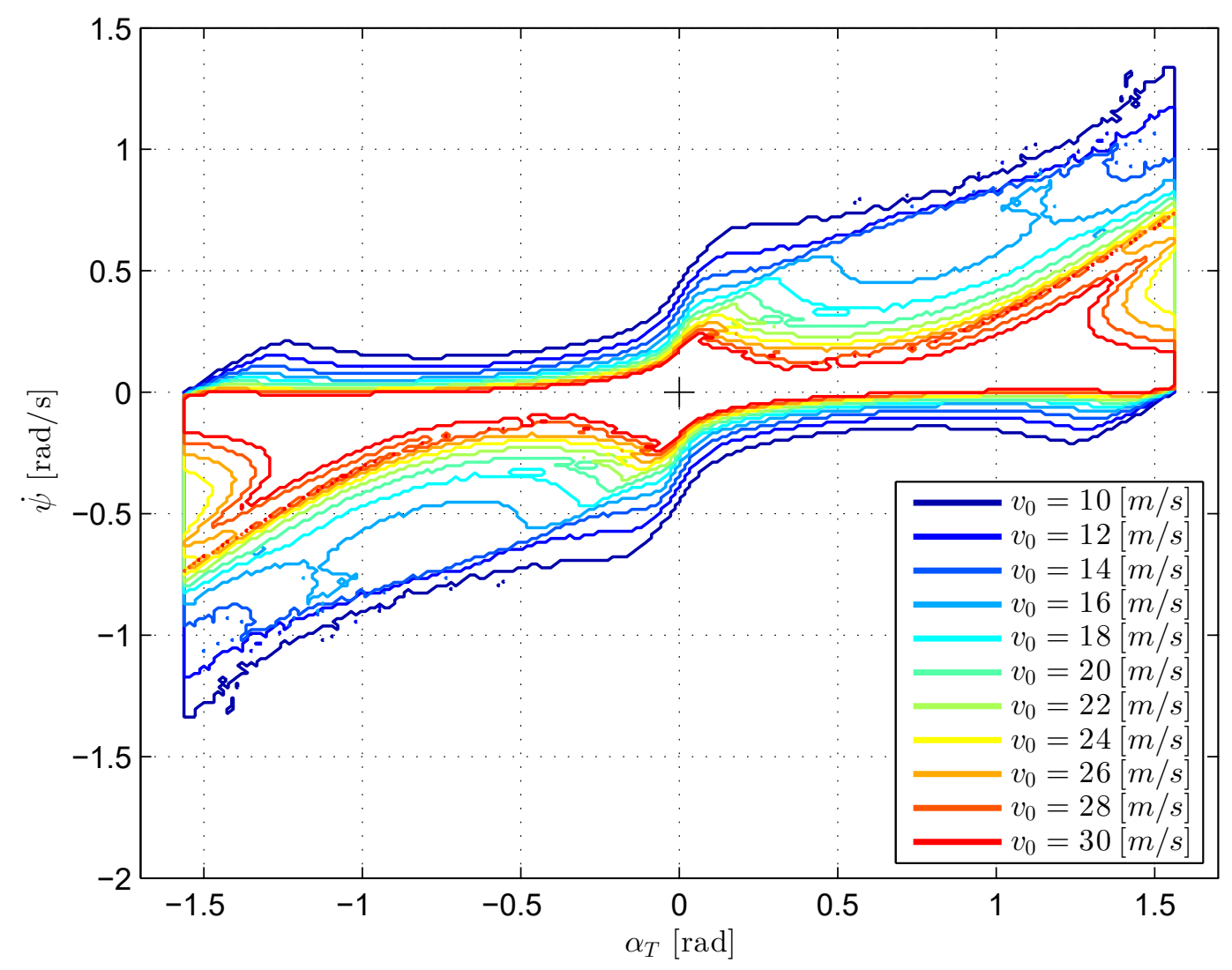

Fonte: Autor

ais menores, sofre uma significativa redução em área conforme a velocidade inicial aumenta. Enquanto isso, no quarto quadrante a movimentação da fronteira da região de convergência é menor.

Uma análise análoga pode ser realizada para valores negativos de $\alpha_{T}$ devido à simetria circular da região de convergência. As características do terceiro quadrante são análogas às descritas no primeiro quadrante, enquanto que as características do segundo quadrante são análogas às do quarto quadrante. Isto é, para uma componente transversal do vetor $\mathbf{v}_{T}$ apontando para a direita do veículo a maior região de convergência é encontrada para valores negativos da velocidade angular (sentido horário). Por outro lado, uma pequena velocidade angular no sentido anti-horário é suficiente para remover o sistema da região de convergência fazendo com que o estado $\alpha_{T}$ não vá para zero.

Resumindo, dado o sentido da velocidade transversal do centro de massa, traduzido pelo estado $\alpha_{T}$, é possível verificar o máximo de velocidade angular que o veículo pode apresentar 
para se manter na região de convergência. Se a componente transversal do vetor velocidade do centro de massa do caminhão-trator aponta para a esquerda $\left(\alpha_{T}>0\right)$, o sistema apresenta maior capacidade de desenvolver velocidades angulares positivas (sentido anti-horário) do que negativas (sentido horário). Se a componente transversal aponta para a direita $\left(\alpha_{T}<0\right)$ o sistema apresenta maior capacidade de desenvolver velocidades angulares negativas (sentido horário) do que positivas (sentido anti-horário). As fronteiras no primeiro e terceiro quadrante são as que apresentam maior sensibilidade com relação à velocidade inicial, diminuindo a região de convergência conforme a velocidade aumenta.

A representação em três dimensões, sendo o terceiro eixo dado pela velocidade inicial, é mostrada na figura 37. As curvas das regiões são projetadas nos três planos. Os eixos representam os estados $\dot{\psi}$ e $\alpha_{T}$ e a condição inicial $v_{0}$.

Figura 37 - Regiões de convergência em função da velocidade inicial do centro de massa do caminhão-trator (No espaço de fase em três dimensões)

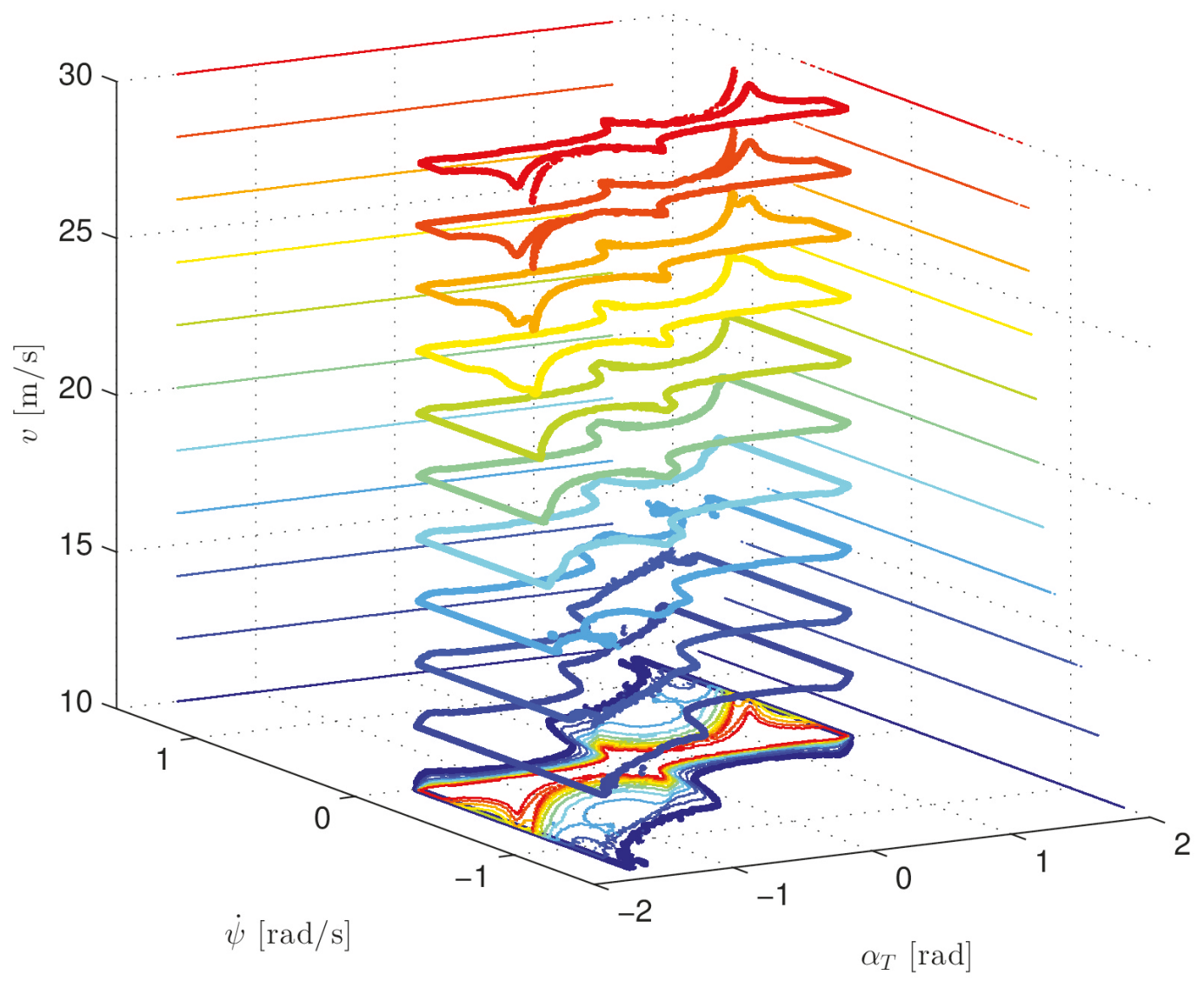

Fonte: Autor

As simulações que deram origem à estes gráficos foram realizadas no equipamento descrito no apêndice A. O tempo total de simulação para as onze regiões apresentadas nas figuras 36 e 37 foi cerca de 63 horas e 52 minutos. 


\subsection{INFLUÊNCIA DO POSICIONAMENTO DA ARTICULAÇÃO}

Como discutido na revisão bibliográfica a análise da estabilidade em função do posicionamento longitudinal da articulação é recorrente na literatura. Nesta seção se encontra a variação da região de convergência provocada pela alteração do ponto de articulação desde a frente até atrás do eixo traseiro. Os valores da grandeza que indica o posicionamento do ponto de articulação em relação ao eixo traseiro do caminhão-trator variam de $c=-0,5 \mathrm{~m}$ até $c=+0,5 \mathrm{~m}$ em passos de $\Delta c=0,1 \mathrm{~m}$, totalizando onze valores. Importante notar que valores negativos de $c$ indicam que o ponto de articulação se encontra entre os eixos do caminhão-trator e valores positivos indicam que a articulação entre os dois módulos é realizada num ponto atrás do eixo traseiro do caminhão-trator.

A discretização do espaço de estados é realizada na direção vertical de $\dot{\psi}=-1,14 \mathrm{rad} / \mathrm{s}$ a $\dot{\psi}=1,14 \mathrm{rad} / \mathrm{s}$ em passos de $\Delta \dot{\psi}=0,015 \mathrm{rad} / \mathrm{s}$ e na direção horizontal de $\alpha_{T}=-1,560 \mathrm{rad}$ a $\alpha_{T}=1,560 \mathrm{rad}$ em passos de $\Delta \alpha_{T}=0,015 \mathrm{rad}$. Na figura 38 se encontram as regiões de convergência no plano de fase para cada valor de $c$.

A região com maior área no plano de fase possui o ponto de articulação dado pela grandeza $c=-0,5 \mathrm{~m}$ e conforme o valor de $c$ aumenta a área total diminui até chegar na menor área obtida dada pela grandeza $c=+0,5 \mathrm{~m}$. Para valores de $c$ a frente do eixo traseiro do caminhão-trator é possível ver uma ligeira predominância da região de convergência sobre os quadrantes um e três, fato que se acentua conforme o ponto de articulação se move para trás.

Dois fenômenos distintos podem ser observados com relação às modificações sofridas pela região de convergência. O primeiro deles consiste no estreitamento da região na direção do estado $\dot{\psi}$, ou seja, para um dado valor do estado $\alpha_{T}$ o conjunto de valores de $\dot{\psi}$ contidos na região de convergência diminui conforme a grandeza $c$ aumenta. O segundo fenômeno consiste na rotação da região de convergência. A região, que para $c=-0,5 m$ é aproximadamente horizontal, sofre uma rotação no sentido anti-horário até se estender na diagnoal quando $c=$ $+0,5 \mathrm{~m}$. Uma consequência destes fenômenos é o aumento da faixa de valores de $\dot{\psi}$ que pode conter condições iniciais convergentes quando $c$ aumenta.

Além disso, conforme a grandeza $c$ aumenta é possível verificar a fragmentação da região em diversas regiões menores. Uma região de convergência maior central se mantém, porém nos extremos ocorre uma espécie de pulverização. Este efeito pode ser decorrência do método utilizado, que faz uso da discretização do plano de fase. Porém, também é razoável admitir que o sistema apresente este tipo de característica. 
Figura 38 - Regiões de convergência em função do posicionamento da articulação em relação ao eixo traseiro do caminhão-trator (No plano de fase em duas dimensões)

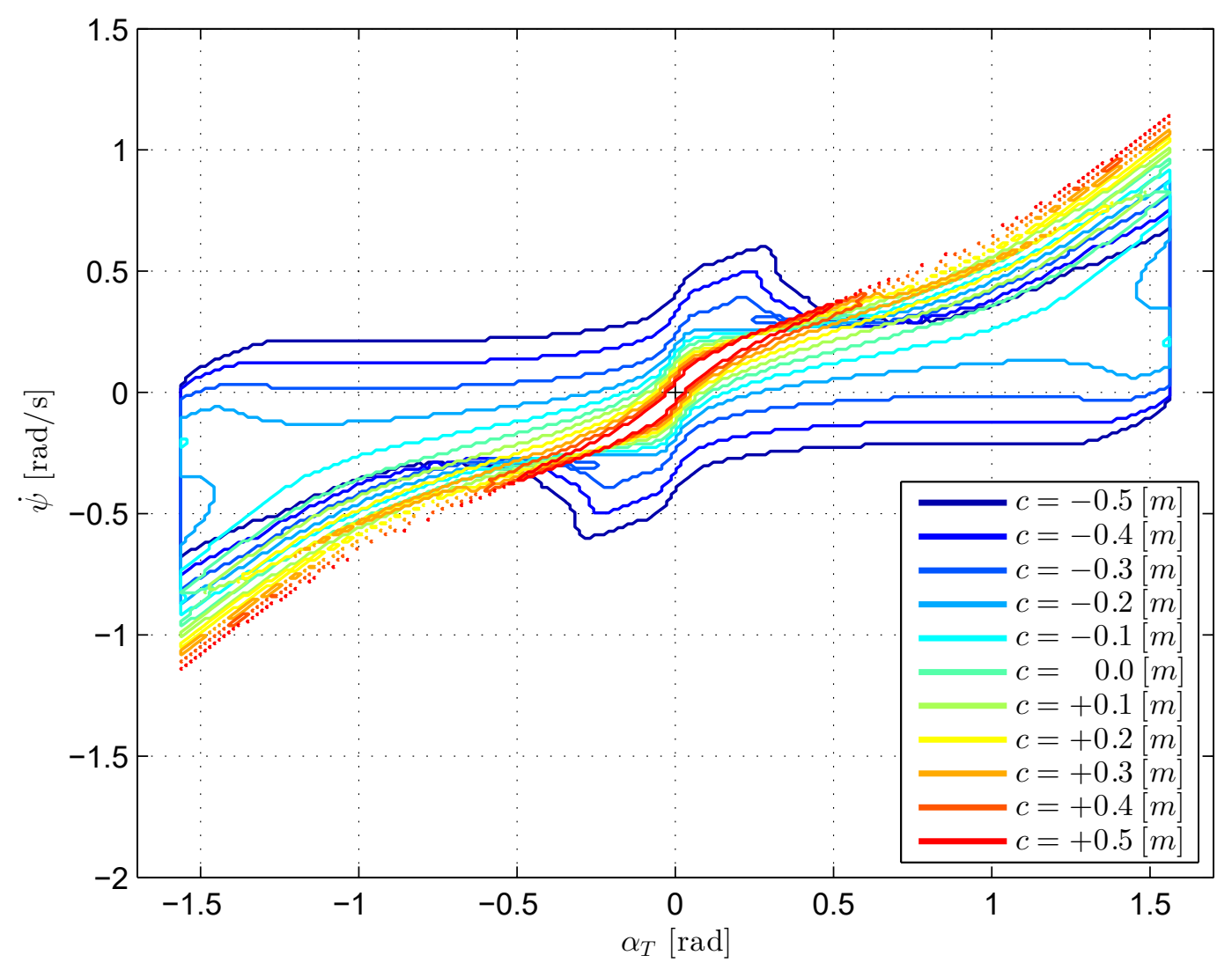

Fonte: Autor

Resumindo, a região de convergência tende a englobar o conjunto de condições iniciais que apresentem velocidade inicial transversal para a esquerda com velocidade angular no sentido anti-horário (primeiro quadrante) e, de maneira análoga, as condições iniciais com velocidade inicial transversal para a direita e velocidade angular no sentido horário (terceiro quadrante). Este efeito é acentuado pela movimentação do ponto de articulação para trás do eixo traseiro do caminhão-trator. Visualmente isto implica no estreitamento e rotação da região de convergência.

A variação da região de convergência é apresentada novamente na figura 39, porém com as curvas sobrepostas num gráfico em três dimensões em que o eixo adicional é dado pela grandeza $c$. Os eixos são dados pelos estados $\dot{\psi}, \alpha_{T}$ e a grandeza $c$.

As simulações que deram origem à estes gráficos foram realizadas no equipamento descrito no apêndice A. O tempo total de simulação para as onze regiões apresentadas nas figuras 36 e 37 foi cerca de 39 horas e 15 minutos. 
Figura 39 - Regiões de convergência em função do posicionamento da articulação em relação ao eixo traseiro do caminhão-trator (No espaço de fase em três dimensões)

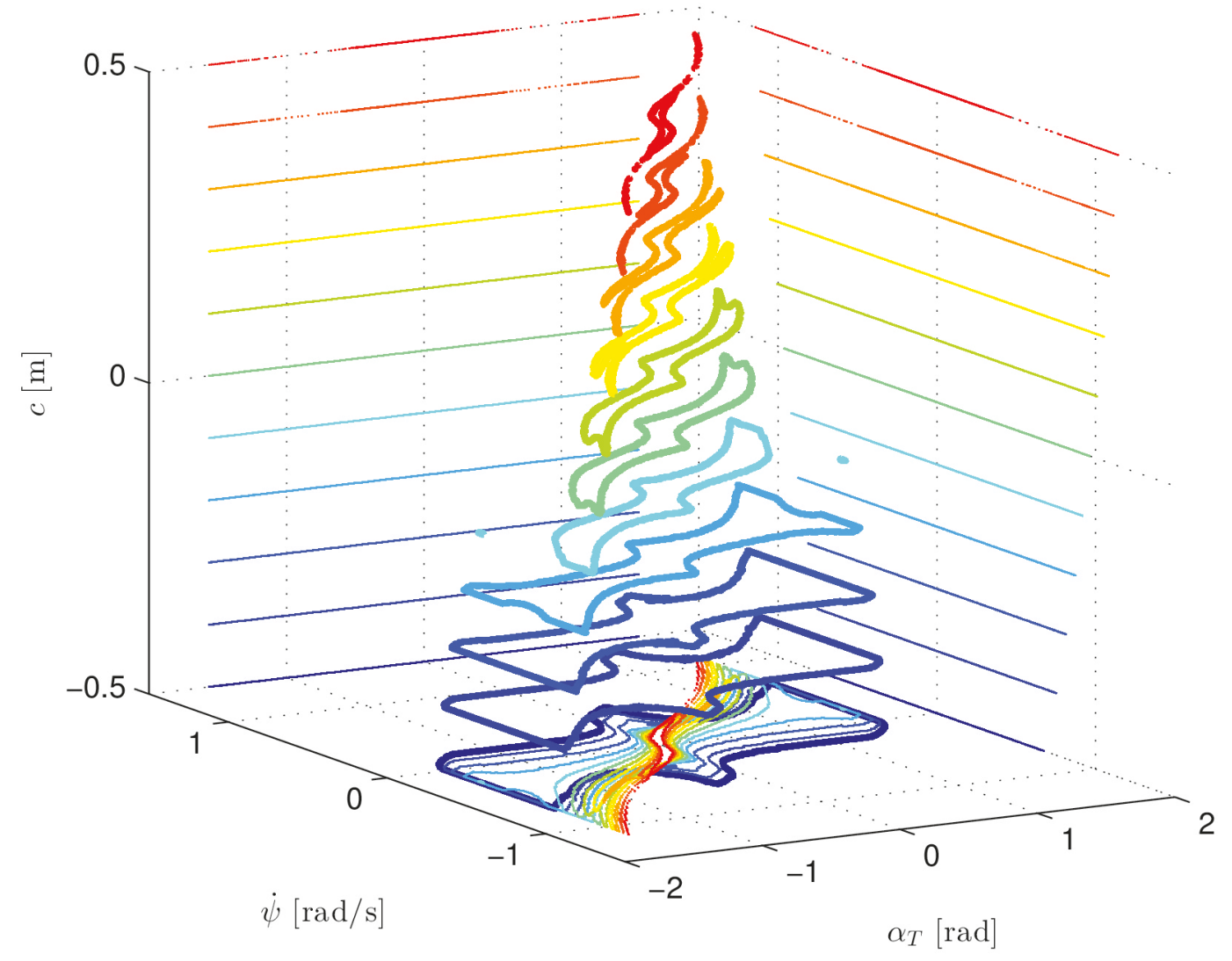

Fonte: Autor

\subsection{INFLUÊNCIA DA CARGA SOBRE O EIXO DO SEMIRREBOQUE}

O veículo articulado pode apresentar diversos níveis e tipos de carregamento. A magnitude e distribuição da carga influencia diretamente a carga vertical sobre todos os eixos. Entretanto, nesta seção é analisada apenas o efeito da carga vertical sobre o eixo do semirreboque na região de convergência do conjunto. Isto é, apenas a carga do eixo do semirreboque é alterada mantendo todos os outros parâmetros do veículo constantes. A massa das unidades e as distâncias dos centros de massa são calculados através das equações apresentadas na seção 5.2.

A carga vertical utilizada varia de $m_{M}=10$ Ton até $m_{M}=19$ Ton em passos de $\Delta m_{M}=1$ Ton, totalizando dez valores de massa. Importante observar que 17 Ton é, pela legislação, a carga limite deste tipo de eixo, ou seja, os valores de 18 Ton e 19 Ton indicam uma sobrecarga de aproximadamente $6 \%$ e $12 \%$, respectivamente.

O espaço de estados é novamente discretizado na direção vertical de $\dot{\psi}=-0,90 \mathrm{rad} / \mathrm{s}$ a $\dot{\psi}=0,90 \mathrm{rad} / \mathrm{s}$ em passos de $\Delta \dot{\psi}=0,015 \mathrm{rad} / \mathrm{s}$ e na direção horizontal de $\alpha_{T}=-1,560 \mathrm{rad}$ 
a $\alpha_{T}=1,560 \mathrm{rad}$ em passos de $\Delta \alpha_{T}=0,015 \mathrm{rad}$. A região de convergência no plano de fase para cada valor de $m_{M}$ se encontra na figura 40.

Figura 40 - Regiões de convergência em função da carga vertical sobre o eixo do semirreboque (No plano de fase em duas dimensões)

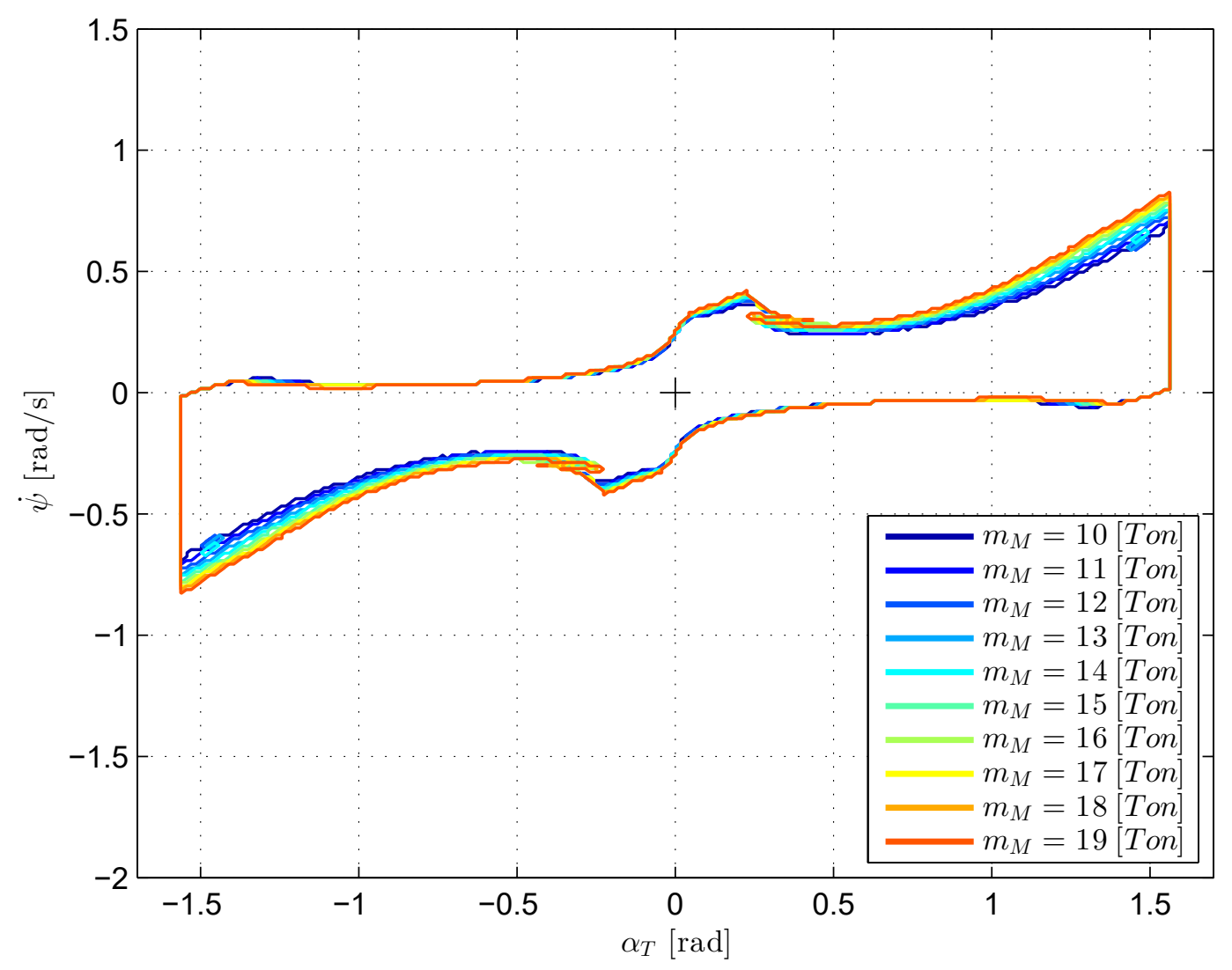

Fonte: Autor

Para todas as cargas a região de convergência abrange predominantemente as condições iniciais ao redor da origem e nos quadrantes um e três. A faixa de $\alpha_{T}>0,5 \mathrm{rad}$ apresenta uma extensão da fronteira superior de convergência na direção positiva de $\dot{\psi}$ conforme $\alpha_{T}$ cresce. De maneira análoga, para $\alpha_{T}<-0,5 \mathrm{rad}$ a fronteira inferior de convergência se estende na direção negativa de $\dot{\psi}$ conforme $\alpha_{T}$ cresce. Nos quadrantes dois e quatro a região de convergência se concentra apenas próxima da origem não apresentando um número significativo de condições iniciais ao se afastar dela. Além disso, pouca diferença pode ser observada nas regiões para cada carga na faixa estipulada. As fronteiras superior do primeiro quadrante e inferior do terceiro quadrante são as únicas que apresentam alguma movimentação em decorrência do aumento da carga vertical sobre o eixo M. Mais do que isso, conforme a carga se eleva estas fronteiras se estendem progressivamente conforme o valor de $\alpha_{T}$ se aproxima dos extremos da 
faixa analisada. Ou seja, a região de estabilidade é ligeiramente maior conforme a carga vertical em $M$ cresce.

Resumindo, o veículo articulado aproximadamente descarregado (10 Ton) apresenta região de convergência muito semelhante à região ligeiramente maior do veículo articulado com sobrecarga de até $12 \%$ (19 Ton). Este fato pode dar a falsa impressão de que o aumento de carga vertical seria atraente neste tipo de veículo. Porém, é importante lembrar que a limitação da carga sobre o eixo em tandem duplo imposta pela legislação brasileira visa atender, também, outros objetivos de segurança como, por exemplo, preservação da integridade física dos pneus e das vias.

A figura 41 ilustra a variação da região de convergência num gráfico em três dimensões. Os eixos são dados pelos estados $\dot{\psi}, \alpha_{T}$ e a massa $m_{M}$.

Figura 41 - Regiões de convergência em função da carga vertical sobre o eixo do semirreboque (No espaço de fase em três dimensões)

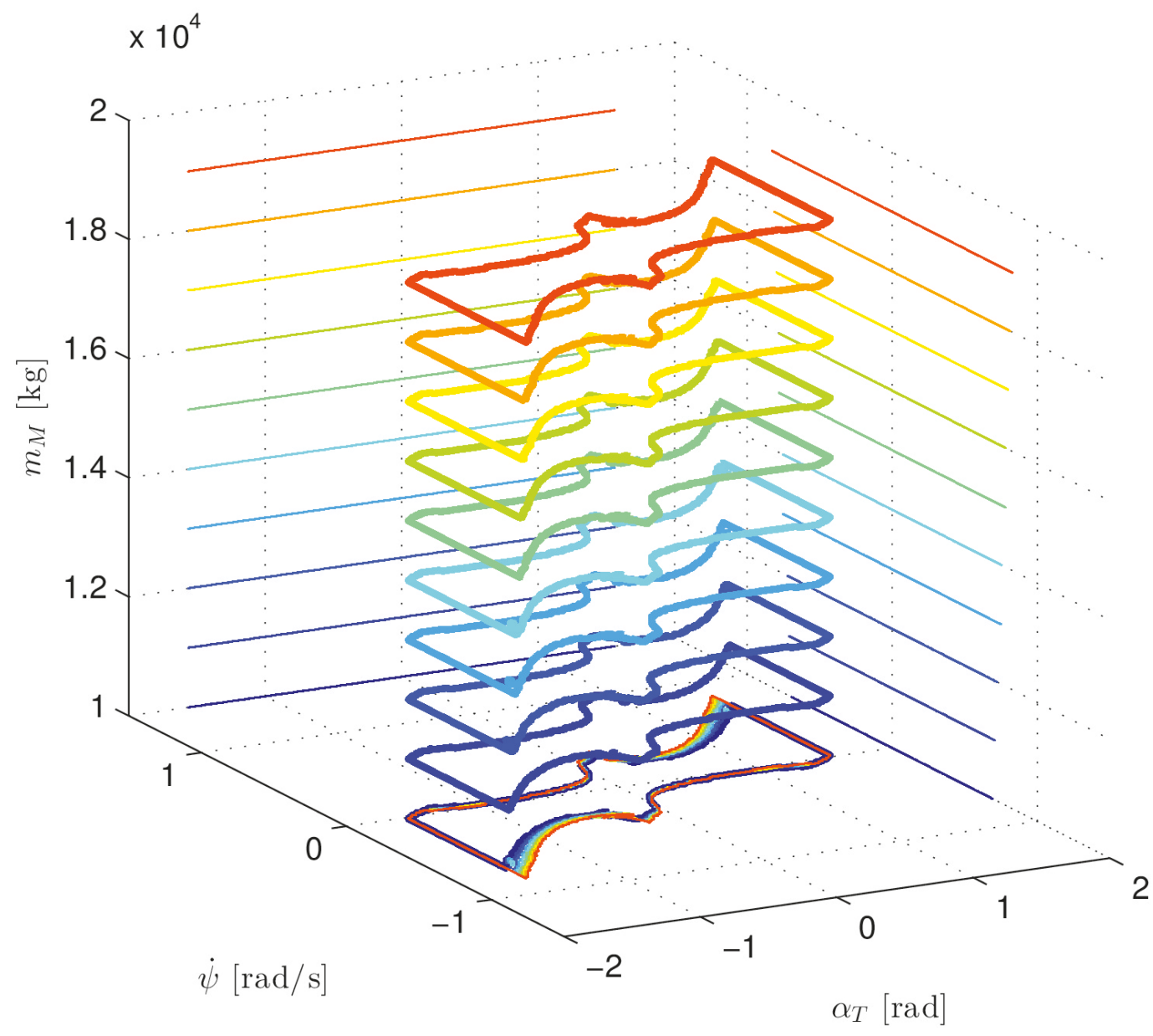

Fonte: Autor 
Os dados computacionais dessa análise estão detalhados no apêndice A. As dez varreduras para a geração das figuras 40 e 41 foram realizadas em cerca de 28 horas e 31 minutos. 


\section{CONCLUSÃO}

O conteúdo exposto nesta dissertação começa com uma contextualização do tema descrevendo os fenômenos de instabilidade, as estatísticas de acidentes e a representatividade dos veículos articulados no cenário de transporte de carga e passageiros. Diante da importância destes veículos e de sua suscetibilidade ao acotovelamento, o objetivo deste trabalho visa determinar as condições necessárias para que a ocorrência de instabilidade em guinada seja evitada. O estado da arte nesta área é apresentado em seguida na seção 2, onde são descritas as abordagens realizadas por outros autores com relação a objetivos específicos, modelos e técnicas de análise utilizadas.

Na seção 3 os modelos matemáticos de pneu e veículo empregados nesta dissertação são apresentados elucidando suas vantagens em relação às demais alternativas. O modelo de pneu mais adequado para se determinar a fronteira de convergência no plano de fase é o Pacejka, pois é capaz de proporcionar aproximadamente a força lateral para ângulos de deriva em toda a faixa de análise, de $\alpha=-180$ graus a $\alpha=+180$ graus. Além disso, é necessário realizar o tratamento proposto na equação 17 para que o a força lateral $F_{y}$ seja igual a zero para os valores de $\alpha=-180$ graus, $\alpha=0$ e $\alpha=+180$ graus. Apresentando o melhor desempenho em reproduzir com fidelidade o acotovelamento, o modelo de veículo articulado do tipo bicicleta, não linear e com quatro graus de liberdade é o escolhido. A adequação destes modelos é confirmada nos exemplos de manobra sem e com acotovelamento da seção 5.3.

A teoria de expoentes de Lyapunov é exposta na seção 4 através da descrição teórica do conceito e de procedimentos de cálculo. Os exemplos contidos nesta seção auxiliam a compreensão do sentido físico dos expoentes e permitem extrair conclusões sobre a sua utilidade prática. Nos exemplos linear e não linear é possível verificar a dependência que existe entre os expoentes e os autovalores do modelo linearizado. Entretanto, a análise de estabilidade por meio dos expoentes de Lyapunov, aparentemente, não apresenta vantagem com relação à verificação do valor da parte real dos autovalores do modelo linearizado no ponto fixo do sistema (no caso de análise de guinada em caminhões articulados). Além disso, a determinação de uma região de estabilidade não é beneficiada por este conceito, pois o critério de convergência é baseado na falha numérica do integrador quando os estados do modelo instável crescem indefinidamente.

A utilização dos modelos do sistema tem início na seção 5, onde os parâmetros do pneu e veículo padrão são definidos e seu comportamento dinâmico é ilustrado em manobras sem e com acotovelamento. A diferença das duas manobras é dada apenas pela alteração da 
condição inicial do sistema. Ou seja, dependendo da perturbação aplicada à coordenada inicial dos estados, o sistema converge para o ponto fixo de interesse ou para os pontos fixos adjacentes. Ambos os casos mostram uma dinâmica em guinada que se desenvolve sem que o limiar de tombamento seja atingido.

Na primeira etapa da seção 6 as equações de movimento são integradas para diferentes condições iniciais varrendo o plano de fase para a obtenção da região de convergência do veículo padrão. Os estados utilizados para a representaçã desta região são $\dot{\psi}$ e $\alpha_{T}$. No plano de fase constituido por estes dois estados, diversas regiões podem ser demarcadas conforme o ponto de convergência, $\alpha_{T, \text { final }}=\ldots,-2 \pi,-\pi, 0, \pi, 2 \pi, \ldots$ rad. A região de convergência de interesse $\alpha_{T, \text { final }}=0$ se estende por toda a faixa de $\alpha_{T}$ e é limitado inferior e superiormente na direção de $\dot{\psi}$. A aceleração lateral dos dois módulos se mantém em níveis baixos para regiões próximas do ponto fixo estável. Numa determinada distância do ponto fixo ocorre o crescimento abrupto da aceleração lateral para um valor que se mantém aproximadamente constante e abaixo do limiar $(0,35 \mathrm{~g})$ por todo o resto da região contida no plano de fase, com exceção da aceleração lateral do módulo dianteiro que pode apresentar um acréscimo ultrapassando o limiar de aceleração lateral em regiões específicas.

Nas etapas restantes da seção 6 a variação da região de convergência é obtida conforme a alteração do módulo do vetor velocidade do centro de massa do caminhão-trator, posicionamento da articulação e carga vertical sobre o eixo do semirreboque. Em todos os casos é possível verificar uma predominância de condições iniciais no primeiro e terceiro quadrante que fazem parte da região de convergência. Para o veículo padrão, o aumento de $v_{0}$ reduz a área de convergência que se mantém sempre contida nas regiões de maior velocidade inicial. A translação do ponto de articulação da frente para trás do eixo traseiro do caminhão-trator também reduz a área de convergência. Entretanto, neste caso, uma região com valor de $c$ menor apresenta algumas condições iniciais que não estão contidas em regiões obtidas para valores maiores de $c$. Por fim, o aumento da massa $m_{M}$ não altera significativamente a região de convergência. Rigorosamente, o modelo, inclusive, indica uma extensão da fronteira de convergência em alguns trechos da região. Portanto, a limitação da legislação para este tipo de eixo tem principal contribuição na manutenção da integridade física dos pneus e da pista.

\subsection{TRABALHOS FUTUROS}

As conclusões obtidas nesta dissertação possibilitam a continuação da pesquisa em diferentes frentes. A primeira delas consiste em validar o modelo utilizado. Para que os resultados 
apresentados atinjam patamares de credibilidade mais elevados é necessário confrontar o modelo proposto com resultados experimentais de veículos articulados. Alternativamente, é possível confrontar o modelo apresentado com um modelo de veículo desenvolvido num programa de multicorpos e validado experimentalmente (procedimento semelhante é realizado por Islam et al. (2014)). Um modelo validado como este pode, como discutido na introdução, reduzir os custos de desenvolvimento transferindo os testes físicos para ambientes computacionais.

Outra oportunidade de continuação consiste na introdução dos graus de liberdade em rolagem dos módulos dianteiro e traseiro. As equações de movimento da seção 3.2 podem ser estendidas acrescentando estes dois estados tendo como resultado um modelo de seis graus de liberdade. Desta forma, o arbitrário limiar de aceleração lateral passa a ser desnecessário, uma vez que as instabilidades em rolagem são verificadas monitorando os estados de inclinação lateral dos módulos. Com este modelo é possível refazer as análises apresentadas e verificar a aplicabilidade do limiar de aceleração lateral. Deve ser do interesse a validação deste modelo também.

Uma maior investigação deve ser realizada sobre a aplicação dos expoentes de Lyapunov na análise de estabilidade de sistemas dinâmicos não lineares. Relacionado à dinâmica veicular, em específico, a ferramenta deve ter seu significado físico consolidado estabelecendo uma relação útil entre o comportamento do veículo e o valor numérico dos expoentes. Este objetivo deve ser explorado, também, através de modificações dos algoritmos utilizados (esforço semelhante pode ser encontrado em Sadri e Wu (2014)). Estas alterações são atraentes pois podem, por exemplo, servir de base para uma métrica que essencialmente reduz a um número toda a oscilação dos autovalores do modelo linearizado ao longo da análise, proporcionando um índice que caracteriza o modelo ao longo da manobra.

Em estudos de estabilidade em guinada, tanto de veículos simples quando de veículos articulados, a variação do coeficiente de atrito deve ser realizada verificando o seu impacto sobre o comportamento dinâmico. Diferentes coeficientes de atrito podem ser aplicados de maneira semelhante à que foi feita nesta dissertação para os itens $v, c$ e $m_{M}$. Ou seja, a comparação pode ser feita no plano de fase variando o coeficiente de atrito. Integrando o modelo para diferentes coeficientes de atrito a aceleração do veículo pode ser estudada de maneira mais abrangente. A figura 32 mostra um ponto de partida para a análise específica da aceleração lateral máxima dos módulos do veículo. Entretanto, um objetivo relevante nesta direção consiste no estudo que aborda os efeitos do coeficiente de atrito nas acelerações máximas e, por consequência, nas regiões de convergência. 
Por fim, os modelos e estudos desenvolvidos nesta pesquisa de mestrado estabelecem uma condição favorável para o desenvolvimento subsequente de projetos de sistemas de controle. Esterçamento e frenagem independente das rodas são exemplos recorrentes de atuações em controladores que visam manter o sistema dentro da região de convergência limitando as instabilidades em guinada e em rolagem. O modelo capaz de caracterizar com precisão o comportamento dinâmico de veículos e definir uma região de estabilidade de maneira confiável pode, além disso, contribuir para o desenvolvimento de sistemas de controle dedicados à movimentação segura de veículos convencionais e, inclusive, autônomos. 


\section{REFERÊNCIAS}

ALLIGOOD, K. T.; SAUER, T. D.; YORKE, J. A. Chaos: An introduction to dynamical systems. [S.1.]: Springer, 1997.

ANDRZEJEWSKI, R.; AWREJCEWICZ, J. Nonlinear dynamics of a wheeled vehicle. [S.1.]: Springer, 2005.

APOSTOL, T. M. Calculus: Multi variable calculus and linear algebra, with applications to differential equations and probability. [S.1.]: John Wiley \& Sons, 1969.

BOARETTO, J. Comportamento estrutural de um chassi de semirreboque submetido a manobras relacionadas às dinâmicas lateral e vertical. Dissertação (Mestrado) Universidade Federal do Rio Grande do Sul, Porto Alegre, 2012.

CONFEDERAÇÃO NACIONAL DO TRANSPORTE. Boletim estatístico. 2015. Disponível em: <http://www.cnt.org.br/Boletim/boletim-estatistico-cnt>. Acesso em: 03 fev. 2016.

CONSELHO NACIONAL DE TRÂNSITO. Resolução 210. 2006. Disponível em: <http://www.denatran.gov.br/resolucoes.htm>. Acesso em: 03 fev. 2016.

Resolução 396. 2011. Disponível em: <http://www.denatran.gov.br/resolucoes.htm>. Acesso em: 03 fev. 2016.

DAHLBERG, E.; WIDEBERG, J. Influence of the fifth-wheel location on heavy articulated vehicle handling. In: INTERNATIONAL SYMPOSIUM ON HEAVY VEHICLE WEIGHTS \& DIMENSIONS, 8., 2004, Johannesburg. Loads, Roads and the Information Highway... Johannesburg: [s.n.], 2004.

DEPARTAMENTO NACIONAL DE INFRAESTRUTURA DE TRANSPORTES. Quadro de fabricantes de veículos. 2012. Disponível em: <http://www.dnit.gov.br/rodovias/ operacoes-rodoviarias/pesagem>. Acesso em: 03 fev. 2016.

DEPARTAMENTO NACIONAL DE TRÂNSITO. Frota nacional. 2015. Disponível em: <http://www.denatran.gov.br/frota2015.htm>. Acesso em: 03 fev. 2016.

DING, N. et al. Analysis of bifurcation and stability for a tractor semi-trailer in planar motion. Vehicle System Dynamics, Taylor \& Francis, v. 52, n. 12, p. 1729-1751, 2014.

EJZENBERG, S. Os veículos pesados e a segurança no projeto das curvas horizontais de rodovias e vias de trânsito rápido. Dissertação (Mestrado) - Universidade de São Paulo, São Paulo, 2009.

EL-GINDY, M.; TONG, L.; TABARROK, B. Frequency Response Analysis of Canadian Logging Trucks. Vehicle System Dynamics, Taylor \& Francis, v. 23, n. 1, p. 325-349, 1994. 
ELHEMLY, M. A. E.; FAYED, M. A. E.; ELMAIHY, A. A. E. Tractor-semitrailer jackknifing elimination using semitrailer differential braking technique. International Journal of Heavy Vehicle Systems, Inderscience, v. 20, n. 1, p. 19-34, 2013.

ERVIN, R. D. An overview of the dynamic performance properties of long truck combinations. The University of Michigan. Transportation Research Institute, 1984.

ERVIN, R. D. et al. The yaw stability of tractor-semitrailers during cornering. The University of Michigan. Highway Safety Research Institute, 1979.

FANCHER, P.; WINKLER, C. Directional performance issues in evaluation and design of articulated heavy vehicles. Vehicle System Dynamics, Taylor \& Francis, v. 45, n. 7-8, p. 607-647, 2007.

FEDERAL MOTOR CARRIER SAFETY ADMINISTRATION. Large truck and bus crash facts 2013. 2015. Disponível em: <https://www.fmcsa.dot.gov/safety/data-and-statistics/ large-truck-and-bus-crash-facts-2013-pdf>. Acesso em: 03 fev. 2016.

GILLESPIE, T. D. Fundamentals of vehicle dynamics. Warrendale: SAE International, 1992.

HAC, A.; FULK, D.; CHEN, H. Stability and control considerations of vehicle-trailer combination. SAE International Journal of Passenger Cars, SAE International, 2008.

ISLAM, M. M. et al. A comparative study of multi-trailer articulated heavy-vehicle models. Journal of Automobile Engineering, v. 229, n. 9, p. 1200-1228, 2014.

JI-HUA, B.; JIN-LIANG, L.; JAN, Y. Lateral stability analysis of the tractor/full trailer combination vehicle. In: INTERNATIONAL CONFERENCE ON ELECTRIC INFORMATION AND CONTROL ENGINEERING, 2011, Wuhan. Electric Information and Control Engineering (ICEICE)... Wuhan: IEEE, 2011.

JOHNSON, D.; HUSTON, J. Nonlinear lateral stability analysis of road vehicles using Liapunov's second method. SAE Technical Paper, SAE International, 1984.

LUIJTEN, M. F. J. Lateral dynamic behaviour of articulated commercial vehicles. Dissertação (Mestrado) — Technische Universiteit Eindhoven, 2010.

MAAS, J. Jackknife stability of a tractor semi-trailer combination. Dissertação (Mestrado) — Technische Universiteit Eindhoven, 2007.

MATHWORKS. Matlab documentation. 2015. Disponível em: <http://www.mathworks. com/help/matlab/>. Acesso em: 03/02/2016.

MENDES, A. S. Vehicle dynamics: lateral. 2015. Disponível em: <https://github.com/ andresmendes/Vehicle-Dynamics>. Acesso em: 03 fev. 2016. 
MONTEIRO, L. H. A. Sistemas dinâmicos. 2. ed. São Paulo: Livraria da Física, 2006.

MUGUCIA, S. W. et al. Frequency response characteristics of a tractor-trailer combination.

The Japanese Society of Agricultural Machinery and Food Engineers, v. 58, n. 2, p. 65-74, 1996.

NOOMWONGS, N. Study on handling and stability using tire hardware-in-the-loop simulator. JSAE Review, Elsevier, v. 24, n. 4, p. 457-464, 2003.

OGATA, K.; YANG, Y. Engenharia de Controle Moderno. Rio de Janeiro: Prentice-Hall do Brasil, 1982.

OREH, S. H. T.; KAZEMI, R.; AZADI, S. Directional Control of Articulated Heavy Vehicles. SAE International Journal of Commercial Vehicles, v. 6, n. 1, p. 143-149, 2013.

OSELEDEC, V. I. A multiplicative ergodic theorem. Lyapunov characteristic numbers for dynamical systems. Transactions of the Moscow Mathematical Society, v. 19, n. 2, p. 197-231, 1968.

PACEJKA, H. B. Tyre and vehicle dynamics. Oxford: Elsevier, 2006.

PACEJKA, H. B.; BAKKER, E. The magic formula tyre model. Vehicle System Dynamics, Taylor \& Francis, v. 21, p. 1-18, 1992.

PAUWELUSSEN, J. P. Excessive yaw behaviour of commercial vehicles, a fundamental approach. In: INTERNATIONAL TECHNICAL CONFERENCE ON THE ENHANCED SAFETY OF VEHICLES, 17, 2001. Enhanced Safety of Vehicles (ESV)... 2001.

RILL, G. Vehicle dynamics: Lecture notes. Hochschule Regensburg, University of Applied Sciences: [s.n.], 2009.

RISPENS, S. et al. A benchmark test of accuracy and precision in estimating dynamical systems characteristics from a time series. Journal of Biomechanics, Elsevier, v. 47, n. 2, p. 470-475, 2014.

ROWELL, D. Time-Domain Solution of LTI State Equations. Massachusetts Institute of Technology, Department of Mechanical Engineering: [s.n.], 2002.

SADRI, S.; WU, C. Q. Lateral stability analysis of on-road vehicles using Lyapunov's direct method. In: INTELLIGENT VEHICLES SYMPOSIUM, 2012. Intelligent Vehicles Symposium... IEEE, 2012.

Stability analysis of a nonlinear vehicle model in plane motion using the concept of Lyapunov exponents. Vehicle System Dynamics, Taylor \& Francis, v. 51, n. 6, p. 906-924, 2013. 
. Modified Lyapunov exponent, new measure of dynamics. Nonlinear Dynamics, Springer, v. 78, n. 4, p. 2731-2750, 2014.

SAMSUNDAR, J.; HUSTON, J. C. Estimating lateral stability region of a nonlinear 2 degree-of-freedom vehicle. SAE Technical Paper, 1998.

SAVI, M. A. Dinâmica não-linear e caos. Rio de Janeiro: E-papers, 2006.

STOTSKY, A.; HU, X. Stability analysis of robustly decoupled car steering system with nonlinear tire model. In: CONFERENCE ON DECISION AND CONTROL, 36, 1997. Decision and Control... IEEE, 1997.

SUN, T.; HE, Y. Phase-Plane Analysis for Evaluating the Lateral Stability of Articulated Vehicles. SAE Technical Paper, 2015.

TEIXEIRA, A. H. P. Expoente de Lyapunov de Séries Temporais. Dissertação (Mestrado) — Universidade de São Paulo, 2011.

VIANA, R. L. Introdução à Dinâmica Não-Linear e Caos em Economia. Universidade Federal do Paraná: [s.n.], 2009.

VIEIRA, J. L. d. M. Estudo de dirigibilidade de veículos longos combinados. Dissertação (Mestrado) - Universidade de São Paulo. Escola de Engenharia de São Carlos, 2010.

VLK, F. Lateral dynamics of commercial vehicle combinations a literature survey. Vehicle System Dynamics, Taylor \& Francis, v. 11, n. 5-6, p. 305-324, 1982.

WIDEBERG, J.; DAHLBERG, E.; SVENSSON, M. A comparative study of legislation and stability measures of heavy articulated vehicles in different regions. International Journal of Heavy Vehicle Systems, Inderscience, v. 16, n. 3, p. 354-361, 2009.

WINKLER, C. B.; ERVIN, R. Rollover of heavy commercial vehicles. The University of Michigan. Transportation Research Institute, 1999.

WINKLER, C. B.; FANCHER, P. S.; MACADAM, C. C. Parametric analysis of heavy duty truck dynamic stability. The University of Michigan. Transportation Research Institute, 1983.

WOLF, A. et al. Determining Lyapunov exponents from a time series. Physica D: Nonlinear Phenomena, Elsevier, v. 16, n. 3, p. 285-317, 1985.

WU, Q. et al. On design of continuous Lyapunov's feedback control. Journal of the Franklin Institute, Elsevier, v. 342, n. 6, p. 702-723, 2005.

YAN, Y.-g.; XU, H.-g.; LIU, H.-f. Estimating Vehicle Stability Region Based on Energy Function. Discrete Dynamics in Nature and Society, Hindawi, v. 2015, p. 1-7, 2015. 
YANG, C.; WU, Q. On stability analysis via Lyapunov exponents calculated from a time series using nonlinear mapping - a case study. Nonlinear Dynamics, Springer, v. 59, n. 1-2, p. 239-257, 2010.

YANG, Y.; CHEN, H.; JIANG, T. Nonlinear response prediction of cracked rotor based on EMD. Journal of the Franklin Institute, Elsevier, v. 352, n. 8, p. 3378-3393, 2015.

YIN, G. et al. Lateral stability region conservativeness estimation and torque distribution for FWIA electric vehicle steering. Science China Technological Sciences, Science China Press, v. 58, n. 4, p. 669-676, 2015.

ZHOU, S.; ZHANG, S. Jackknife control on tractor semi-trailer during high speed curve driving. Sensors \& Transducers, v. 16, p. 277-284, 2012.

Lateral stability control on tractor semi-trailer based on anti-jackknife apparatus. In: CONFERENCE AND EXPO TRANSPORTATION ELECTRIFICATION ASIA-PACIFIC (ITEC ASIA-PACIFIC), 2014. Transportation Electrification Asia-Pacific (ITEC Asia-Pacific)... IEEE, 2014.

ZIEGLER, H. Die Querschwingungen von Kraftwagenanhängern. Archive of Applied Mechanics, v. 9, n. 2, p. 96-108, 1938.

ZONG, C. et al. Multi-objective stability control algorithm of heavy tractor semi-trailer based on differential braking. Chinese Journal of Mechanical Engineering, Chinese Mechanical Engineering Society, v. 25, n. 1, p. 88-97, 2012. 
APÊNDICE A - DADOS COMPUTACIONAIS 
As simulações apresentadas nesta dissertação foram realizadas num computador disponível no Centro Universitário FEI para os alunos de pós-graduação. A máquina possui processador Intel ${ }^{\circledR}$ Xeon $^{\circledR}$ com unidade de processamento de 2,00 GHz (2 processadores). A memória instalada (RAM) é de 16,0 GB. O sistema operacional instalado é o Windows 7 Enterprise Service Packl de 64 Bits.

O programa utilizado para a execução das rotinas é o Matlab ${ }^{\circledR}$ R2013a. As integrações numéricas presentes nesta dissertação são realizadas utilizando a função ode 45 destinada à integração de equações diferenciais não duras através do método de Runge-Kutta. Maiores detalhes sobre o programa e a função podem ser encontrados em Mathworks (2015).

Todos os modelos usados nesta dissertação são mantidos por Mendes (2015) num pacote de simulação dinâmica de veículos para Matlab ${ }^{\circledR}$ chamado Vehicle Dynamics - Lateral. Este pacote é aberto e se encontra hospedado na plataforma GitHub, que possibilita a colaboração entre os programadores no desenvolvimento de códigos. A coleção de funções de modelo de pneu, veículo e geração de gráficos (por exemplo: figura 23) e animações estão disponíveis.

Todos os dados citados estão resumidos na tabela 7.1

Tabela 18 - Dados computacionais

\begin{tabular}{ll}
\hline Item & Descrição/Valor \\
\hline Processador & Intel $^{\circledR}$ Xeon $^{\circledR}$ de 2,00 GHz (2 processadores) \\
Memória instalada (RAM) & $16 G B$ \\
Tipo de sistema & Sistema operacional de 64 Bits \\
Sistema operacional & Windows 7 Enterprise Service Pack1 \\
Programa & Matlab ${ }^{\circledR}$ R2013a \\
Integrador numérico & ode45 \\
Pacote de dinâmica veicular & Vehicle Dynamics - Lateral @ GitHub \\
\hline
\end{tabular}

Fonte: Autor 